\title{
BURRS PRODUCED BY END MILLING
}

Published September 1976

Project Leader:

L. K. Gillespie

Department 822

Project Team:

B. J. Neal

R. K. Albright

PDO 6984405

Topical Report

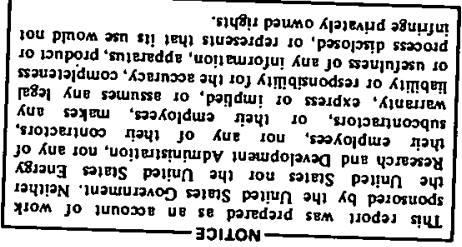

Technical Communications
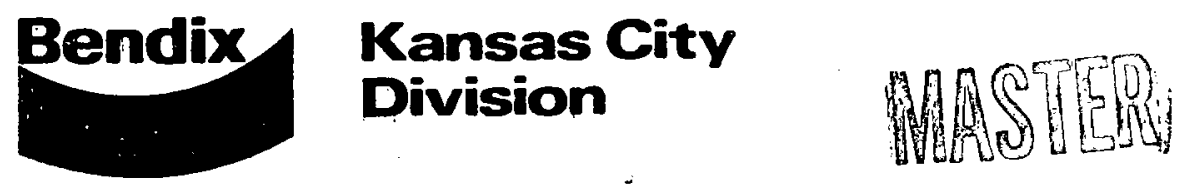


\section{DISCLAIMER}

This report was prepared as an account of work sponsored by an agency of the United States Government. Neither the United States Government nor any agency Thereof, nor any of their employees, makes any warranty, express or implied, or assumes any legal liability or responsibility for the accuracy, completeness, or usefulness of any information, apparatus, product, or process disclosed, or represents that its use would not infringe privately owned rights. Reference herein to any specific commercial product, process, or service by trade name, trademark, manufacturer, or otherwise does not necessarily constitute or imply its endorsement, recommendation, or favoring by the United States Government or any agency thereof. The views and opinions of authors expressed herein do not necessarily state or reflect those of the United States Government or any agency thereof. 


\section{DISCLAIMER}

Portions of this document may be illegible in electronic image products. Images are produced from the best available original document. 
THIS PAGE

\section{WAS INTENTIONALLY \\ LEFT BLANK}




\section{BURRS PRODUCED BY END MILLING}

\section{BDX-613-1503, UNCLASSIFIED Topical Report, Published September 1976}

Prepared by L. K. Gillespie, D/822, under PDO 6984405

The operation of small precision mechanisms such as timers, switches, or actuators depends on burr-free, sharp-edged component parts. Traditional methods of producing these near-perfect edges on miniature parts are costly and not as precise or repeatable as some piecepart designs require. By controlling the size of burrs produced in machining operations, burr removal costs can be lowered, and the repeatability of the resulting edges improved. This investigation sought to determine how machining variables influence burr size in end-milling operations. It was concluded that the low feed rates which are commonly used in precision miniature machining create larger burrs than do more conventional feedrates. Dull tools double the size of burrs. Increasing the radial depth of cut also increases burr size on many edges. A single end-milling cut can produce eight different burrs. Burr properties vary noticeably even along a single edge. Burrs in 1018 steel, 6061-T6 aluminum, $303 \mathrm{Se}$, and 17-4 $\mathrm{PH}$ stainless were typically 0.003 inch $(76.2 \mu \mathrm{m})$ thick. Burr heights ranged from 0.0001 to 0.070 inch $(2.5$ to $1778 \mu \mathrm{m})$. Conceptual and mathematical descriptions of burr formation have been developed.

WPC-mlb

This report was prepared as an account of work sponsored by the United States Government. Neither the United States nor the United States Energy Research and Development Administration, nor any of their employees, nor any of their contractors, subcontractors, or their employees, makes any warranty, express or implied, or assumes any legal liability or responsibility for the accuracy, completeness or usefulness of any information, apparatus, product or process disclosed, or represents that its use would not infringe privately owned rights.
THE BENDIX CORPORATION

KANSAS CITY DIVISION

P.O. BOX 1159

KANSAS CITY, MISSOURI 64141

A prime contractor for the United States Energy Research and Development Administration Contract Number E(29-1)-613 USERDA 
THIS PAGE

\section{WAS INTENTIONALLY LEFT BLANK}




\section{CONTENTS}

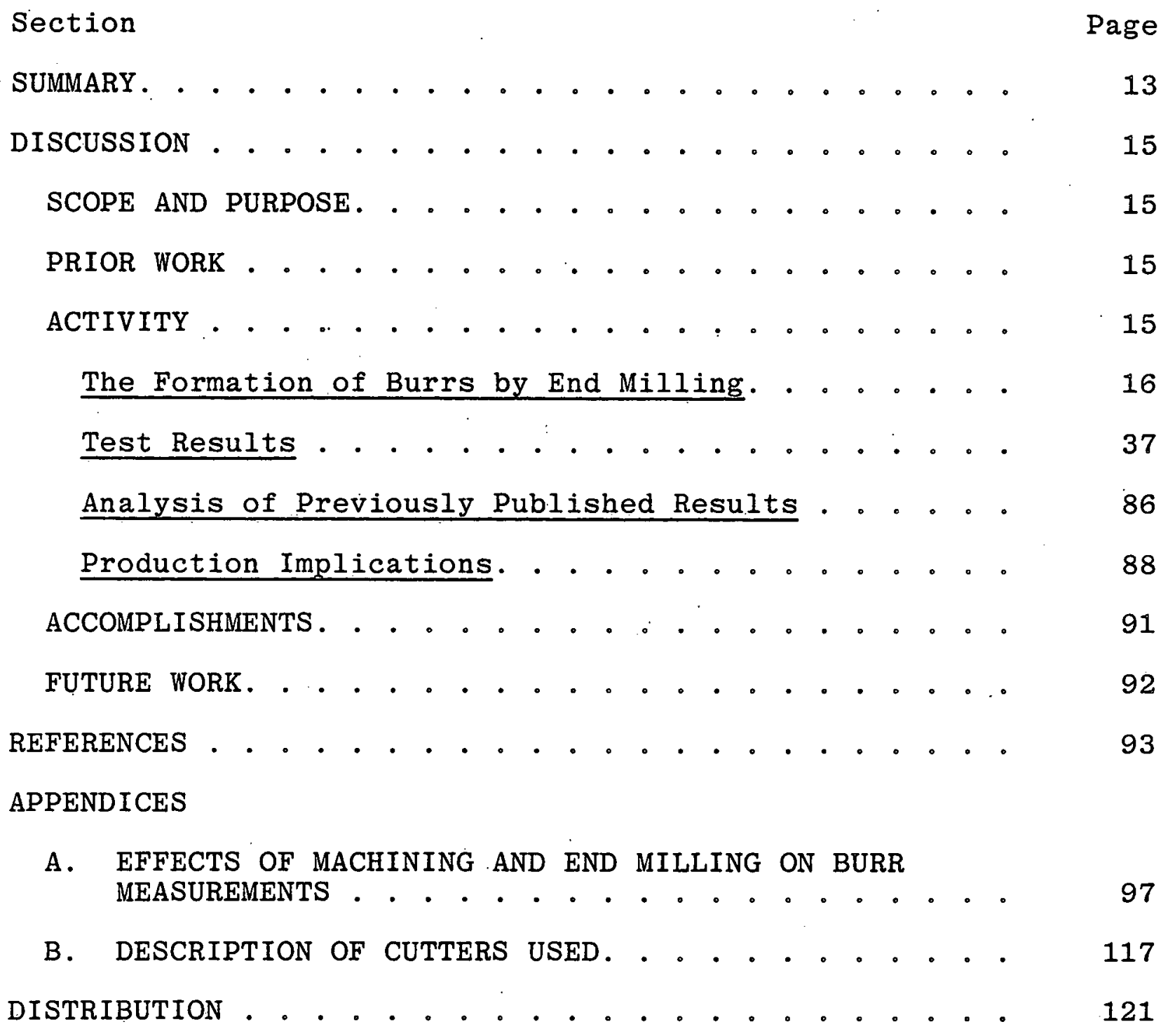


THIS PAGE

\section{WAS INTENTIONALLY \\ LEFT BLANK}




\section{ILLUSTRATIONS}

Figure

Page

Identification of Burr Locations in End Milling-Profiling Cut. . . . . . . . . . 。

Identification of Burr Locations in End Milling-Slotting Cut . . . . . . . . . .

Chip Deformation Modes . . . . . . . . .

Cutting Action Near Edge . . . . . . . . .

21

Variation in Chip Thickness. . . . . . . . .

Exaggerated Illustration of Roll-Over Burr Formed by a Number of Miling Teeth. . . .

Effect of Angle $\phi$ on Maximum Burr Height at Edge 3...................

Cutter at Entrance and Exit of Slot. .....

Membrane Analogy of Material Stretching at Corner of End-Mill Tooth (P-92405) . . . . .

Cutting Edge Produces Indentation Burr as it Enters Workpiece . . . . . . . . . . . .

Effect of Strain-Hardening Exponent on Ridging Burr Formation (From Reference 26) . . . .

Material Displacement, Using Spherical Indentors (From Reference 26). . . . . .

14 Maximum Possible Size and Shape of HelixGenerated, Roll-Over Burr. . . . . . . . 
Effect of Radial Depth of Cut on Burr Height at Edge 3... . . . . . . . . . . . . .

Effect of Feedrate on Burr Height at Edges 1,

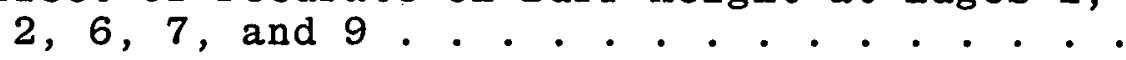

Effect of Tool Sharpness on Burr Height at Edges $1,2,3,5$, and $9 . . . . . . . . . .$.

Burr Height as a Function of Workpiece Material

Edge 1: Effect of Feedrate and Tool Sharpness on Burr Height . . . . . . . . .

Edge 2: Effect of Feedrate and Tool Sharpness on Burr Height ... . . . . . . .

Edge 3: Effect of Feedrate and Tool Sharpness on Burr Height . . . . . . . .

Edge 4: Effect of Feedrate and Tool Sharpness on Burr Height . . . . . . . .

Edge 5: Effect of Feedrate and Tool Sharpness on Burr Height . . . . . . . . .

Edge 6: Effect of Feedrate and Tool Sharpness on Burr Height . . . . . . . . .

Edge 7: Effect of Feedrate and Tool Sharpness on Burr Height . . . . . . . . . .

Edge 8: Effect of Feedrate and Tool Sharpness on Burr Height . . . . . . . .

Edge 9: Effect of Feedrate and Tool Sharpness on Burr Height . . . . . . . : . .

Edge 1: Effect of Cutter Diameter and Burr Thickness.

Edge 6: Effect of Radial Depth of Cut on Burr Thickness . . . . . . . . . . . . .

Effect of Feedrate on Burr Thickness at Edges 2, 3, and 5. . . . . . . . . . . 
Effect of Workpiece Material on Burr Thickness. . . . . . . . . . . . . .

37 Edge 1: Effect of Feedrate and Tool Sharpness on Burr Thickness. . . . . . .

Edge 2: Effect of Feedrate and Tool Sharpness on Burr Thickness.

Edge 3: Effect of Feedrate and Tool Sharpness on Burr Thickness.

Edge 5: Effect of Feedrate and Tool Sharpness on Burr Thickness. . . . . . .

Edge 6: Effect of Feedrate and Tool Sharpness on Burr Thickness. . . . . . .

Edge 7: Effect of Feedrate and Tool Sharpness on Burr Thickness. . . . . .

Edge 9: Effect of Feedrate and Tool Sharpness on Burr Thickness. . .......

Edge 1: Effect of Axial Depth of Cut on Burr Radius. . . . . . . . . . . . .

Edges 1 and 2: Effect of Tool Sharpness on Burr Radius. . . . . . . . . . . .

Edge 3: Effect of Radial Depth of Cut on Burr Radius. . . . . . . . . . . .

Edges 3 and 5: Effect of Feedrate on Burr Radius . . . . . . . . . . . . . . .

Edges 1, 5, and 9: Effect of Workpiece Material on Burr Radius. . . . . . . . . .

Edge 1: Effect of Feedrate and Tool Sharpness on Burr Radius . . . . . . . . .

Edge 2: Effect of Feedrate and Tool Sharpness on Burr Radius . . . . . . . .

Edge 3: Effect of Feedrate and Tool Sharpness on Burr Radius . . . . . . . . . 
60

61

62

63

64

65

Edge 7: Effect of Feedrate and Tool Sharpness on Burr Radius . . . . . . . .

Edge 9: Effect of Feedrate and Tool Sharpness on Burr Radius . . ... . . . .

Burr Height at Edge 1 as a Function of Length of Cut. . . . . . . . . . . . .

Specimen Used in Hiperco 50 End-Milling Study. . . . . . . . . . . . . . . .

Feathery Burr on Edge 1, Produced by FaceMilling Low-Carbon Steel (P-93622) . . . .

Feathery Burr on Edge 1, Produced by Slotting 17-4 PH Stainless Steel (P-72146).. . . .

Feathery Burr on Edge 2, Produced by Slotting 17-4 PH Stainless Steel (P-72145).. . . . .

Smail Burrs Produced on Edge 1 With Sharp End Mill in 1018 Steel $\left(R_{C} 20\right)$ (P-92200). ..

Feathery Burr on Edge 1, Produced by Dull End Mill in 1018 Steel $\left(R_{C} 20\right)(P-92199)$. .

Feathery Burr on Edge 1, Produced by End Milling 6061-T6 Aluminum (P-92198) . . . .

Uniform Burr Formed on Edge 9, Produced by a Face Mill in 1018 Steel (P-93621). . . . .

Possible Definitions of Burr Height for Feather-Like Burrs . . . . . . . . . . .

Shape of Burrs Observed on Edge 5 (Plan View) 


\section{TABLES}

Number

Page

1

End-Milling Conditions Used. . . . . . . . . .

ANOVA of Burr Height . . . . . . . . . . . .

ANOVA of Burr Thickness. . . . . . . . . .

ANOVA Summary of Effects on Burr Radius. . .

Typical Burr Properties From End Milling . .

Properties of Burrs Produced by End Milling Hiperco 50 . . . . . . . . . . . . . . .

Effect of Helix Angle on Burr Size......

Influence of Measuring Technique on Observed Burr Length . . . . . . . . . .

Burr Heights Obtained in Two Similar Studies. . . . . . . . . . . . . . .

Effect of Machining Conditions on Burr Height . . . . . . . . . . . . . . .

Effect of Machining Conditions on Burr 
THIS PAGE

\section{WAS INTENTIONALLY LEFT BLANK}


Component parts of small mechanisms have typically required near-sharp edges to assure reliable component operation. A burr-free condition is needed to minimize possible electrical and mechanical jamming of the mechanism, which would result if burrs were to break loose during operation. In the past, reliable removal of machining burrs, combined with protection of the near-sharp edge requirements, has dictated that deburring be done only by hand, which is time consuming and inherently operator variable. The repeatability of burr removal and the time required for removal are directly related to burr size. Small burrs are easily removed by many deburring processes.

The investigation, based on 6000 measurements, showed that low feedrates and duli tools are the two most significant factors which increase burr size. Burr properties also increase with increasing radial depth of cut on many edges.

A single end-milling cut can produce burrs on eight different edges. The thickness, height, and radius on the backside of the burrs are different for each edge. Contrary to popular opinion, burrs can form on the edges in which the cutter enters the part. Changing such factors as feedrates does not equally influence burr size on all edges. On some edges; such changes will decrease burr size while on others it will increase burr size or have no effect. Burr properties vary noticeably, even along a single edge.

Burrs in 1018 steel, 6061-T6 aluminum, $303 \mathrm{Se}$, and 17-4 $\mathrm{PH}$ stainless steel typically were 0.003 inch $(76.2 \mu \mathrm{m})$ thick. Burr height varied from 0.0001 to 0.070 inch $(2.5$ to $1778 \mu \mathrm{m})$, depending upon edge location. The radius on the backside of the burr typically was 0.0015 inch $(38.1 \mu \mathrm{m})$. Burr hardness has previously been found to be up to 10 Rockwell-C $\left(R_{C}\right)$ points harder than the parent material.

Conceptual and mathematical descriptions of burr formation have been developed. Three distinct mechanisms are responsible for the burrs produced by end mills.

The information obtained from this study will be combined with similar data from other machining operations to determine optimum fabrication conditions. 
THIS PAGE

\section{WAS INTENTIONALLY \\ LEFT BLANK}




\section{DISCUSSION}

\section{SCOPE AND PURPOSE}

The objective of this study was to determine how conventional end-milling practices influence burr size. Specifically, the goal was to determine how burrs produced by end milling are affected by feedrate, axial depth of cut, radial depth of cut, tool diameter, workpiece material, and tool wear. Burr thickness, height, and radius were monitored at six of the 10 edges produced by end milling.

\section{PRIOR WORK}

Earlier Bendix investigations provided some background data. In a preliminary study, the effects of helix angle and feedrate were evaluated on burrs produced at two locations in 303 Se stainless steel and in beryllium copper. ${ }^{1}$ A subsequent study evaluated the effects of end-mill diameter, radial depth of cut, and feedrate on burr heights in 303 Se stainless steel. ${ }^{2}$

In related investigations, the effects of drilling, reaming, and ball broaching parameters on burr properties have also been studied. ${ }^{3}, 4,5$ A general theory of burr formation has been developed, 2,6,7 and some experimental work has been reported by other agencies on drilling burrs, ${ }^{-12}$ punching burrs, $13-19$ and burrs produced by the EDM method. ${ }^{20}$

\section{ACTIVITY}

All conventional machining operations produce some burrs. The size of these burrs depends upon the tool geometries used and the workpiece material properties. The cost of removing the burrs is proportional to the burr size. In many instances, on precision miniature parts, because of close tolerances, minute part size, and large burr size, the burr removal costs approach the cost of machining the parts. To minimize these fabrication costs, one has to anlayze how deburring costs vary with burr size and how machining conditions influence burr size. A series of tests has been initiated to provide data on burr properties as a function of machining conditions. These tests will include the most common machining operations.

The ways by which end milling produces burrs are discussed below, and the results of four end-milling studies are presented. In the first study, 128 combinations of cutter geometry, workpiece material, and cutting conditions were used to determine 
how burr properties vary with these parameters. The effects of tool wear on burr properties were evaluated in the second study. The burrs produced in Hiperco 50 were evaluated in the third study, and the impact of the helix angle was studied in the fourth test. These results were then compared to the theory of burr formation and with previously published results.

The Formation of Burrs By End Milling

An end mill can produce eight different burrs in a single slotting operation. A total of 10 different groups of burrs can be produced by an end mill, but eight is the maximum which can be produced in a single cut. These burrs all occur on different edges. For example, in a bottom-cutting profiling operation, six edges are produced, and a different group of burrs occurs on each edge (Figure 1). When a blind channel slot is produced, six edges and six groups of burrs occur (Figure 2). In a through slot, eight edges and eight groups of burrs occur. (Figure 2). The height, the thickness, the radius on the back side of each burr, the hardness, and the appearance of each of these groups of burrs is different from the other groups.

Two different mechanisms are involved in the production of these burrs. The burrs along edges 3,7 , and 9 are the result of a chip's rolling over, rather than having been sheared from the workpiece. Burrs on edges 1, 2, and 10 are the result of lateral deformation due to Poisson's ratio. These two types of burrs are defined respectively as roll-over and Poisson burrs. The burrs along edges 4 and 6 result from material flowing 180 degrees to the direction of tool travel. This entrance burr is one form of the Poisson burr. Burrs along edges 8 and 5 vary noticeably along each edge. They are a combination of entrance burr and roll-over burr.

The Roll-Over Burr

When a cutting edge exits from a workpiece; a roll-over burr forms (Figure 3 ). This burr occurs when it is easier to bend the chip than it is to cut it. To illustrate the basic phenomenon, one may consider a shaping operation in which the depth of cut is constant. An estimate of burr thickness can be made if one makes the assumption that a roll-over burr occurs whenever the energy required to bend the chip is equal to or less than the energy required to cut the chip. As indicated elsewhere, ${ }^{2}, 6$ the work to cut a length of $\lambda$ can be expressed by

$W_{c}=F_{c}\left[\lambda-\frac{t}{2 \tan \phi}\right]$, for $\lambda \geq \frac{t}{\tan \phi}$, or

Text continued on page 20. 

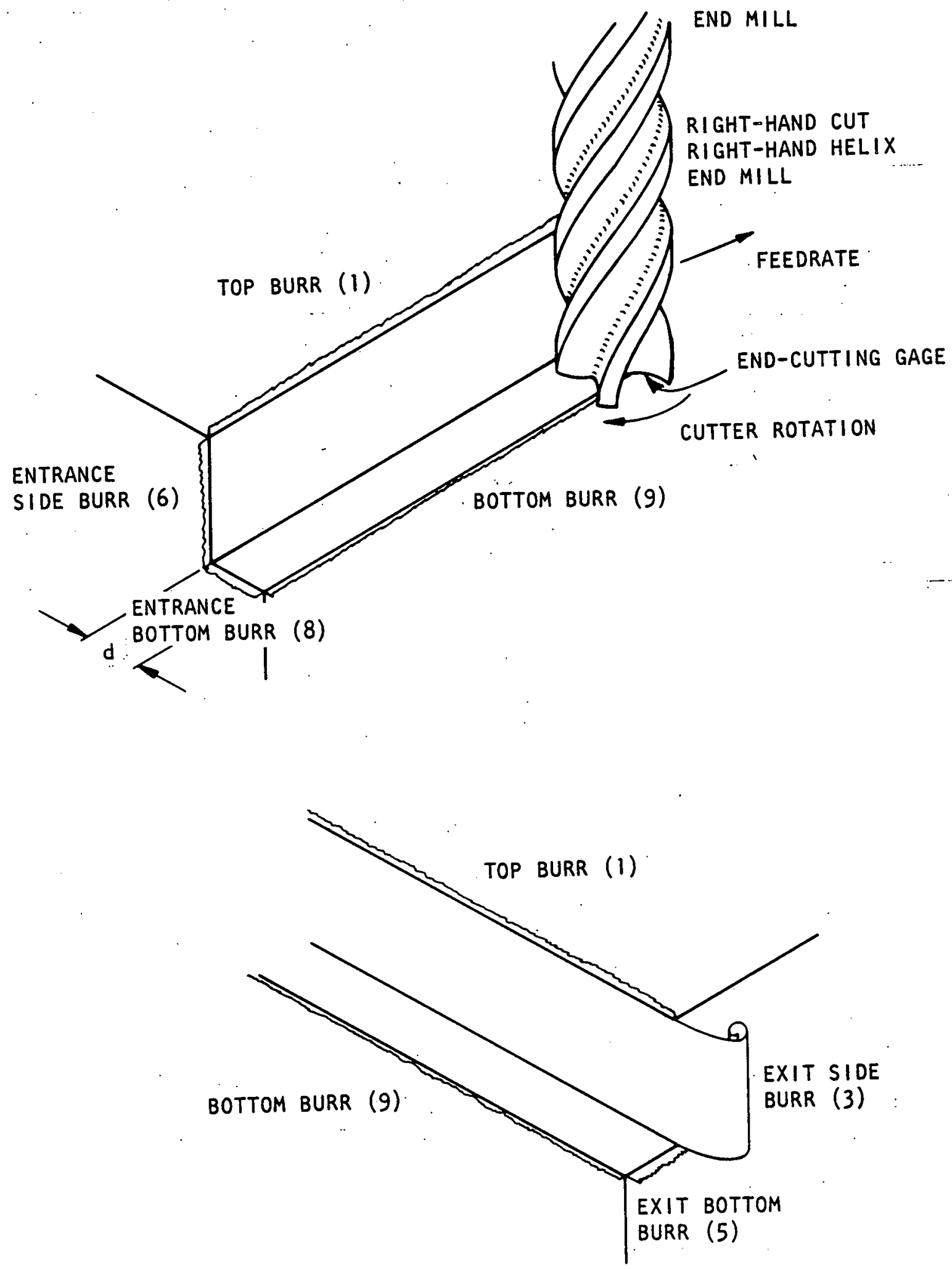

Figure 1. Identification of Burr Locations in End MillingProfiling, Cut 


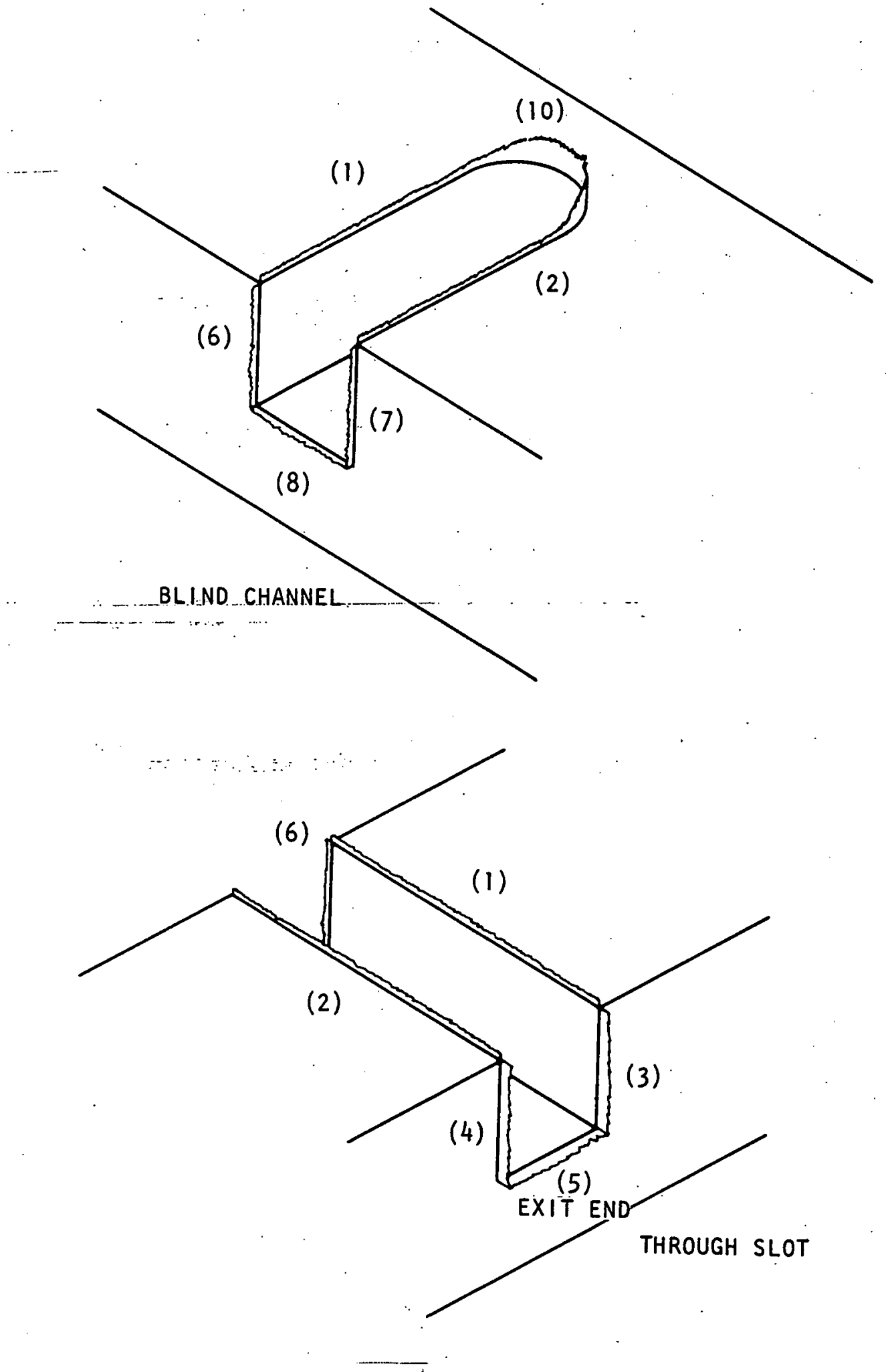

Figure 2. Identification of Burr Locations in End Milling-Slotting Cut 

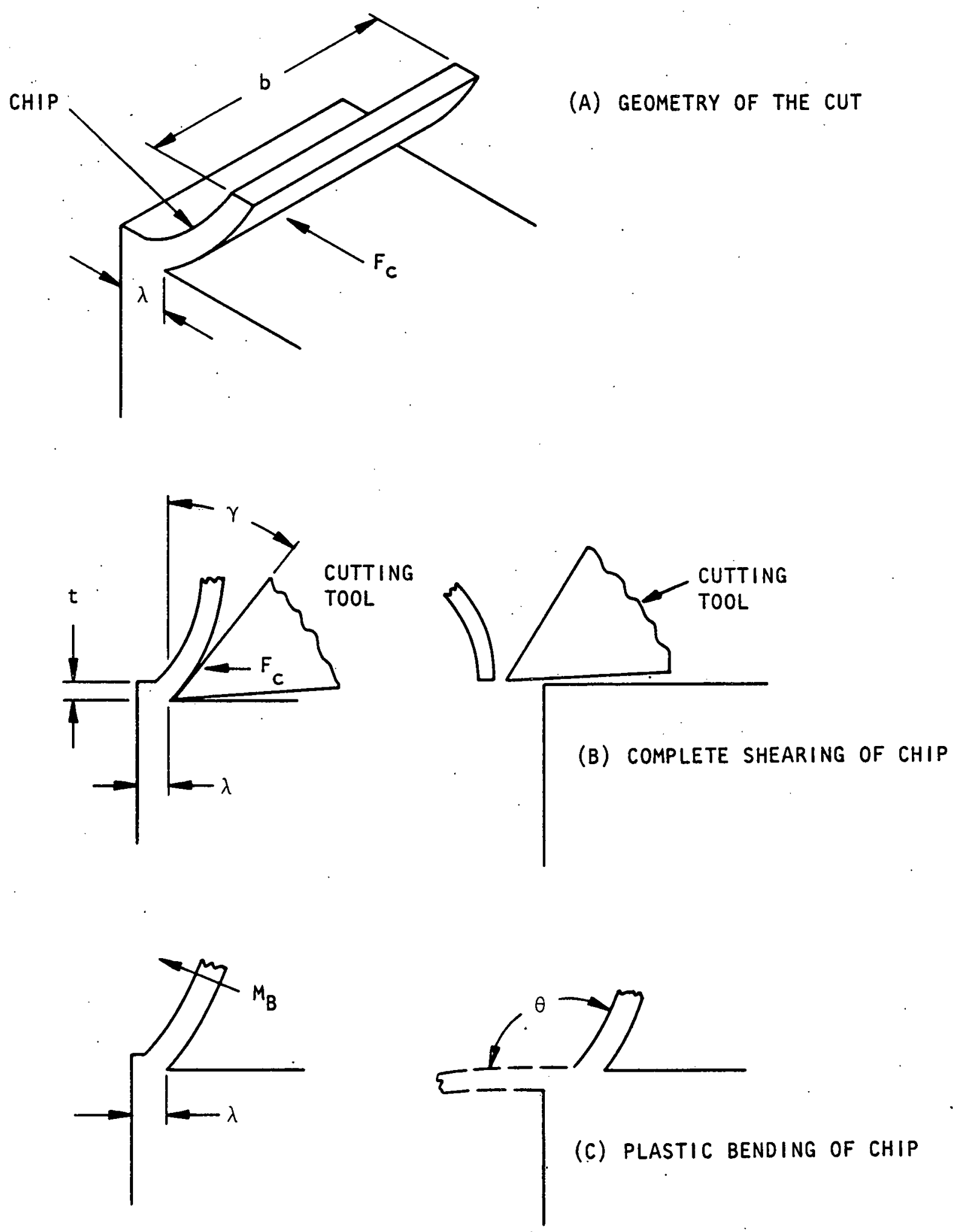

Figure 3. Chip Deformation Modes, 


$$
W_{c}=F_{c_{i}}\left[\frac{t_{i}}{2 \tan \phi}\right] \text {, for } \lambda<\frac{t}{\tan \phi} \text {, }
$$

where

$\mathrm{w}_{\mathrm{c}}=$ work in cutting,

$F_{c}=$ cutting force,

$F_{c_{i}}=$ instantaneous cutting force near end of cut $=\frac{F_{c} t_{i}}{t}$,

$\lambda=$ burr thickness,

$t=$ uncut chip thickness,

$\phi=$ shear angle in cutting $=\frac{C-\tau+\alpha}{2}$, $t_{i}=\underset{\text { instantaneous uncut chip thickness near end of cut }=\lambda \tan \phi,}{(\text { Figure } 4)}$

$C$ is a material constant,

$\tau=$ friction angle $=\operatorname{arc} \tan \mu$,

$\mu=$ coefficient of friction between chip and tool, and

$\alpha=$ tool rake angle.

The work in bending a burr of a perfectly plastic material, assuming no redundant work occurs, is given by equation 3. (Most plastic deformation operations exhibit a great deal of redundant work. This implies that such processes do not deform by paths requiring the least energy.)

$W_{B}=\frac{C_{1} b \lambda^{2} \sigma_{e} \theta}{4}$

where

$\mathrm{C}_{1}=$ redundant work factor $(=1.0$ when no redundant work occurs $)$,

$W_{B}=$ work in bending,

$\mathrm{b}=$ length of tool engaged in cut, 


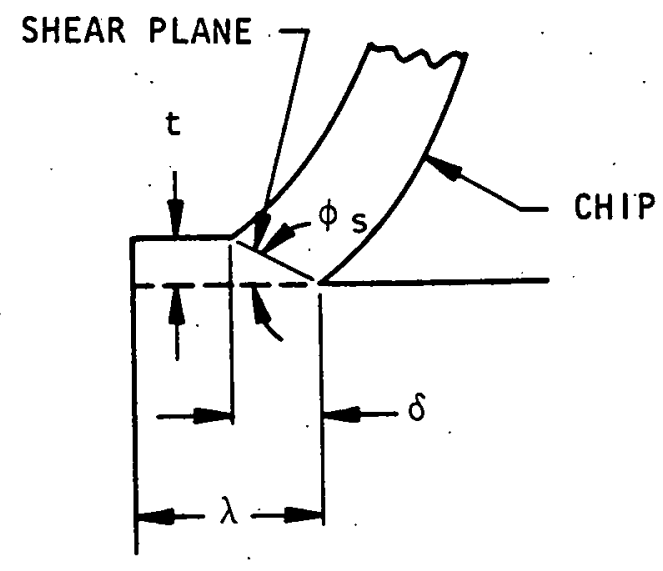

(A) SHEAR PLANE IN CUTTING

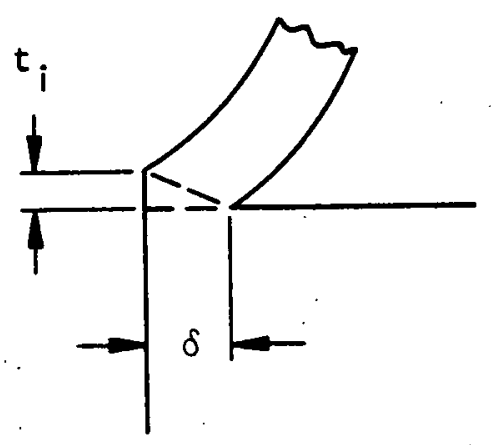

(B) SHEAR PLANE INTERSECTING EDGE

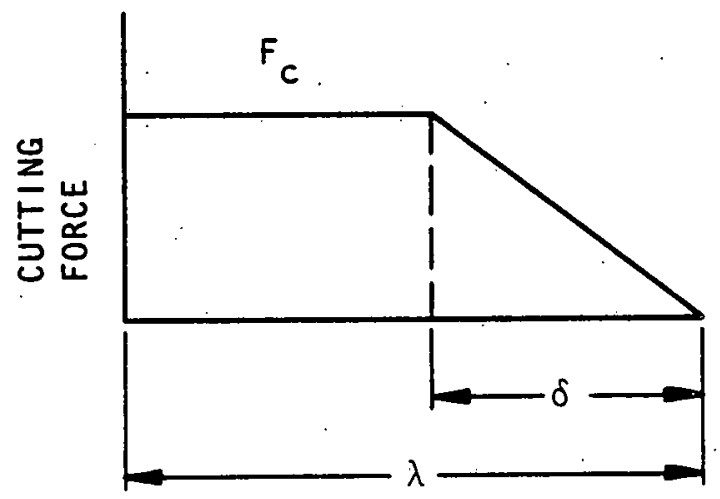

(c) CUTTING FORCE AS TOOL NEARS EDGE

Figure 4. Cutting Action Near Edge 
$\sigma_{e}=$ elastic limit of perfectly plastic material, and

$\theta=$ angle through which the burr is bent $(\pi / 2+$ rake angle $)$.

Equating $W_{c}$ and $W_{B}$ and solving for $\lambda$, results in

$\lambda=\left[2 F_{c}+\sqrt{4 F_{c}^{2}-\frac{C_{1} 2 b e_{e} \theta t F_{c}}{\tan \phi}}\right]\left[\frac{1}{C_{1} b \sigma_{e}^{\theta}}\right]$ for $\lambda \geq \frac{t}{\tan \phi}$.

For a strain-hardening material,

$\lambda=\left[2 F_{c}+\sqrt{4 F_{c}^{2}-\frac{C_{1} 2 b \sigma_{o} \varepsilon_{f}^{n} t \theta F}{c}} \frac{n+1}{(n+1) \tan \phi}\right]\left[\frac{t}{C_{1} b \sigma_{o} \theta \varepsilon_{f}^{n}}\right]$ for $\lambda \geq \frac{t}{\tan \phi}$,

where

$\sigma_{0}=$ true material stress at a true strain of 1.0 ,

$\varepsilon_{f}=$ true strain at fracture, and

$\mathrm{n}$ = strain-hardening exponent.

As noted elsewhere, ${ }^{21}$ equations 4 and 5 predict thicker burrs than one actually finds on parts when the redundant work is assumed to be zero. Recent studies ${ }^{2}$ indicate that total work can be from 1.2 to 7.0 larger than the work calculated by minimum energy principles. When $C_{1}$ is 3.0 , equations 4 and 5 closely predict roll-over burr size in 303 Se. stainless steel.

In an end-milling operation, the depth of cut varies as the cutter rotates (Figure 5 ). Since $t$ and $F_{c}$ must be known before burr thickness can be calculated, and since $t$ is not constant, equations 4 and 5 are not convenient to use in production.

It is possible to use a trial and error method with these equations if $t$ is known as a function of distance from the back edge. By inserting a value of $t$, calculating $F_{c}$ from Merchant's equation, ${ }^{2}$ (equation 6 , below) a tentative value of burr thickness can be obtained.

$F_{C}=\operatorname{tb\sigma } \sigma_{S}\left[\tan \left(\frac{C+\tau-\alpha}{2}\right)+\operatorname{cotan}\left(\frac{C-\tau+\alpha}{2}\right)\right]$,

where 


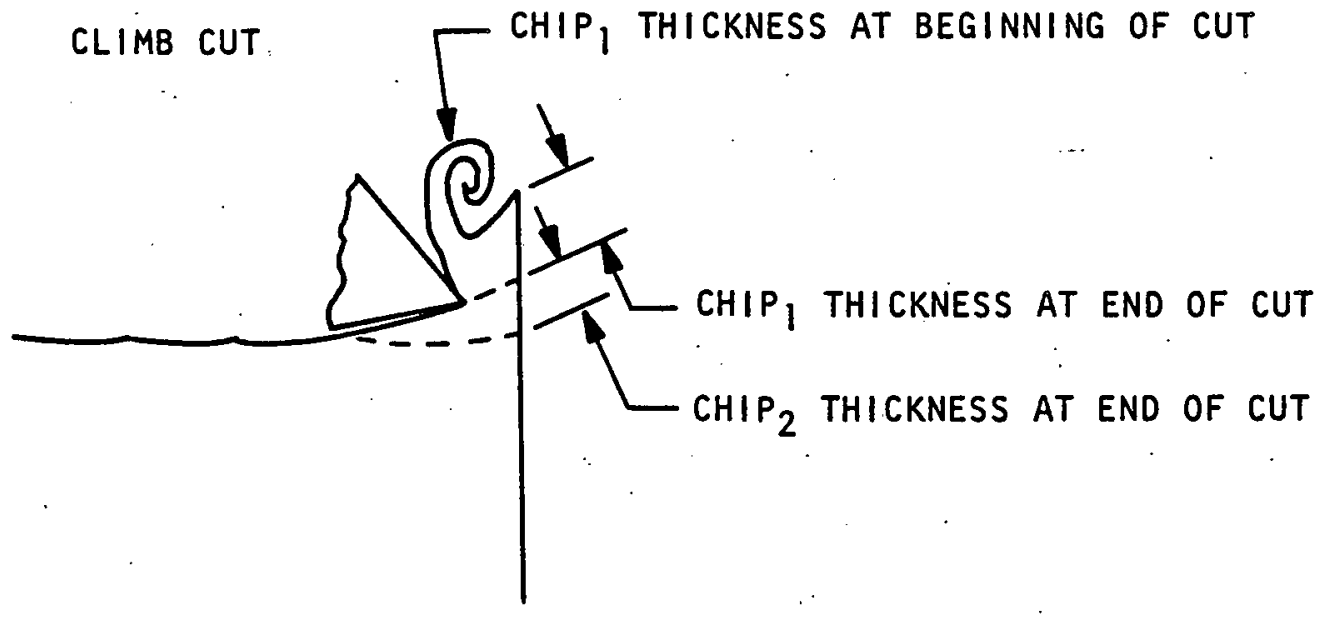

CONVENTIONAL CUT

Figure 5. Variation in Chip Thickness

$\sigma_{s}=$ shear strength of the workpiece, $\lambda$ must then be compared with the restriction

$\lambda \geq \mathrm{t} / \mathrm{tan} \phi$.

If $\lambda$ does not satisfy this restriction, then the substitution process must be repeated with. a different value of $t$. The difficulty with this approach is that because of workpiece tolerances on length, and the inability to start each cut with the cutter teeth in a specific position relating to the part, $t$ cannot be conveniently described as a function of distance from the back edge.

Despite the limitations in equations 4 and 5 , they are useful in illustrating how the process variables influence the results. By using an average value for uncut chip thickness, it is also possible to obtain a reasonably close approximation to burr thickness as will be shown later.

The burr forms much like a banana is peeled. As each tooth exits from the back surface of the part it adds more material to the length of the burr (Figure 6 ).

From a subjective standpoint, it would seem that the roll-over burr should be composed of a number of tightly stacked flaps of material (Figure 6). In practice, however, these distinct flaps have not been observed. The burrs when cross-sectioned, have a uniform cross section.

In viewing Figure 5 , it appears that in removing the third chip, any burr already produced would be cut off because the depth of 

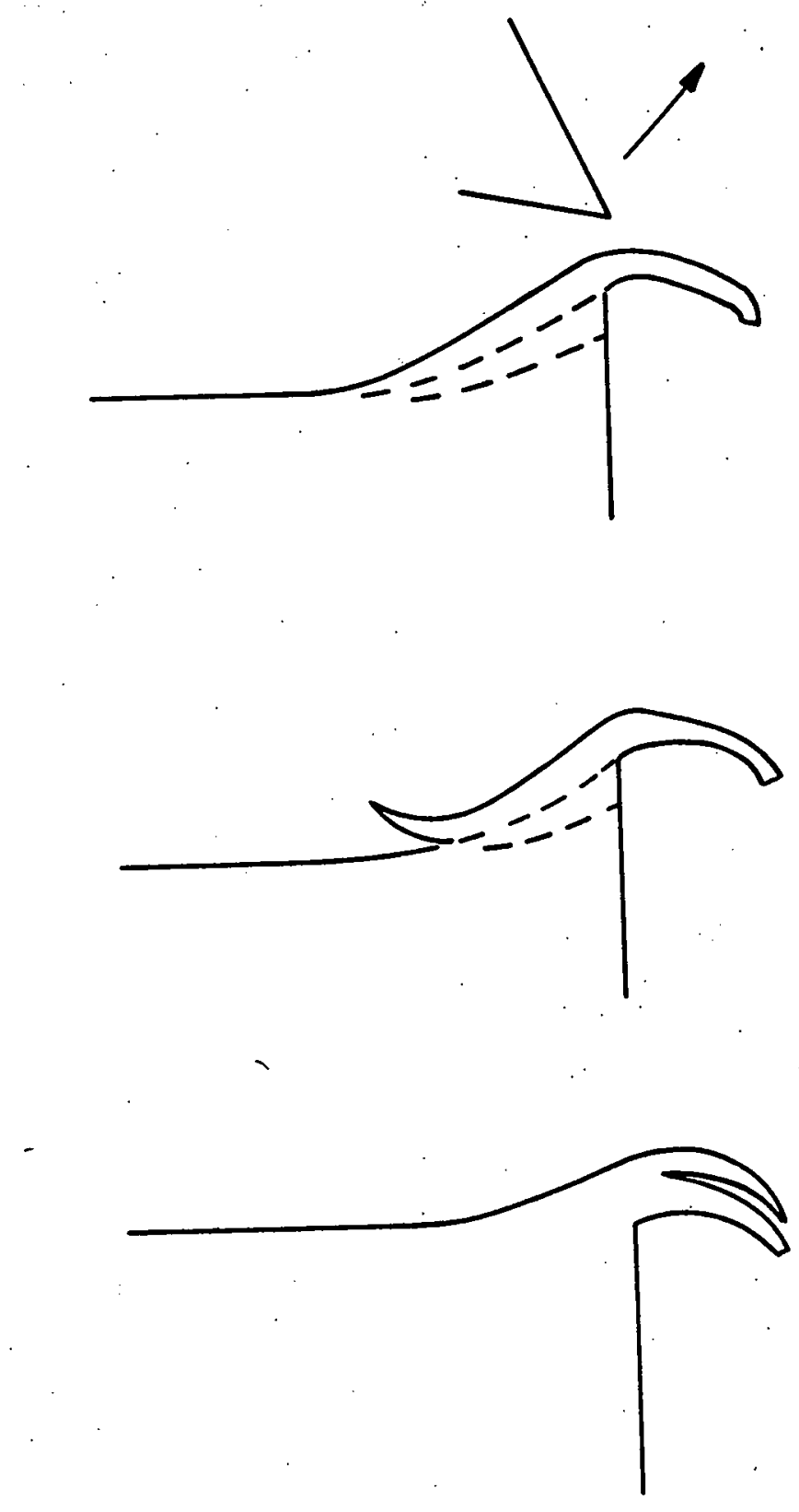

Figure 6. Exaggerated Illustration of Rol1-Over Burr Formed by a Number of Milling Teeth

24. 
cut is so small. This is not the case, however, because the burr will be rolled out of the path of the cutter when the second chip is rolled over. On the third pass the tooth will essentially only rub the root of the burr.

Although the discussion thus far has tacitly assumed a zero helix angle, the same effect occurs when the cutters have a helix angle.

The height of the roll-over burr is directly proportional to the radial depth of cut up to a depth of 0.6 of the cutter diameter (Figure 7). At this value of radial depth of cut, the material ahead of the cutter tears. Thus, roll-over burr height can be up to 0.6 times the cutter diameter. (The maximum chip thickness occurs directly in front of the cutter on its centerline. Thus, the maximum force and the thinnest web of material occurs at this point. The fact that the tear occurs past the centerline probably results from the direction of the cutting force as well as from the two factors mentioned.)

After the cutter breaks this web, the burr will bend over to edge 3. The material left near edge 4 will be removed by the cutter, since the cutter sees this edge as the entrance side of a climb cut (Figure 8 ). The long portion of the roll-over burr is often broken off in handling. Thus, it would appear to the casual observer that no burr or little burr had been produced at this edge.

Burrs can be longer than indicated if the radial depth of cut $d$ is greater than $\mathrm{D} / 8$, where $\mathrm{D}$ is the cutter diameter (Figure 7). Schafer's work ${ }^{24}$ indicates that whenever the angle $\phi$ is less than 150 degrees, a roll-over burr can form. As the angle decreases (d/D increases), the likelihood increases that a roll-over burr will form, beginning on the top surface. Thus, the burr height of the case shown in Figure $7 \mathrm{C}$ is the sum of the length of the backside and the top surface. In practice, this critical angle will probably vary with the material used. Once the d/D ratio approaches 0.5 , the long burr is almost certain to occur. The relationship between $\phi, d$, and $D$ is

$\phi=\sin ^{-1}\left(\frac{D-2 d}{D}\right)+90$ degrees.

The height of the roll-over burr formed on edge 7 will be much shorter than that formed at edge 3 . This is a result of three factors. As shown in Figure 8, as the end mill enters the workpiece, the angle $\phi$ at edge 7 is very large. Thus, no burr can form until the cutter has advanced at least until $\phi=150$ degrees. Although a chip begins forming as the cutting edge enters edge 6 of the workpiece, this chip cannot roll over because the material ahead of the cutter confines the chip to the flute of the cutter. 
7A. $\frac{d}{D}=0.075$.

$\phi=149$ DEGREES

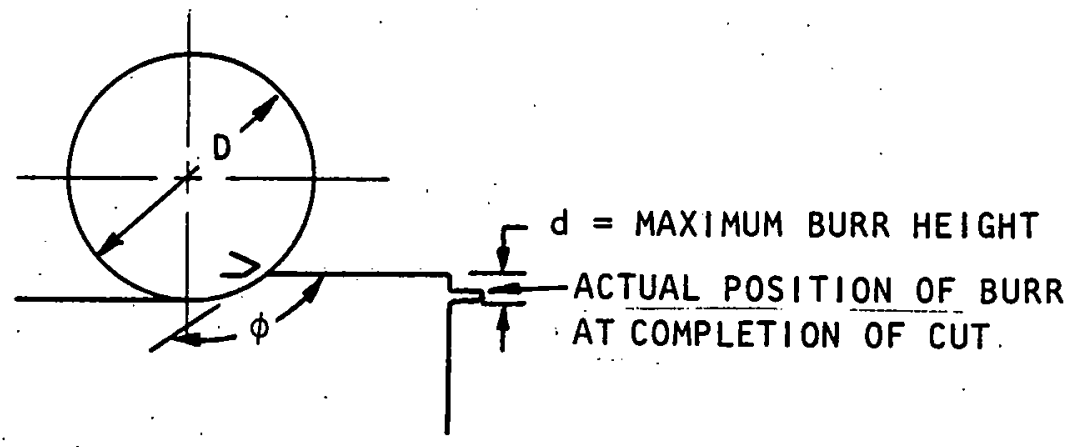

7B. $\frac{\mathrm{d}}{\mathrm{D}}=0.2$

$\phi=120$ DEGREES

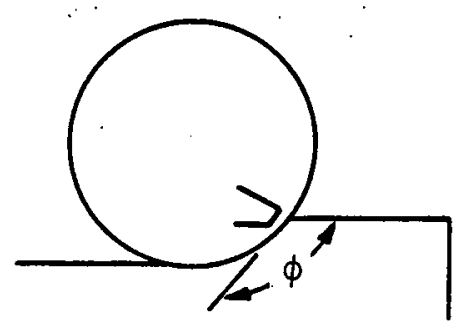

7C. $\frac{d}{D}=0.5$

$\phi=90$ DEGREES

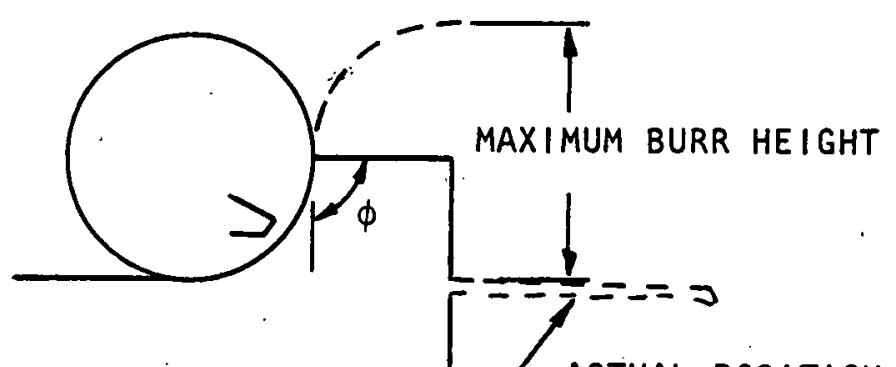

ACTUAL POSITION OF BURR

AT COMPLETION OF CUT

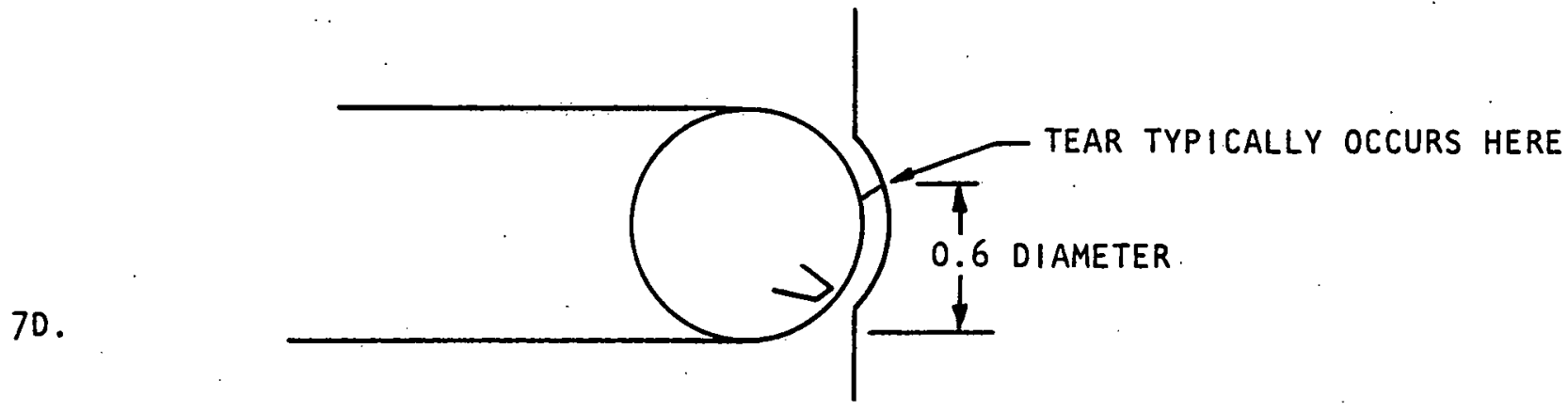

Figure 7. Effect of Angle $\phi$ on Maximum Burr Height at Edge 3 


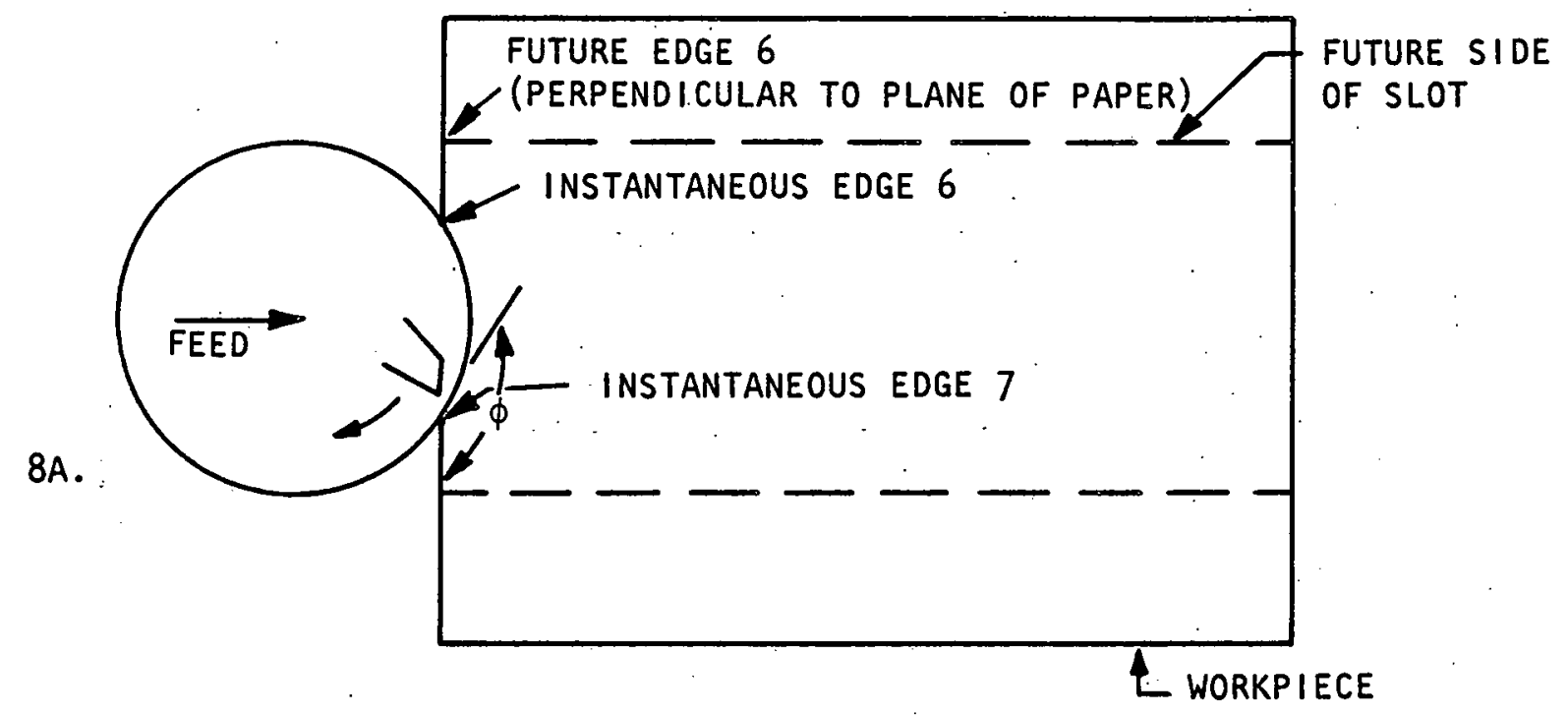

8B.

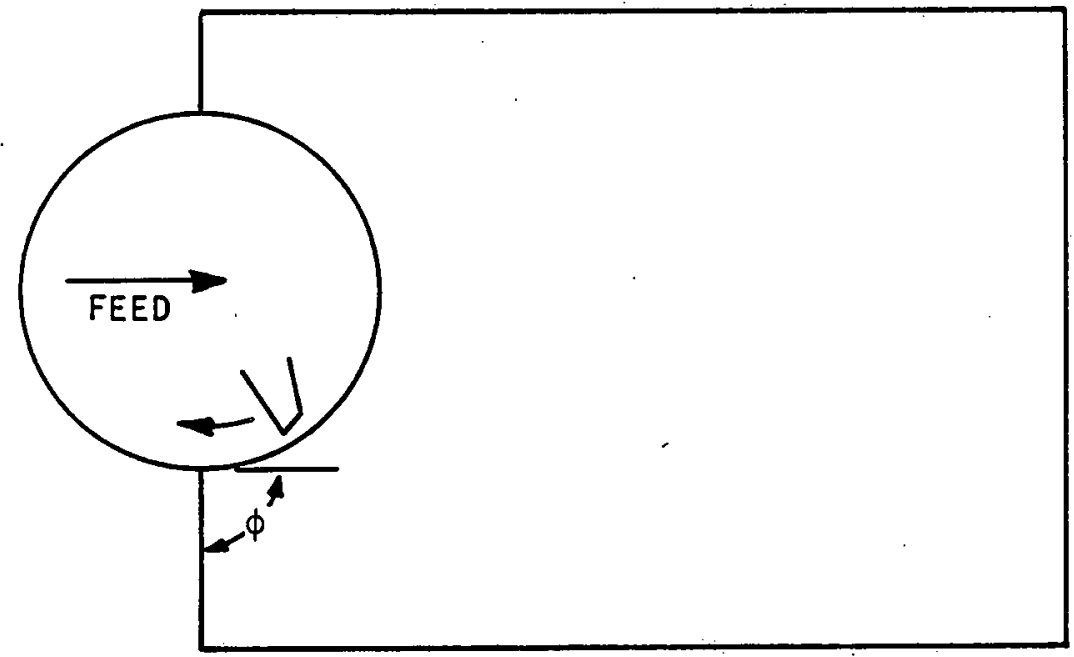

$8 \mathrm{C}$.

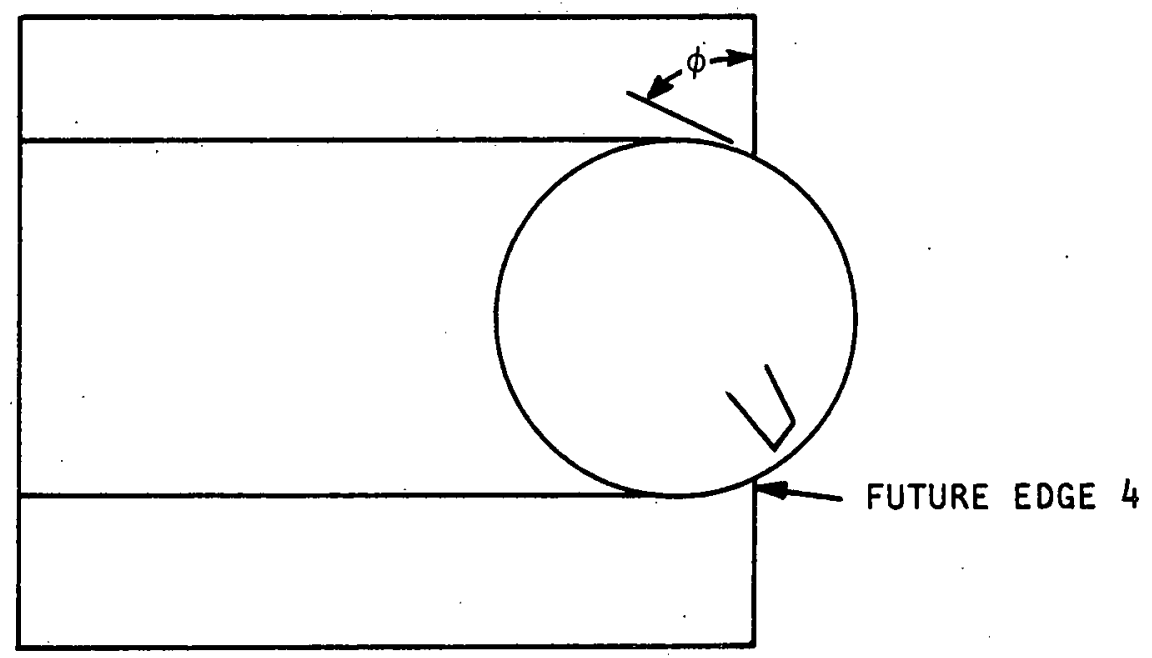

Figure 8. Cutter at Entrance and Exit of Slot 
This generally breaks up- the chip. The chip thickness as the tool exits from edge 7 is zero, since the tool is climb-cutting at this edge (Figure 5). Therefore, it is not possible, at least, theoretically, to have a long burr at this edge. The burr which is produced is formed before the full diameter of the cutter is in the cut. Subsequent cutting edges then only burnish the side of the burr.

The roll-over burr occurring on edge 9 is formed by the flutes and the bottom of the cutter. The action that occurs is easier to visualize if one thinks of the material in front of the tool as a rubber membrane. As the bottom corner of the flute exits over edge 9, it stretches the membrane (Figure 9). Eventually, the membrane tears at the corner of the tool, and the material ahead of the end-cutting edge is rolled over the edge. Because of small differences in the height of the end-cutting edges on the end mill, subsequent teeth scrape the bottom surface and may further increase burr height or thickness.

\section{The Entrance Burr}

When the cutting edge first indents the workpiece, it is possible for another type of burr to form (Figure 10). This entrance burr consists of material which has flowed opposite the direction of the tool. It is similar to the ridge which forms around the indentation made by a Brinnell Hardness Tester.

Whether or not a burr forms at this point depends on the workpiece properties and the actual shape of the cutting edge. Assuming that a cylinder-indenting metal produces effects somewhat similar to those of a ball-indenting metal, then strain-hardening plays. an important role. Based on Brinnell Hardness results, it has been shown ${ }^{25}$ that a lip of material forms when the material has a low strain-hardening exponent (Figures 11 and 12). Materials having high strain-hardening exponents cause a bulge but not a sharp burr. Assuming constancy of volume, this bulge will be wide, but short. In the previous case, the burr will be long, but narrow. In the case of high strain-hardening exponents, the bulge will probably be so short that it is difficult to detect. Unlike indentors, however, after the initial entry, further advancement of the tool does not increase burr size. The entrance burr is the result of material deformation within the first few thousandths inch of the surface.

Based on work with flat-nosed indentors ${ }^{26}$ a die roll rather than a burr will occur on the entrance edge if the cutting tool is very sharp, or if the cutting edge is fractured in such a way that it has a flat surface rather than a radius for the cutting edge. Occasionally a chip carried by the tool from a previous part will weld to this edge, making it appear that a burr was produced. All entrance burrs are small and easily removed. 


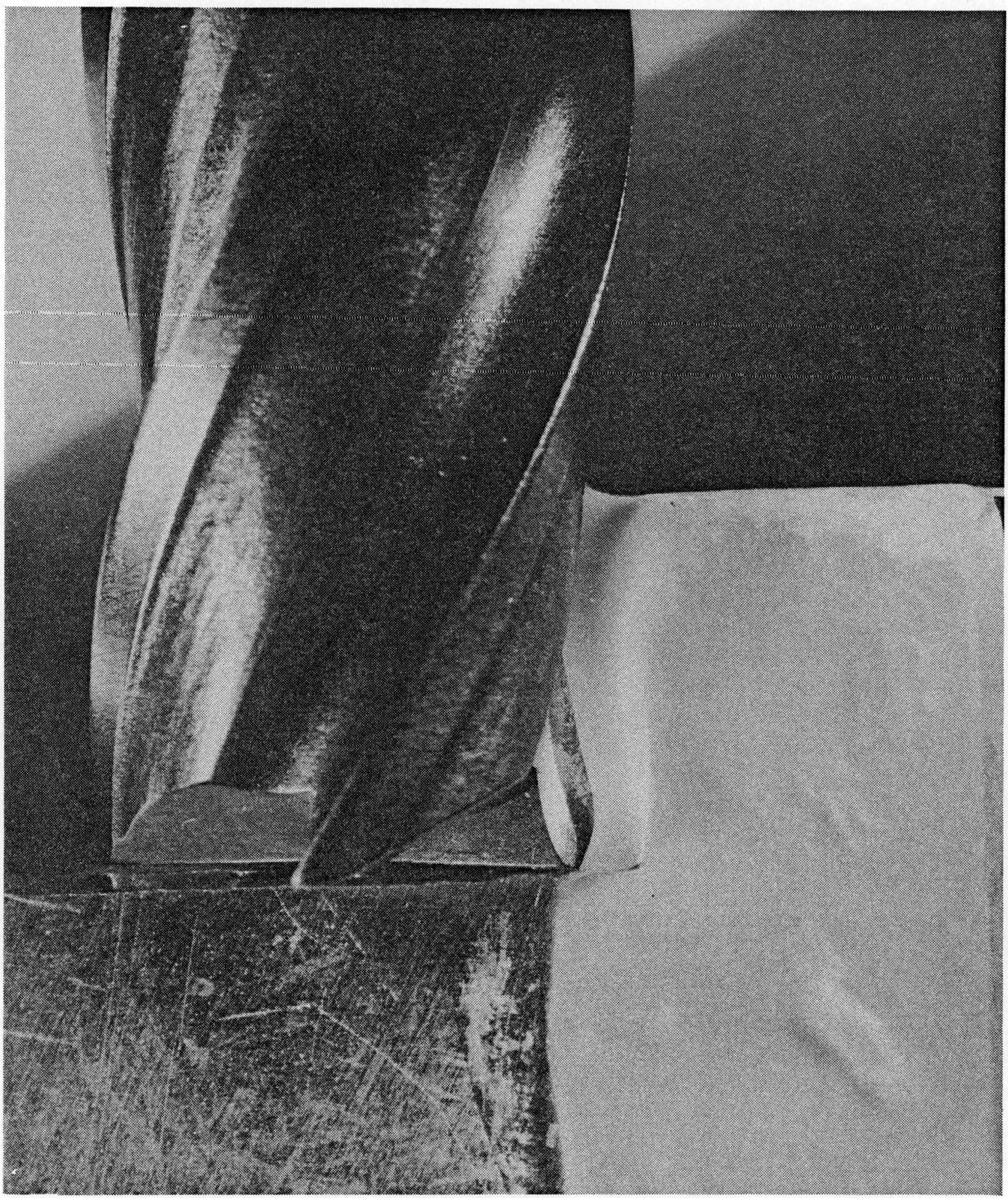

Figure 9. Membrane Analogy of Material Stretching at Corner of End-Mill Tooth 

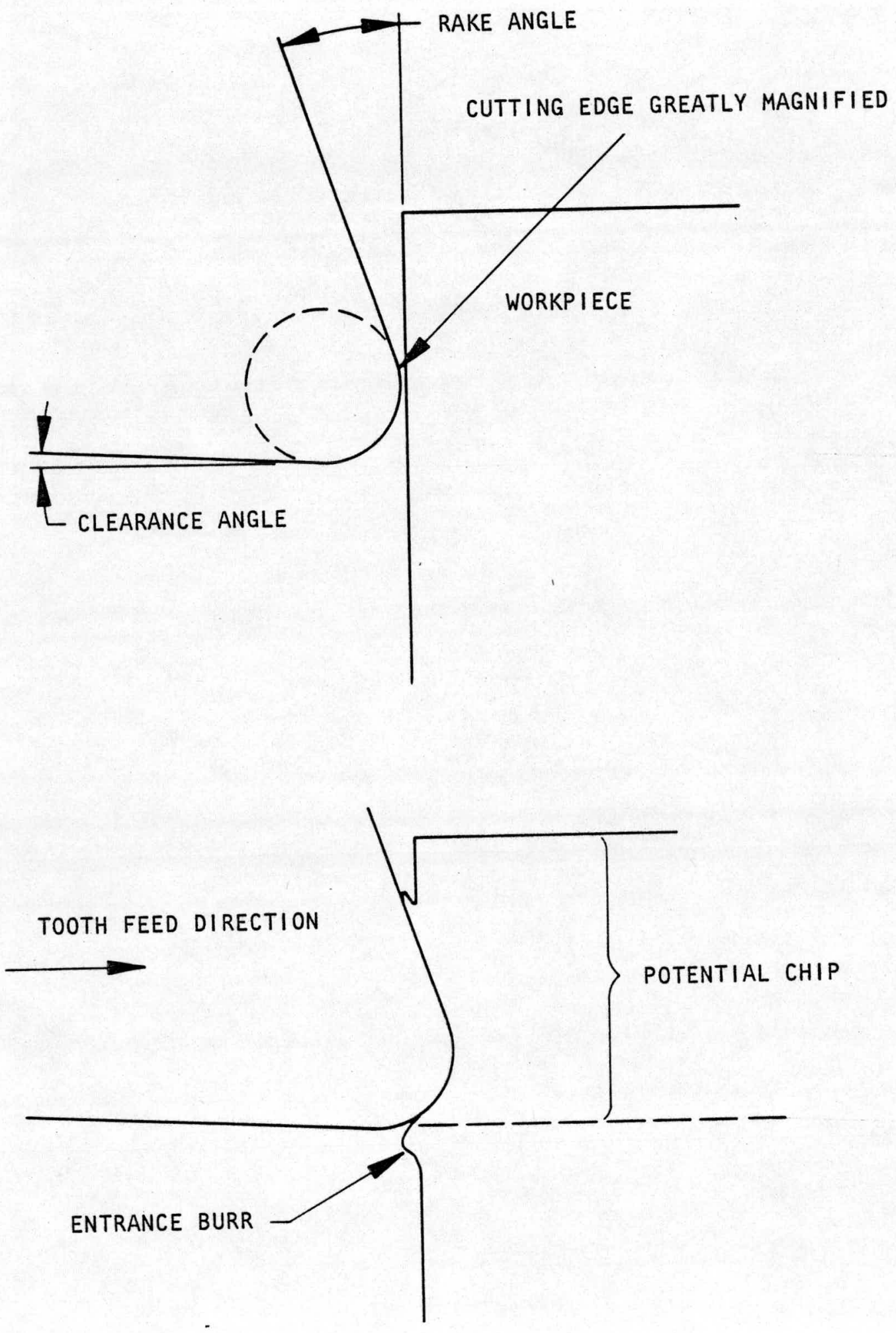

Figure 10. Cutting Edge Produces Indentation Burr as it Enters Workpiece 


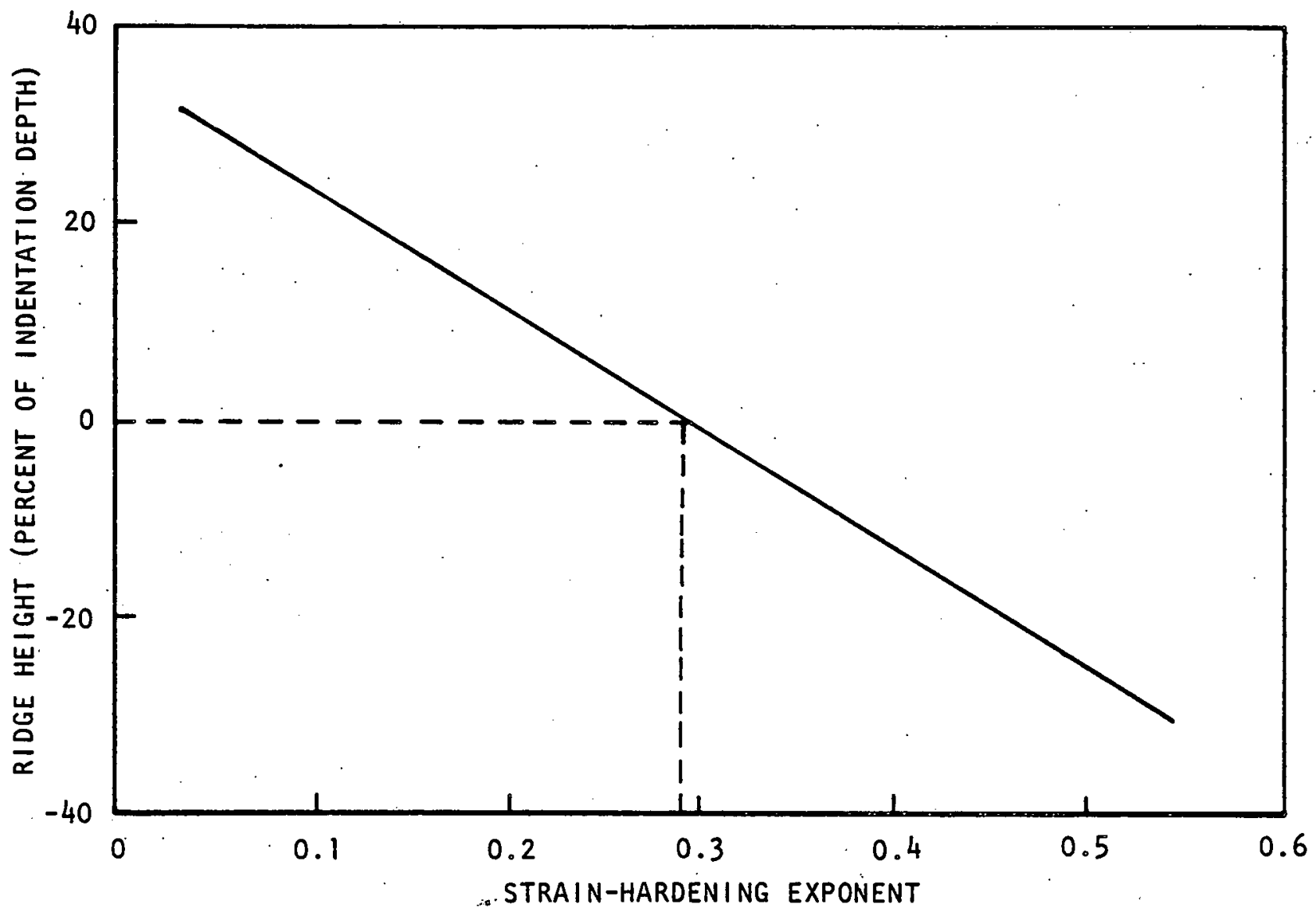

Figure 11. Effect of Strain-Hardening Exponent on Ridging Burr Formation (From Reference 26)
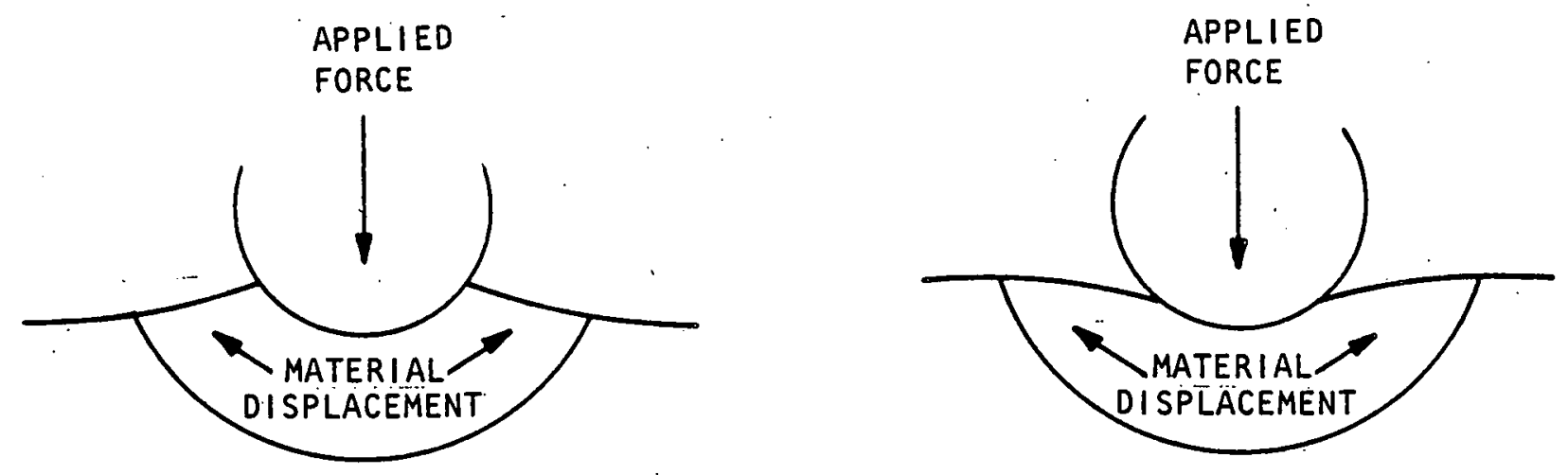

Figure 12. Material Displacement, Using Spherical Indentors (From Reference 26) 
An entrance burr occurs on edges 6 and 4 . The burrs on edges 5 and 8 are a combination of entrance burr and roll-over burr. From Figure 1, it can be seen that at the left half, the cutter produces an entrance burr on edge 8 . Since the right half of the cutter is actually exiting over edge 8 , it can only produce a roll-over burr. Thus, in a slotting operation, essentially no burr will occur on half of edges 5 and 8 , and a roll-over burr will occur on the other half. Because the angle at which the cutting edges exit from the workpiece varies as the tool enters and exits from the cut, the roll-over burr length will vary on these edges. It is also significant to note that the exit, burr on these two edges, as well as on edge 9, is actually a series of burrs. Each tooth produces a complete burr. However, these burrs are connected to each other to form a band of burrs which extends across the tool exit portion of the edge.

\section{The Poisson Burr}

A Poisson burr forms on edges 1, 2, and 10. This burr occurs whenever the cutting edge extends past an edge of the workpiece (Figure 13). In essence, it is the lateral deformation that occurs whenever any solid is compressed. The term Poisson burr is derived from the fact that this burr is directly related to Poisson's ratio. The extent of this deformation is a function of the workpiece material, the size and the shape of the contacting body, and the applied load. In the case of a cutting tool in which no rubbing occurs on clearance surfaces, the effective shape of the indentor is a cylinder. Because cutting tools have cutting edge radii of 0.0002 to $0.0050 \mathrm{inch}(5.08$ to $127.0 \mu \mathrm{m})$, the extent of the lateral deformation (burr size) is also relatively small. The actual size of the burr is proportional to cutting edge radius and the applied pressure.

Equations 8 and 9 predict burr size when the burr formation mechanism is assumed to be similar to that of the plastic expansion of a hollow cylinder. While equation 9 underpredicts burr thickness by a factor of 20 , these two equations are useful for showing the basic relationships between the significant variables. The major limitation in using these equations (other than underprediction) is in defining the magnitude of the pressure on the cutting edge of the tool.

$$
\begin{aligned}
& b_{L}=\left[\frac{h(1+v) \sigma_{e} \exp ^{-\left(\sqrt{3} \phi_{a}\right)}}{\sqrt{3} \mathrm{E}}\right]\left[-\frac{\sin \phi}{2(\sqrt{3} \cos \phi+\sin \phi)}\right], \\
& b_{t}=r\left[e^{\left.-\left(\sqrt{3} \phi_{a}\right) \cos \phi_{a}-1\right], \text { and }}\right.
\end{aligned}
$$




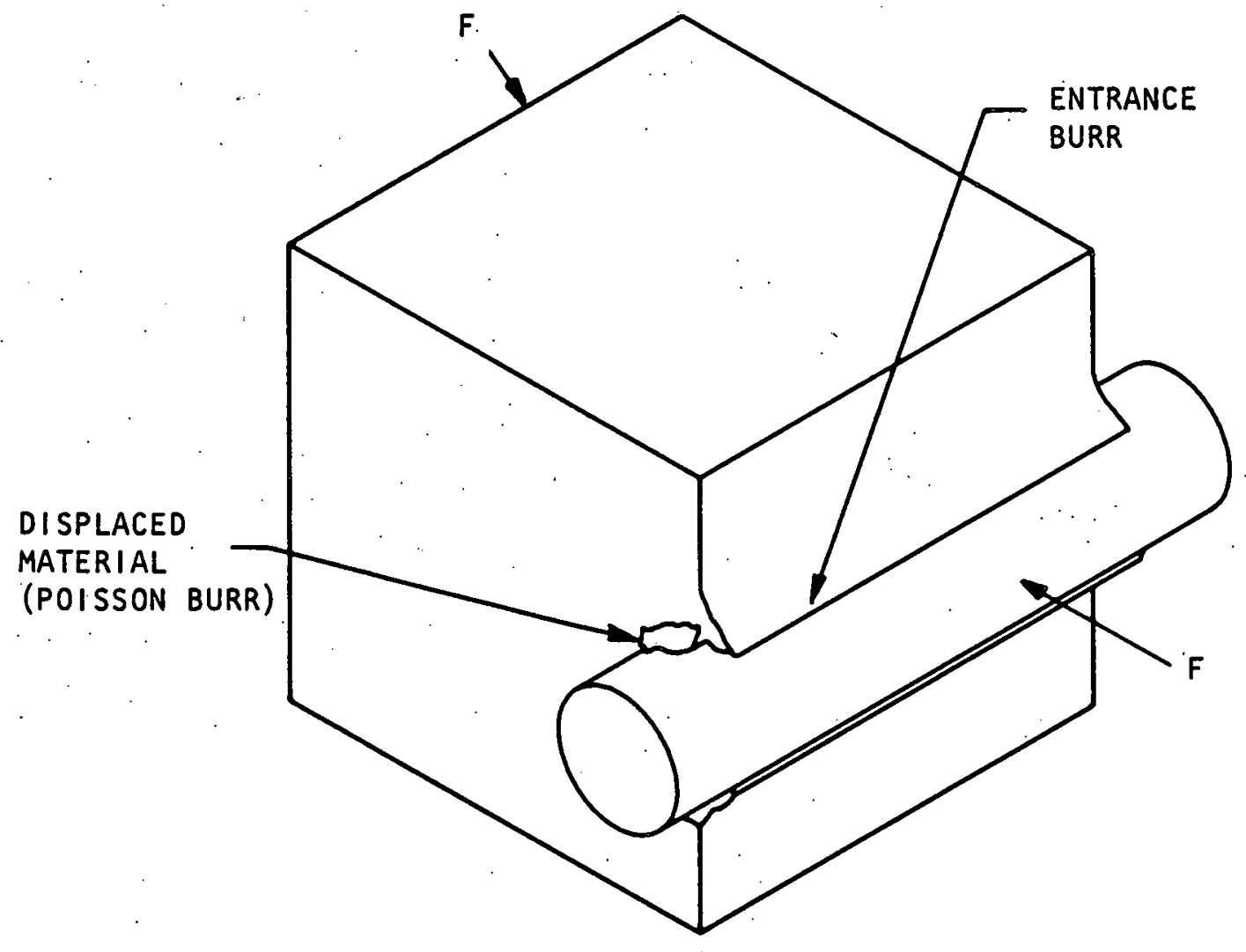

Figure 13. Formation of a Poisson Burr

$\phi_{a}=-\sin ^{-1}\left[\frac{\sqrt{3} \mathrm{p}}{2 \sigma_{\mathrm{e}}}\right]+\pi / 6$,

where

$b_{L}=$ burr length,

$\mathrm{b}_{t}=$ burr thickness

$\mathrm{h}=$ depth of cut,

$\nu=$ Poisson's ratio for elastic stresses,

$\sigma_{e}=$ yield stress of a perfectly plastic material,

$\mathrm{E}=$ modulus of elasticity,

$\underline{r}=$ cutting edge radius, 
$\mathrm{P}=$ pressure on cutting edge, and

$\phi=$ angle defining state of plastic flow.

Although the cutter takes the same depth of cut on edge 1 as it does on edge 2 , a significant difference in burr properties can occur. This difference is apparently the result of force differences between climb milling and conventional milling and the length of path traversed by the cutting teeth.

No upward force component exits on an end mill having a zero helix angle. Thus, any difference in burrs between:edges 1 and 2 can only be the result of the type of cut (climb versus conventional). When, as is typically the case, the tool has a helix angle, there is a tendency for the helix to produce a roll-over burr on top of the Poisson Burr. (Actually, the force systems act at the same time, and thus the burr is a composite rather than one distinct burr on top of another.) When the cutting edge (along the helix) enters the cut at point $1^{\prime}$ (Figure 4), it begins rolling up a chip. This chip is rolled approximately perpendicular to the helix angle. When the helix reaches point 1", the maximum chip length has been produced. If this chip were uncurled before it.was sheared from the edge, point $1^{\text {' }}$ would be at point $1^{\prime \prime}$.

The maximum height of the burr would be

$b_{h \max }=\ell$,

where

$\ell=$ axial depth of cut (slot depth).

The lateral dimension $w$ to point $1^{\text {". }}$ would be

$w=\frac{\ell}{\tan \theta}$,

where $\theta$ is the helix angle of the tool.

In actual practice, the burr size will seldom approach that shown in Figure 14 because the severe strain induced by chip curling causes the chip to break into many pieces. In addition, for feedrates above 0.002 inch $(50.8 \mu \mathrm{m})$ per revolution, as each cutting edge rotates, it shears off the burr left by the previous cutting edge. On edges 1 and 2 , however, each cutting edge leaves a short arc of material (and its burr) from the previous cut (Figure 15). Thus, the burr along these edges is actualiy a series of burrs. From Figures 14 and 15, it is apparent that burr height is proportional to the axial depth of cut, the feedrate, and the helix angle. 


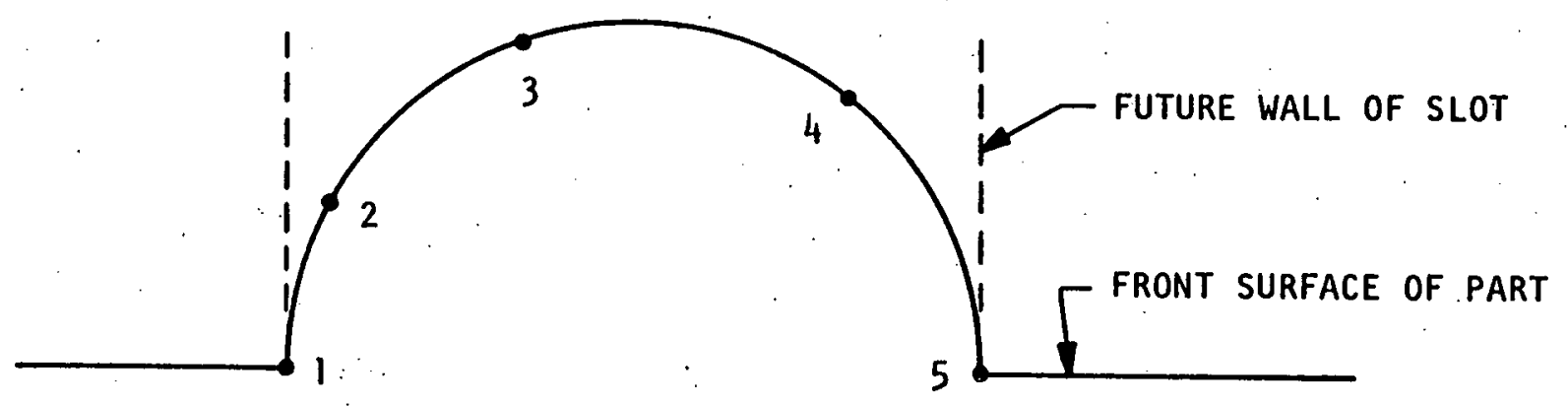

TOP VIEW OF PART AS FULL DIAMETER OF CUTTER. ENTERS WORKPIECE

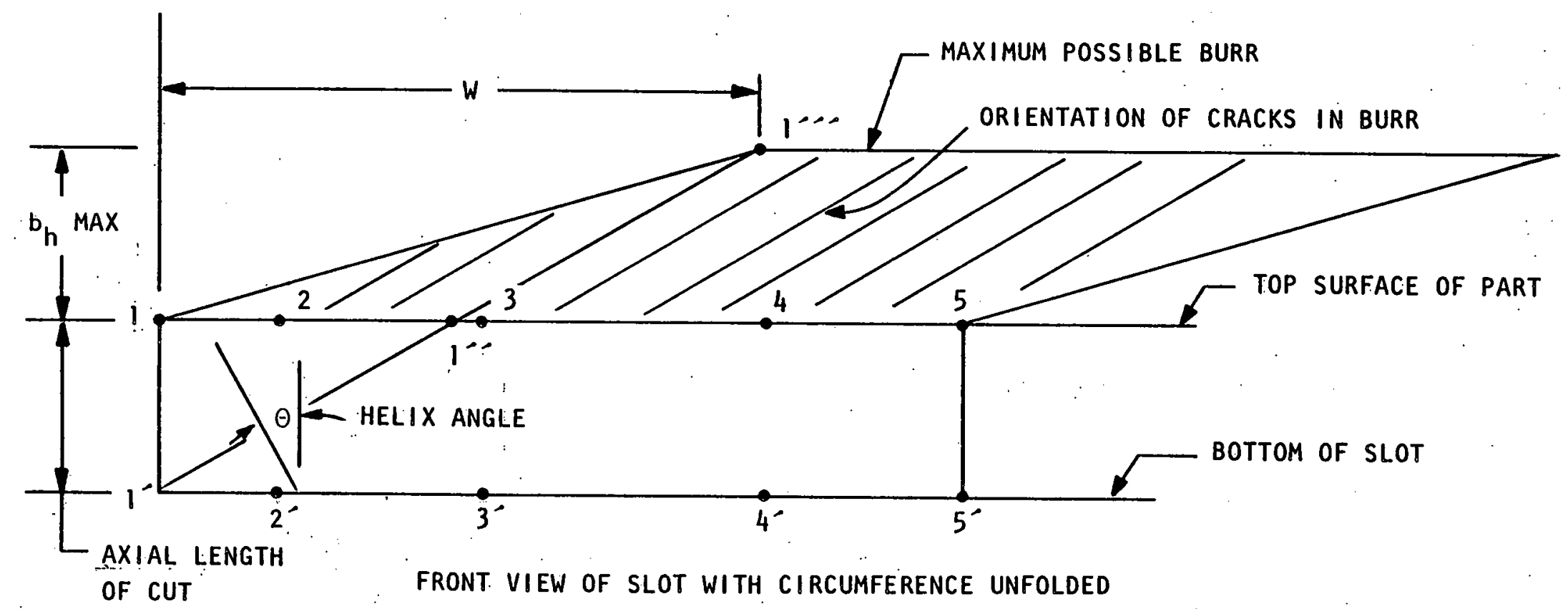

Figure 14. Maximum Possible Size and Shape of Helix-Generated, Roll-Over Burr 


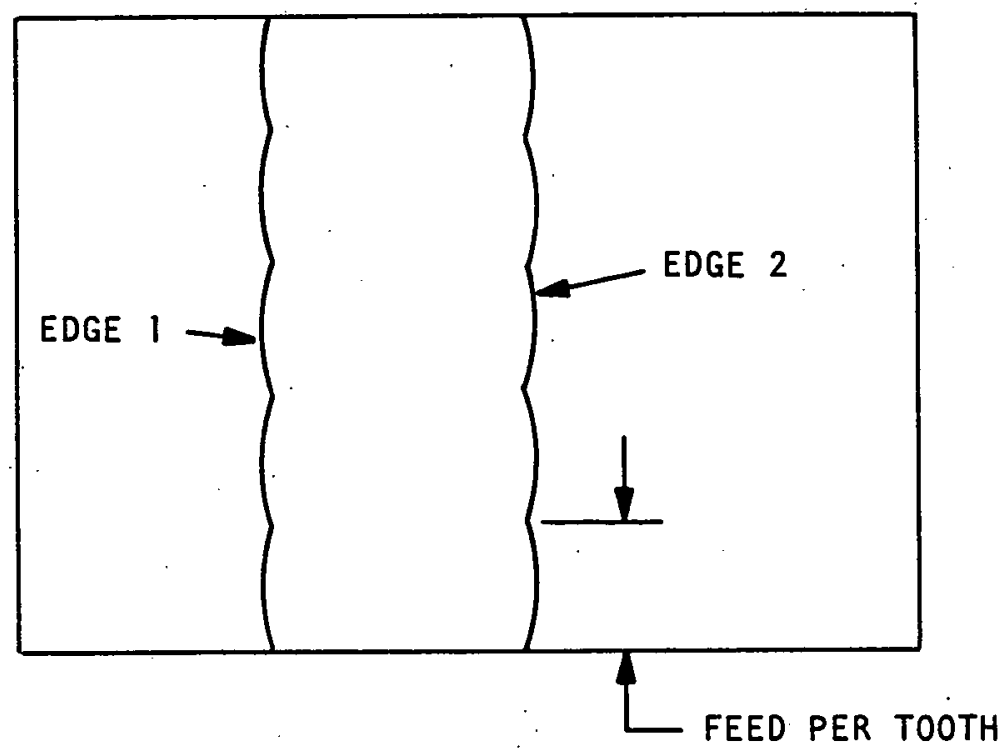

Figure 15. Enlarged View of

Edges 1 and 2

High-speed movies of end mills at feedrates of 0.002 inch or less indicate that the burr formed in front of the cutter increases in height with each revolution of the cutter. Periodically, the cutter takes enough material to completely cut off this burr.

Material Effects

As a general rule, long burrs will not form in brittle materials. The heat generated in some processes, however, is sufficient to anneal the material during burr and chip formation. When this happens, a burr will occur that is larger than predicted. This is particularly true of heat-sensitive, brittle materials.

Burrs are harder than the parent material because they are the result of severe straining. Most materials strain-harden by the relationship given in equation 13 .

$\sigma=\sigma_{0} \varepsilon^{\mathrm{n}}$

where

$\sigma$ is the true yield stress,

$\sigma_{0}$ is a material constant,

$\varepsilon$ is the true strain, and 
$\mathrm{n}$ is the strain-hardening exponent.

Since material hardness is a linear function of the yield strength, it is obvious that the more the material is strained, the harder it will become. Because not all the material in a burr is strain-hardened equally, measurements of hardness are made at the root of the burr (Figure 16).

\section{Climb Cut Versus Conventional Cut}

Throughout this discussion; a conventional cut has been tacitly assumed. When a climb cut is utilized, the burr properties will differ from the conventional cut. The burr normally produced at edge 1 will be produced at edge 2. A similar transformation occurs at other edges. To minimize confusion, climb-milled edges in the remainder of the report will be identified as edges 2,4 , and 7 , corresponding to the climb-milled edges in. a slotting operation.

\section{Test Results}

Four tests were performed to determine burr properties from end milling. In the first test, 128 combinations of cutting conditions and material were evaluated. Burrs were measured at seven of the 10 edges. In the second test, effects of tool wear on burr properties were studied. In the third test, the effects of end-milling Hiperco 50 (a highly magnetic material) were recorded. In the fourth test, the effects of helix angle were briefly studied. As previously indicated, high-speed motion pictures were also taken of burrs as they formed on edges 1 and 2 .

\section{Effects of Machining Conditions}

In the first test, 128 combinations of cutter diameter, axial depth of cut, radial depth of cut, feedrate, tool sharpness, and workpiece material were studied. One specimen was produced at each combination of the factors shown in Table 1 . All cutters were high-speed steel and were rotated at 1115 RPM. A water soluble coolant was used on all cuts.

Figures 1 and 2 illustrate how the specimens were machined and the location of burrs studied. All specimens were ground prior to machining in the shape of a cube with $1.0-i n c h(25.4 \mathrm{~mm})$ sides. Burr heights were then measured optically. Specimens were then cross-sectioned, mounted in metallurgical mounts, and polished to show the cross section of burrs $1,2,3,5,6$, 7 , and 9. Both height and thickness were then recorded on these burrs. The mounted specimens were then ground down, optically repolished, and again burr height and thickness were measured. This provided two measurements on each burr. 


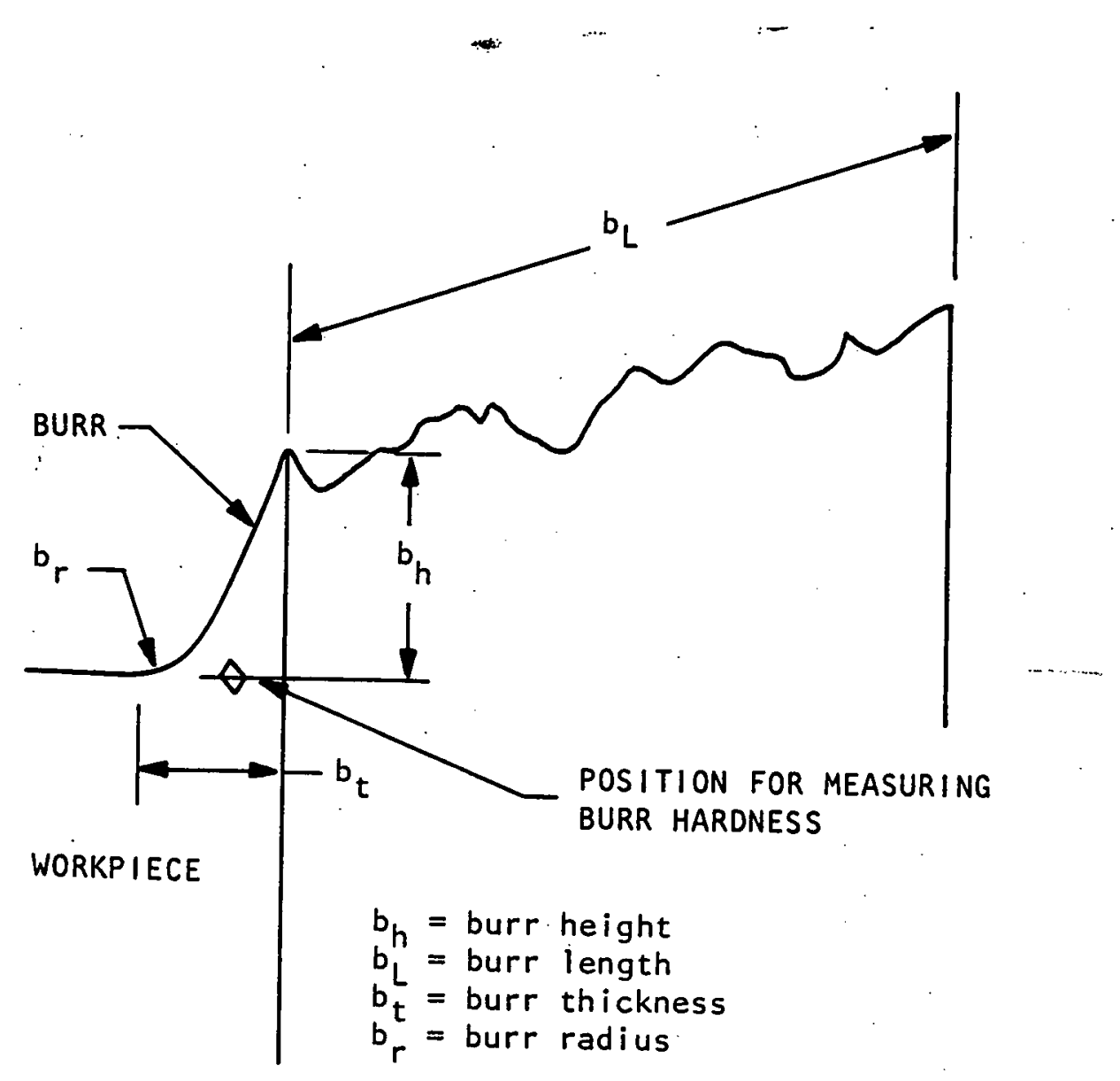

Figure 16. Definition of Burr Properties

The data were analyzed as a $2^{5} \times 4$ factorial design, having one repeat (two measurements) for each of the 128 cutting combinations. The analysis of variance (ANOVA) of the results is indicated in Tables 2,3 , and 4 . The asterisks in these tables indicate combinations which statistically affected burr size. The tool diameter, for example, influenced the height of the burr on edges $1,2,5$, and 9 , but the diameter did not affect the height of burrs on edges 3,6 , or 7 .

While the ANOVA indicates statistically significant variables, it does not of itself indicate whether the variable increases or decreases the burr size. Plotting the data, however, reveals the nature of the trends. The ANOVA tables indicate the existence of a large number of higher order interactions; that is, combinations of variables which affect burr size much more than one would predict from a knowledge of average trends. Plotting these significant interactions would require at least 100 graphs. At this time, such an analysis does not seem warranted.

Text continued on page 49. 
Table 1. End-Milling Conditions Used

\begin{tabular}{|c|c|c|c|c|c|c|c|}
\hline \multirow[b]{2}{*}{$\begin{array}{l}\text { Code } \\
\text { Level }\end{array}$} & \multirow{2}{*}{$\begin{array}{l}\text { A } \\
\text { Tool } \\
\text { Diameter } \\
\text { (in.)* }\end{array}$} & $\begin{array}{l}\text { B } \\
\text { Depth } 0 \\
\end{array}$ & $\begin{array}{c}\mathrm{C} \\
\mathrm{Cut}\end{array}$ & $\mathrm{D}$ & \multirow{2}{*}{$\begin{array}{l}\text { E } \\
\text { Tool } \\
\text { Sharpness } \\
(\text { in. })^{*}\end{array}$} & \multirow{2}{*}{$\begin{array}{l}\text { F } \\
\text { Workpiece } \\
\text { Material }\end{array}$} & \multirow{2}{*}{$\begin{array}{l}\mathrm{G} \\
\text { Hardness } \\
\left(\mathrm{R}_{\mathrm{c}}\right)\end{array}$} \\
\hline & & $\begin{array}{l}\text { Axial } \\
(\text { in. })^{*}\end{array}$ & $\begin{array}{l}\text { Radial } \\
\text { (Percent } \\
\text { Diameter) }\end{array}$ & $\begin{array}{l}\text { Feed } \\
(I P R / t)\end{array}$ & & & \\
\hline 1 & $0.250 * *$ & 0.050 & 0.1 & 0.0005 & Sharp & $\begin{array}{l}17-4 \text { PH SST } \\
(\mathrm{H} \mathrm{900)}\end{array}$ & 46 \\
\hline 2 & $0.375 * *$ & 0.100 & 1.0 & 0.0020 & $0.001 \mathrm{R}$ & $303 \mathrm{Se} \mathrm{SST}$ & 24 \\
\hline 3 & & & & . & & $\begin{array}{l}\text { 6061-T6 } \\
\text { Aluminum }\end{array}$ & 63 \\
\hline 4 & & & & & & 1018 steel & 90 \\
\hline
\end{tabular}

$* 0.001$ inch equals $25.4 \mu \mathrm{m}$

**Bendix Kansas City tool numbers 51105222 and 5113202 . Descriptions are presented in Apendix $B$. 
Table 2. ANOVA of Burr Height

\begin{tabular}{|c|c|c|c|c|c|c|c|}
\hline \multirow[b]{2}{*}{ Effect } & \multicolumn{7}{|c|}{ Edge Number } \\
\hline & 1 & 3 & 6 & 2 & 5 & 7 & 9 \\
\hline Tool Diameter A (A) $\dagger$ & $*$ & & & * & $* * *$ & & $*$ \\
\hline $\begin{array}{l}\text { Axial Depth B (B) } \\
\text { Radial Depth C }\end{array}$ & & * & & $*$ & $* * *$ & & \\
\hline $\begin{array}{l}\text { Radial Depth C } \\
\text { Feed Rate D (C) }\end{array}$ & & $* * *$ & & - & - & - & $\overline{-}$ \\
\hline $\begin{array}{l}\text { Feed Rate D (C) } \\
\text { Tool Sharpness E (D) }\end{array}$ & $* * *$ & & $*$ & $\begin{array}{l}* * * \\
*\end{array}$ & & $* * *$ & $\begin{array}{l}* * * \\
* * *\end{array}$ \\
\hline $\begin{array}{l}\text { Tool Sharpness E (D) } \\
\text { Workpiece Material } \cdot F(E)\end{array}$ & $*$ & $* *$ & * & $*$ & $* *$ & $* * *$ & \\
\hline Tool Diameter $x$ Axial Depth & & & & * & $* *$ & & \\
\hline Tool Diameter x Radial Depth & & & $*$ & - & - & - & - \\
\hline Tool Diameter x Feed Rate. & & & * & $*$ & & & \\
\hline Tool Diameter x Tool Sharpness & & $* *$ & & & $* * *$ & ** & \\
\hline Tool Diameter $x$ Workpiece Material & * & $* *$ & $* *$ & & $* * *$ & & $* *$ \\
\hline Axial Depth x Radial Depth & & & & - & - & - & - \\
\hline Axial Depth x Feed Rate & & & & $* *$ & & $* *$ & \\
\hline Axial Depth x Tool Sharpness & & & & & $* * *$ & & \\
\hline Axial Depth x Workpiece Material & & & * & & $* * *$ & $* *$ & \\
\hline Radial Depth x Feed Rate & & & & - & - & - & - \\
\hline Radial Depth $x$ Tool Sharpness & & $* * *$ & & - & - & - & - \\
\hline Radial Depth $x$ Workpiece Material & & $* * *$ & & - & - & - & - \\
\hline Feed Rate $x$ Tool Sharpness & & & $*$ & & & $* *$ & \\
\hline Feed Rate $\mathrm{x}$ Workpiece Material & $*$ & ** & & $*$ & & $* *$ & \\
\hline $\begin{array}{l}\text { Tool Diameter x Axial Depth } \\
\text { x Radial Depth. }\end{array}$ & $*$ & * & ** & - & - & - & - \\
\hline Tool Diameter x Axial Depth & & & & & & & \\
\hline $\begin{array}{l}\text { x Feed Rate } \\
\text { Tool Diameter } x \text { Axial Depth }\end{array}$ & & & . & & & * & \\
\hline $\begin{array}{l}\text { Tool Diameter x Axial Depth } \\
x \text { Tool Sharpness }\end{array}$ & & & & $* * *$ & * & & \\
\hline $\begin{array}{l}\text { Tool Diameter x Axial Depth } \\
\text { x Workpiece Material }\end{array}$ & $*$ & $* *$ & $* *$ & $*$ & $* * *$ & & \\
\hline $\begin{array}{l}\text { Tool Diameter x Radial Depth } \\
\times \text { Feed Rate }\end{array}$ & & & & - & - & - & - \\
\hline
\end{tabular}


Table 2 Continued. ANOVA of Burr Height

Edge Number

Effect

1

3

6

2

Tool Diameter $x$ Radial Depth $x$ Tool Sharpness

Tool Diameter $x$ Radial Depth $x$ Workpiece Material.

Tool Diameter $x$ Feed Rate $x$ Tool Sharpness

Tool Diameter $x$ Feed Rate $x$ Workpiece Material

Tool Diameter $x$. Tool Sharpness $x$ Workpiece Material

Axial Depth x Radial Depth $x$ Feed Rate

Axial Depth $x$ Radial Depth $x$ Tool Sharpness

Axial Depth $x$ Radial Depth $x$ Workpiece Material

Axial. Depth $x$ Feed Rate $x$ Tool Sharpness

Axial Depth $x$ Feed Rate $x$ Workpiece Material:

Axial Depth x Tool Sharpness $x$ Workpiece Material

Radial Depth $x \cdot$ Feed Rate $x$ Tool Sharpness

Radial Depth x Feed Rate $x$ Workpiece Material

Radial Depth x Tool Sharpness $x$ Workpiece Material

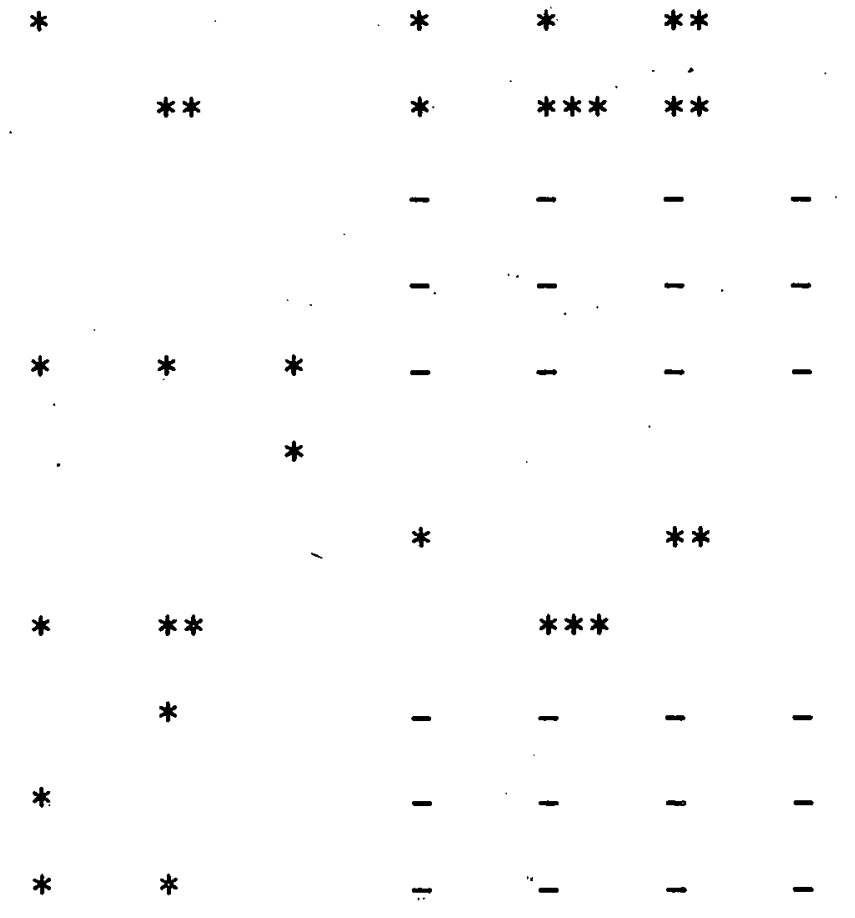


Table 2 Continued. ANOVA of Burr Height

Edge Number

\begin{tabular}{lllllllll} 
Effect & 1 & 3 & 6 & 2 & 5 & 7 & 9 & \\
\hline
\end{tabular}

Feed Rate $x$ Tool Sharpness

$x$ Workpiece Material

*Indicates significant at 95-percent confidence level.

**Indicates significant at 99-percent confidence level.

***Indicates significant at level much greater than 99-percent.

†Because of the nature of the test, burr numbers $2 ; 5,7$, and 9 are

only produced on half of the parts. The variable codes ( $A, B, C$,

$D, E$, and F) were renamed for these burrs, as indicated by the code

letter in brackets. 
Table 3. ANOVA of Burr Thickness

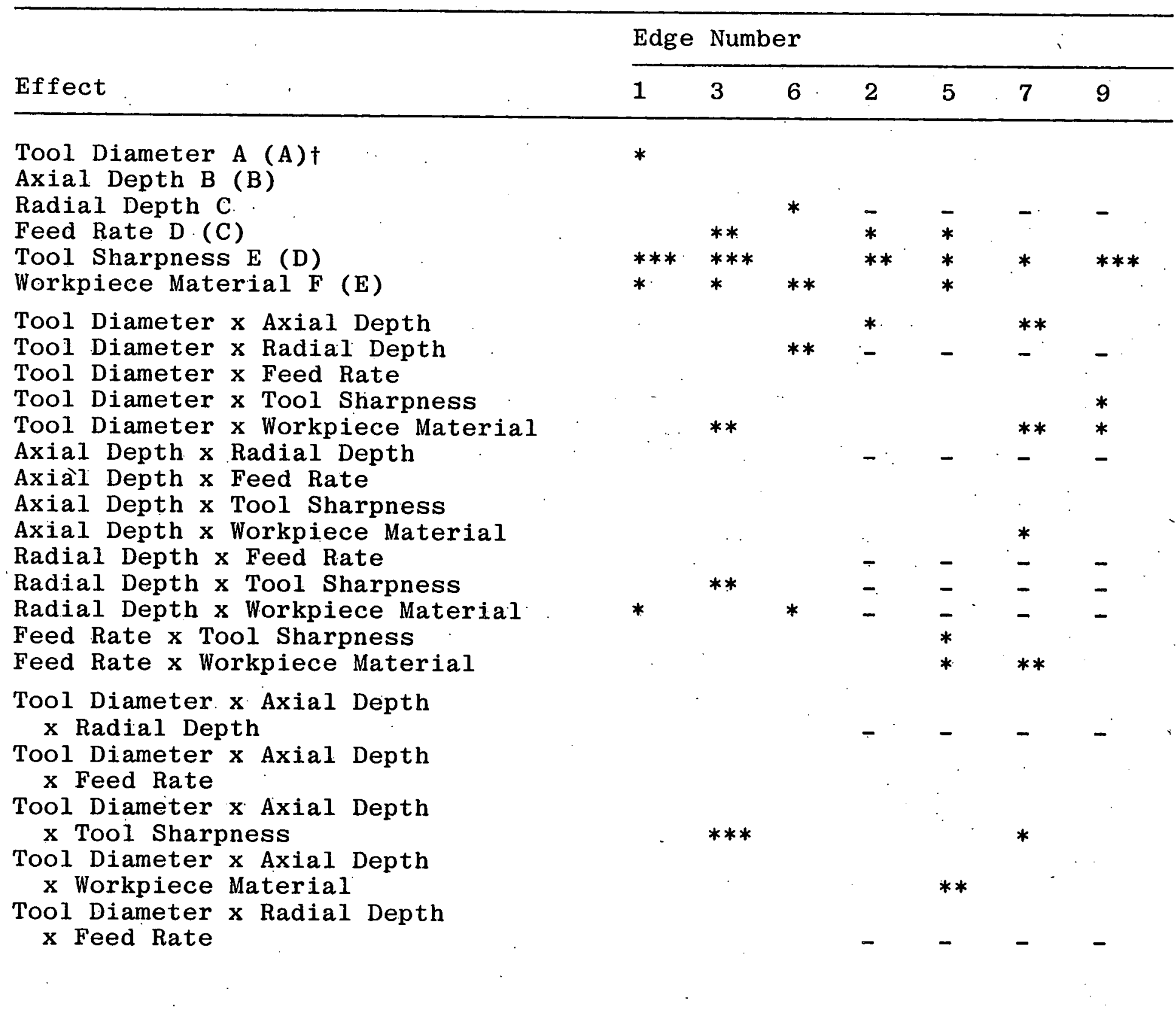


Table 3 Continued. ANOVA of Burr Thickness

Edge Number

Effect

\begin{tabular}{llllllll}
\hline 1 & 3 & 6 & 2 & 5 & 7 & 9
\end{tabular}

Tool Diameter $x$ Radial Depth $x$ Tool Sharpness

Tool Diameter $x$ Radial Depth

$x$ Workpiece Material

Tool Diameter $x$ Feed Rate

$x$ Tool Sharpness

Tool Diameter $x$ Feed Rate

$x$ Workpiece Material

Tool Diameter $x$ Tool Sharpness

$x$ Workpiece Material

Axial Depth $x$ Radial Depth

$x$ Feed Rate

Axial Depth $x$ Radial Depth

$x$ Tool Sharpness

Axial Depth $x$ Radial Depth

$x$ Workpiece Material.

Axial Depth $x$ Feed Rate

$x$ Tool Sharpness

Axial Depth $x$ Feed Rate

$x$ Workpiece Material

Axial Depth $x$ Tool Sharpness

$x$ Workpiece Material

Radial Depth x Feed Rate $x$ Tool Sharpness

Radial Depth $x$ Feed Rate

$x$ Workpiece Material

Radial Depth $x$ Tool Sharpness

$x$ Workpiece Material 
Table 3. Continued. ANOVA of Burr Thickness

\begin{tabular}{|c|c|c|c|}
\hline \multirow[b]{2}{*}{ Effect } & \multicolumn{3}{|l|}{ Edge Number } \\
\hline & 1 & 2 & 9 \\
\hline $\begin{array}{l}\text { Feed Rate } x \text { Tool Sharpness } \\
\text { x Workpiece Material }\end{array}$ & . & * & k \\
\hline $\begin{array}{l}\text { *Indicates significant at } 95 \text {-percent } \\
\text { **Indicates significant at 99-percent } \\
\text { ***Indicates significant at level much } \\
\text { †Because of the nature of the test, } \\
\text { only produced on half of the parts. } \\
\text { D, E, and F) were renamed for these } \\
\text { letter in brackets. }\end{array}$ & $\begin{array}{l}\text { confidence } 1 \\
\text { confidence } 1 \\
\text { greater than } \\
\text { burr numbers } \\
\text { The variab } \\
\text { burrs, as i }\end{array}$ & $\begin{array}{l}\text { level. } \\
\text { level. } \\
\text { n } 99-\text { percent. } \\
\text { s } 2,5,7 \text {, and } 9 \\
\text { ble codes. (A, B, } \\
\text { indicated by the }\end{array}$ & $\begin{array}{l}\text { are } \\
\text { C } \\
\text { code }\end{array}$ \\
\hline
\end{tabular}


Table 4. ANOVA Summary of Effects on Burr Radius

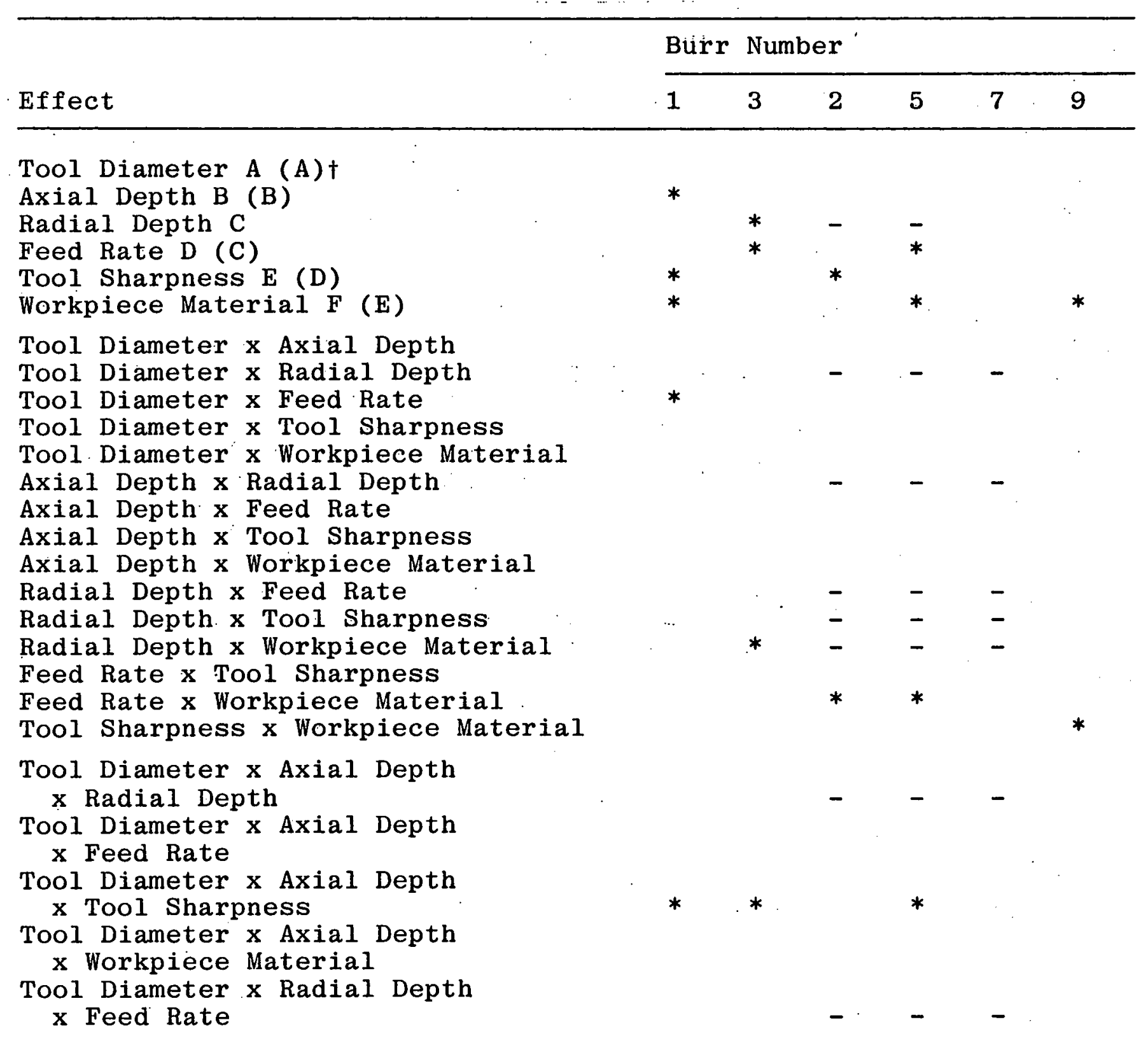


Table :4 Continued. ANOVA Summary of Effect on Burr Radius

Burir Number

Effect

$1 \quad 3 \quad 2 \quad 5$

$\begin{array}{ll}7 & 9\end{array}$

Tool Diameter $x$ Radial Depth $x$ Tool Sharpness

Tool Diameter $x$ Radial Depth $x$ Workpiece Material

Tool Diameter $x$ Feed Rate $x$ Tool Sharpness

Tool Diameter $x$ Feed Rate $x$ Workpiece Material

Tool Diameter $x$ Tool Sharpness

$x$ Workpiece Material

Axial Depth $x$ Radial Depth $x$ Feed Rate

Axial Depth x Radial Depth $x$ Tool Sharpness

Axial Depth x Radial Depth

$x$ Workpiece Material

Axial Depth $x$ Feed Rate

$x$ Tool Sharpness

Axial Depth x Feed Rate

$x$ Workpiece Material

Axial Depth $x$ Tool Sharpness

$x$ Workpiece Material

Radial Depth $x$ Feed Rate

$x$ Tóol Sharpness

Radial Depth $x$ Feed Rate

$x$ Workpiece Material

Radial Depth $x$ Tool Sharpness

$x$ Workpiece Material 
Table 4 .Continued. ANOVA Summary of Effect on Burr Radius

Burr Number

Effect

1

3

25

7

9

Feed Rate $x$ Tool Sharpness

$\mathrm{x}$ Workpiece Material

†Because of the nature of the test, burr numbers 2, 5, 7, and 9 are only produced on half of the parts. The variable codes ( $A, B, C$, $D, E$, and F) were renamed for these burrs, as indicated by the code letter in brackets.

*Indicates that the factor, or combination of factors, shown is statistically significant at the 95-percent confidence level. 
To provide a readable and usable analysis, only part of the data have been presented in a graphical format:

- All the significant main effects which have been plotted are presented on subsequent pages.

- In addition to plots of significant main effects, plots of burr size as a function of tool sharpness and feedrate have been included for $303 \mathrm{Se}$ and 17-4 PH stainless steel when these plots revealed some notable trends.

No plot is shown for the effect of tool diameter on the burr height at edge 3 , since the ANOVA table indicated that no significant trends existed. plots for the main effects are an average of results for all four materials used in this study. No graphs are presented specifically for aluminum or low-carbon steel. These materials were not plotted, primarily because burrs in stainless steel are more representative of typical Bendix production situations. In the interest of brevity, tool diameter, axial depth of cut, and radial depth of cut are not plotted in most cases, and also because the geometry of the part dictates these factors in production situations. Production personnel, however, can readily control feedrate and tool sharpness; therefore, graphs are presented for these factors. The fact that many combinations have not been plotted does not imply that they are not significant, but only that they are of less direct interest to production. While three factor interactions are significant, it is difficult to use them in production. Since actual burr measurements are presented in Appendix $A$ of this report, it is possible to evaluate any combination not specifically plotted.

Average burr property data are presented in Table 5. As shown, burr height varies from 0.0001 inch $(2.5 \mu \mathrm{m})$ to 0.0700 inch ( $1.778 \mathrm{~mm}$ ), depending upon the edge on which the burr is found. Burr thickness typically varies from 0.002 to 0.004 inch ( 50.8 to $101.6 \mu \mathrm{m})$, while the radius on the backside of the burr varies from 0.001 to 0.002 inch $(25.4$ to $50.8 \mu \mathrm{m})$. Metallurgical mounts were not made of edges 4 and 6 . The values shown for them in Table 5 were obtained from optical measurements prior to sectioning the samples. Burr thickness and radius could not be accurately measured without metallurgical mounts so data is not available for these properties at edges 4 and 8 . Because of the extremely small size of burrs on edge 6 , it was not possible to obtain measurements of burr radius on this edge.

Burr Height

The end-mill diameter influenced burr height on four edges (Figure 17). On edges 2 and 5, a larger cutter produced higher

Text continued on page 53 . 
Table 5. Typical Burr Properties From End Milling

\begin{tabular}{|c|c|c|c|}
\hline \multirow{2}{*}{$\begin{array}{l}\text { Burr } \\
\text { Location } \\
\text { (Edge } \\
\text { Number) }\end{array}$} & $\begin{array}{l}\text { Burr } \\
\text { Height } \\
\text { (in.)* }\end{array}$ & $\begin{array}{l}\text { Burr } \\
\text { Thickness } \\
\text { (in.)* }\end{array}$ & $\begin{array}{l}\text { Burr } \\
\text { Radius } \\
\text { (in.)* }\end{array}$ \\
\hline & \multicolumn{3}{|c|}{ 17-4 PH Stainless Steel } \\
\hline 1 & 0.0081 & 0.0022 & 0.0014 \\
\hline 2 & 0.0113 & 0.0020 & 0.0012 \\
\hline 3 & 0.0365 & 0.0035 & 0.0018 \\
\hline 4 & 0.0052 & -- & -- \\
\hline 5 & 0.0058 & 0.0026 & 0.0016 \\
\hline 6 & 0.0014 & 0.0013 & -- \\
\hline 7 & 0.0168 & 0.0033 & 0.0012 \\
\hline 8 & 0.0031 & -- & -- \\
\hline \multirow[t]{2}{*}{9} & 0.0050 & 0.0022 & 0.0012 \\
\hline & \multicolumn{3}{|c|}{303 Se Stainless Steel } \\
\hline 1 & 0.0087 & 0.0023 & 0.0016 \\
\hline 2 & 0.0084 & 0.0021 & 0.0015 \\
\hline 3 & 0.0650 & 0.0035 & 0.0017 \\
\hline 4 & 0.0121 & -- & -- \\
\hline 5 & 0.0105 & 0.0035 & 0.0023 \\
\hline 6 & 0.0010 & 0.0009 & -- \\
\hline 7 & 0.0289 & 0.0042 & 0.0020 \\
\hline 8 & 0.0048 & -- & -- \\
\hline 9 & 0.0036 & 0.0029 & 0.0023 \\
\hline
\end{tabular}


Table 5 Continued. Typical Burr Properties From End Milling

\begin{tabular}{|c|c|c|c|}
\hline \multirow{2}{*}{$\begin{array}{l}\text { Burr } \\
\text { Location } \\
\text { (Edge } \\
\text { Number) }\end{array}$} & $\begin{array}{l}\text { Burr } \\
\text { Height } \\
\text { (in.)* }\end{array}$ & $\begin{array}{l}\text { Burr } \\
\text { Thickness } \\
\text { (in.)* } \\
\end{array}$ & \multirow[t]{2}{*}{$\begin{array}{l}\text { Burr } \\
\text { Radius } \\
\text { (in。)* }\end{array}$} \\
\hline & \multicolumn{2}{|c|}{$\overline{6061-\mathrm{T}} 6$ Aluminum } & \\
\hline 1 & 0.0053 & 0.0014 & 0.0007 \\
\hline 2 & 0.0059 & 0.0018 & 0.0011 \\
\hline 3 & 0.0500 & 0.0029 & 0.0015 \\
\hline 4 & 0.0048 & -- & -- \\
\hline 5 & 0.0146 & 0.0029 & 0.0014 \\
\hline 6 & 0.0003 & 0.0006 & -- \\
\hline 7 & 0.0208 & 0.0033 & 0.0016 \\
\hline 8 & 0.0061 & -- & -- \\
\hline \multirow[t]{2}{*}{9} & 0.0047 & 0.0022 & 0.0009 \\
\hline & \multicolumn{2}{|c|}{1018 Steel } & \\
\hline 1 & 0.0083 & 0.0021 & 0.0014 \\
\hline 2 & 0.0061 & 0.0023 & 0.0012 \\
\hline 3 & 0.0699 & 0.0037 & 0.0017 \\
\hline 4 & 0.0089 & -- & -- \\
\hline 5 & 0.0165 & 0.0038 & 0.0020 \\
\hline 6 & 0.0001 & 0.0004 & -- \\
\hline 7 & 0.0078 & 0.0033 & 0.0016 \\
\hline 8 & 0.0022 & -- & -- \\
\hline 9 & 0.0063 & 0.0026 & 0.0024 \\
\hline
\end{tabular}

$* 0.001$ inch equals $25.4 \mu \mathrm{m}$. 


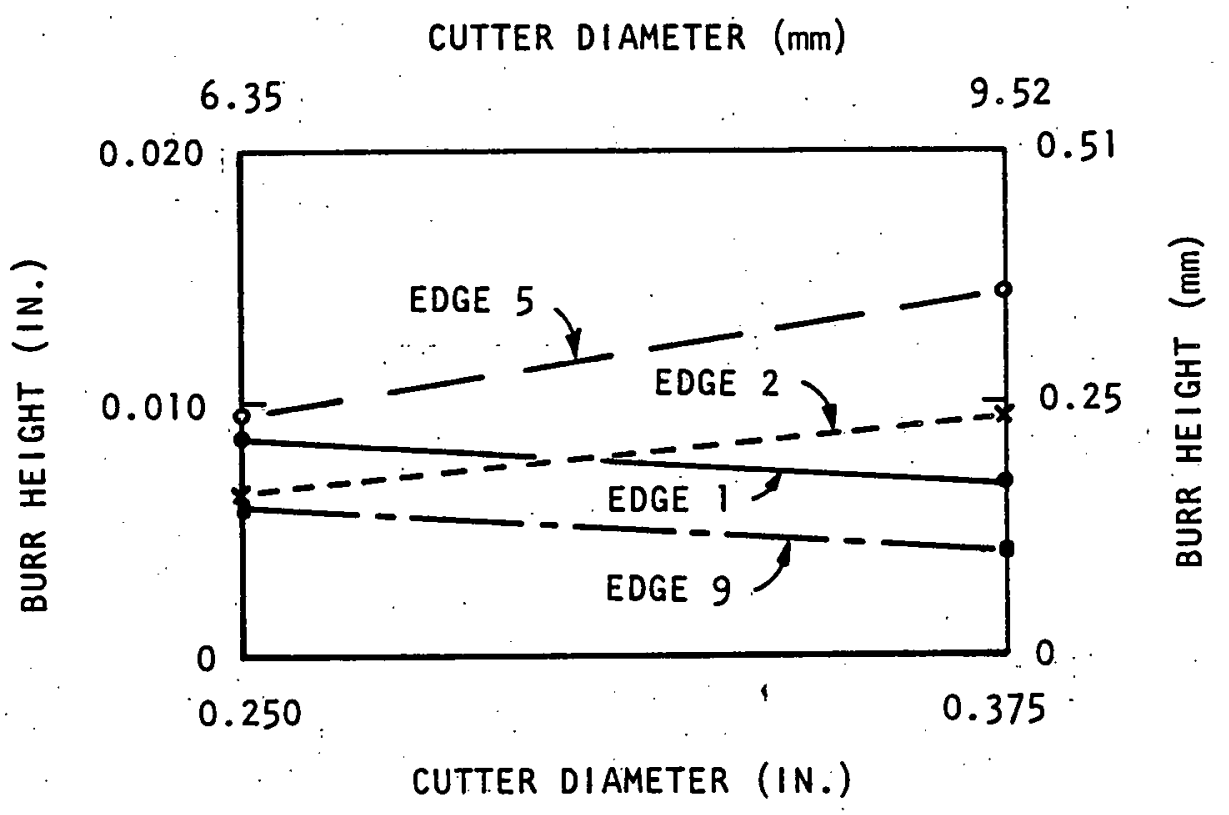

Figure 17. Effect of Cutter Diameter on Burr Height at Edges 1, 2, 5, and 9

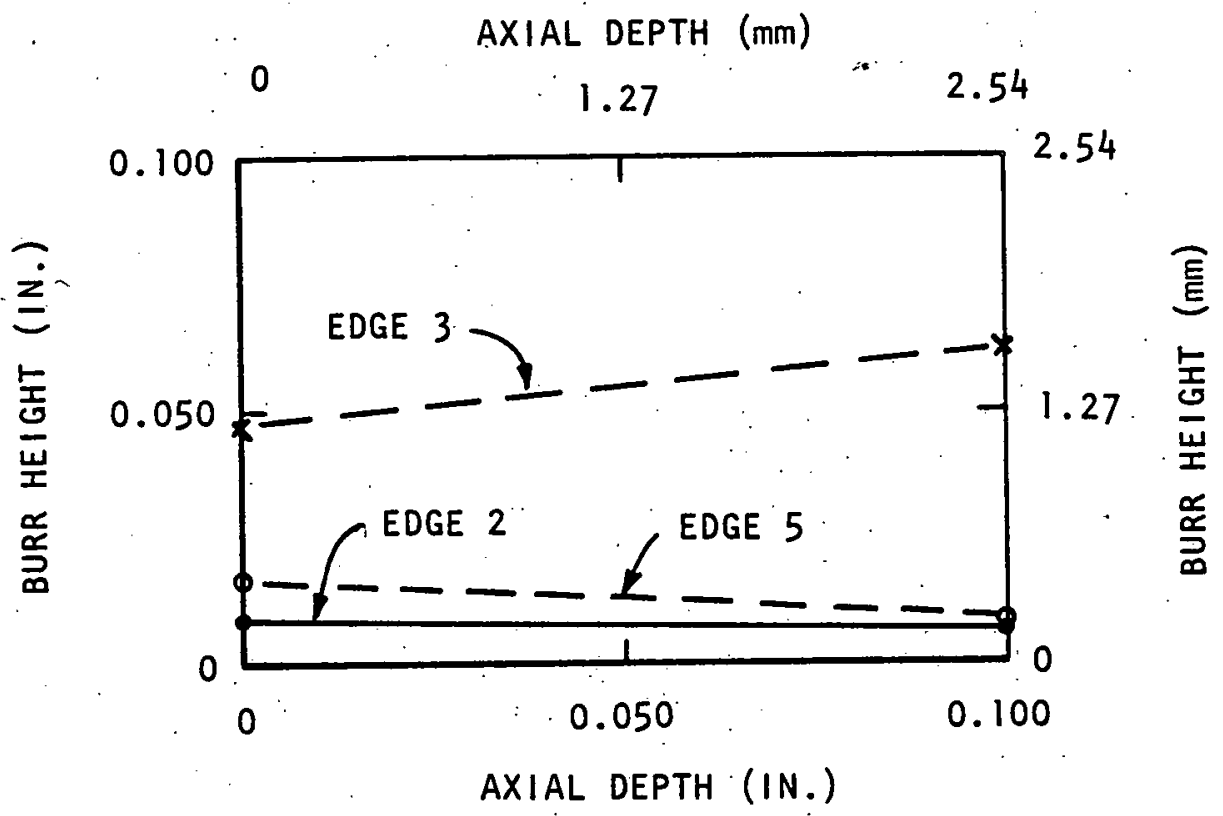

Figure 18. Effect of Axial Depth of Cut on Burr Height at Edges 2, 3, and 5 
burrs. On edges 1 and 9 , burr height decreased with increasing cutter diameter. No effect was noted on edges 3,6 , and 7 . Although the changes were notable, there is nothing in the rationale of burr formation that accounts for the effect of cutter diameter.

Increasing the axial depth of cut reduced burr height on edges 2 and 5 , but increased it on edge 3 (Figure 18). From the nature of the cutting action, the burr produced by the bottom of the cutter (edge 5) should be independent of axial depth of cut as should the roll-over burr produced at edge 3. From the discussion of burr formation, increasing the depth of cut should increase the height of the burr at edge 2. Figure 18 fails to confirm any of these observations, however.

Increasing the radial depth of cut increased the height of the burr at edge 3 (Figure 19). This is consistent with the theory of the formation of this burr.

Increasing the feedrate lowered the burr height on most edges (Figure 20). This is probably the result of two factors. At low feedrates, cutter rubbing occurs, which increases burr formation forces. On edges 1 and 2 , low feedrates do not allow the tool to cut away the burr formed by the previous flute. High-speed movies indicate that at low feedrates the burr height in front of the cutter grows with each pass of a flute.

Dull tools create higher burrs (Figure 21). This is particularly evident for the burr produced on edge 3. Burr height doubled when the cutting edge radius increased from near zero to a 0.001 -inch $(25.4 \mu \mathrm{m})$ radius.

Burr height was a function of workpiece material as well as edge location (Figure 22). As a general rule, the shortest burrs occurred on 17-4 PH stainless steel and 6061-T6 aluminum.

While burr height in the two stainless steel materials often followed similar patterns, there were many differences (Figures 23 to 31). For example, on edge 1, a sharp tool at a low feedrate resulted in the smallest burr (Figure 23). On edge 2, a sharp tool and a fast feedrate produced the smallest burr (Figure 24). On edge 3, minimum burr height is a function of workpiece material (Figure 25).

Burr Thickness

Increasing the cutter diameter decreased the thickness of the burr on edge 1 (Figure 32), but did not affect the thickness of any other burr. Increasing the radial depth of cut increased 


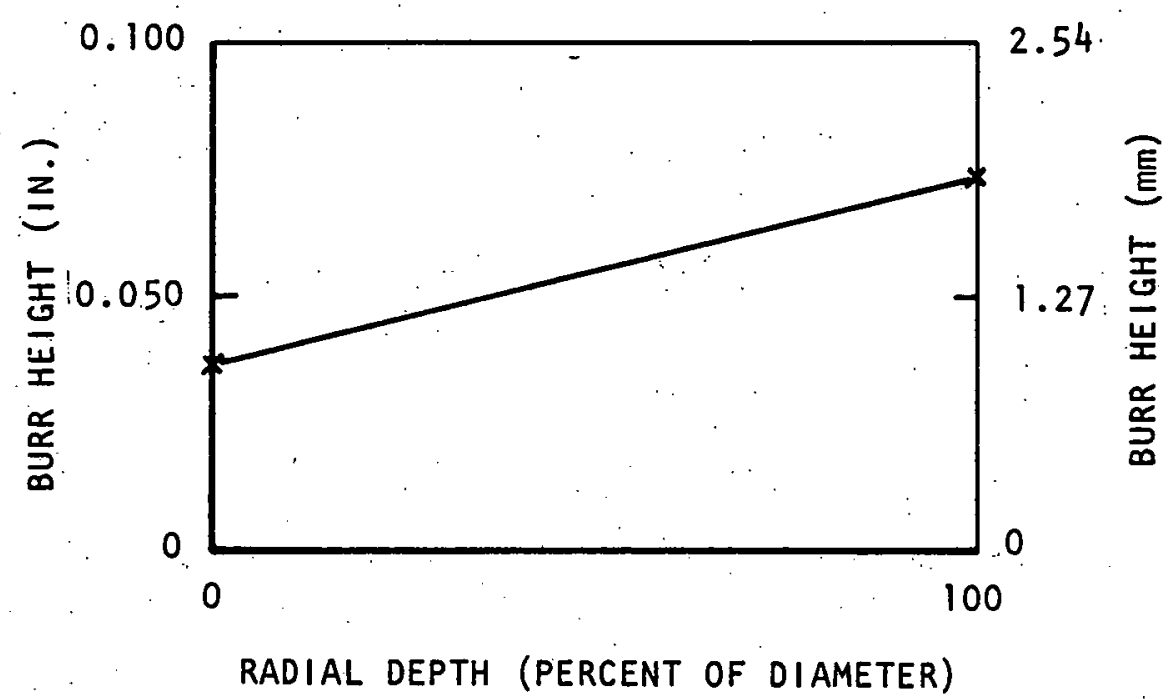

Figure 19. Effect of Radial Depth of Cut on Burr Height at Edge 3

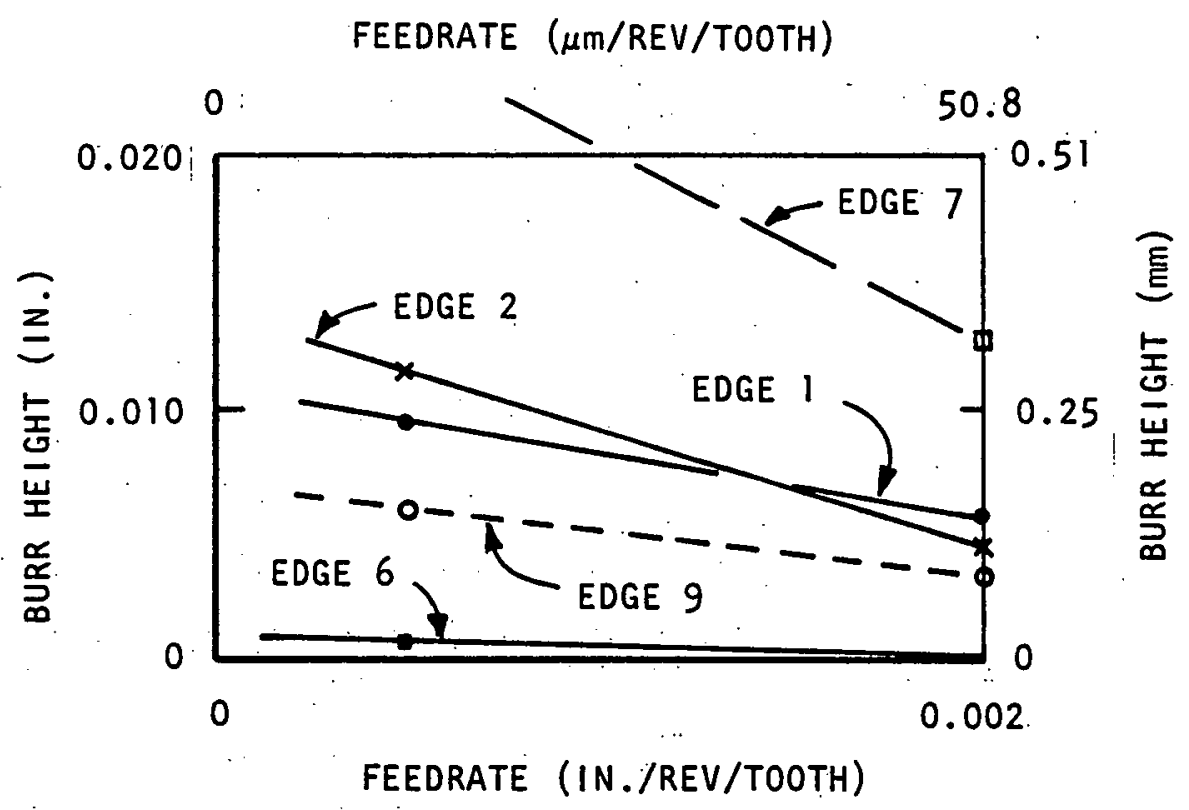

Figure 20. Effect of Feedrate on Burr Height at Edges 1, 2, 6, 7, and 9 . 
TOOL SHARPNESS (RADIUS $-\mu \mathrm{m}$ )

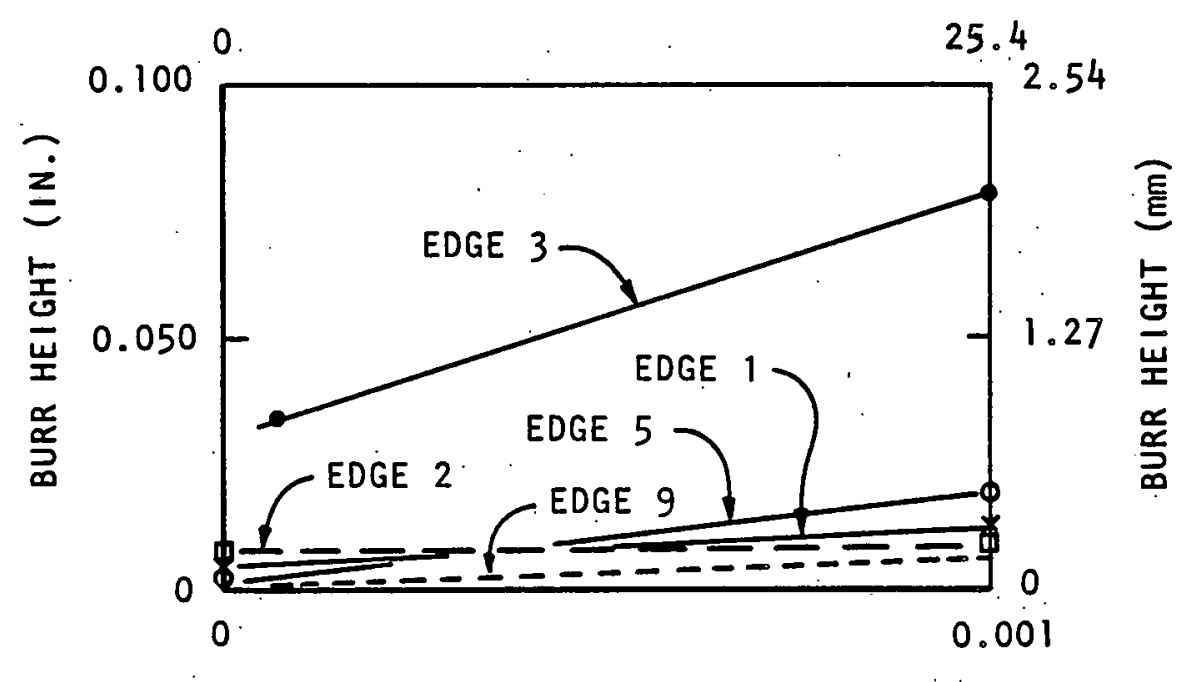

TOOL SHARPNESS (RADIUS-IN.)

Figure 21. Effect of Tool Sharpness on Burr

Height at Edges $1,2,3,5$, and 9

the thickness of the burr at edge 6 (Figure 33), but did not affect the thickness of any other burr. The axial depth of. cut did not affect any burr thicknesses.

Increasing the feedrate resulted in thicker burrs on edges 3 and 5 but resulted in a thinner burr on edge 2 (Figure 34). Other edges were not affected. By theory, burr thickness at edge 3 should increase with feedrate as should thickness at edges 5,7 , and 9. The thinner burr at edge 2 is probably the result of decreased rubbing. It will be noted that the primary burr formation at edge 2 is due to the Poisson effect, while the rollover burr phenomenon is responsible for the burr at edges 3,5 , 7 , and 9 .

Dull tools produced thicker burrs on all edges excepting edge 6 (Figure 35). This is in agreement with the general theories of burr formation.

As a general rule, burrs in aluminum were thinner than those in other materials (Figure 36). There was little difference in the average burr thickness of the other three materials.

With only three notable exceptions, burr thickness in 303 Se and 17-4 PH were practically identical (Figures 37 to 43 ). Low feedrates and dull tools typically resulted in the thickest

Text continued on page 68 . 


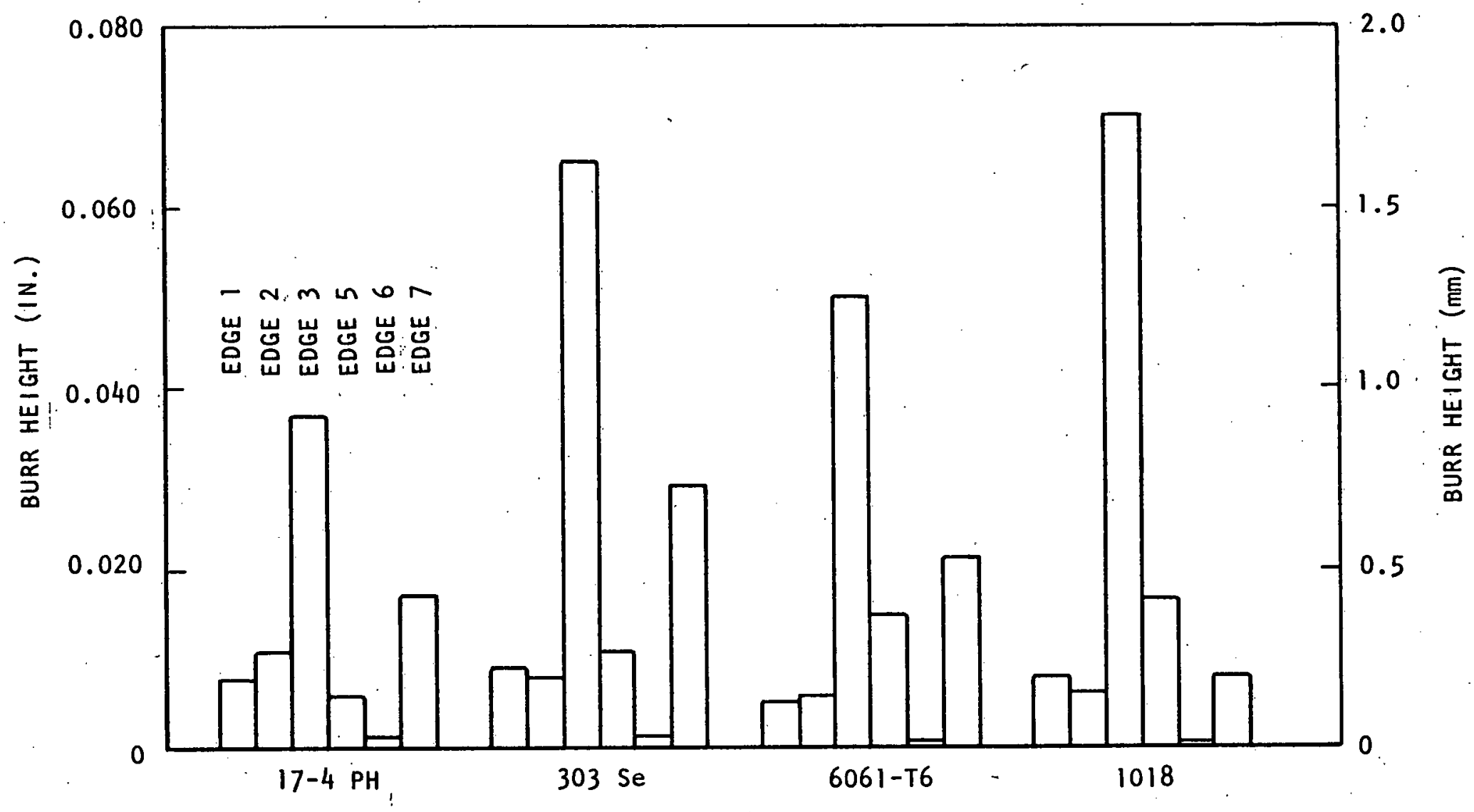

Figure 22. Burr Height as a Function of Workpiece Material 


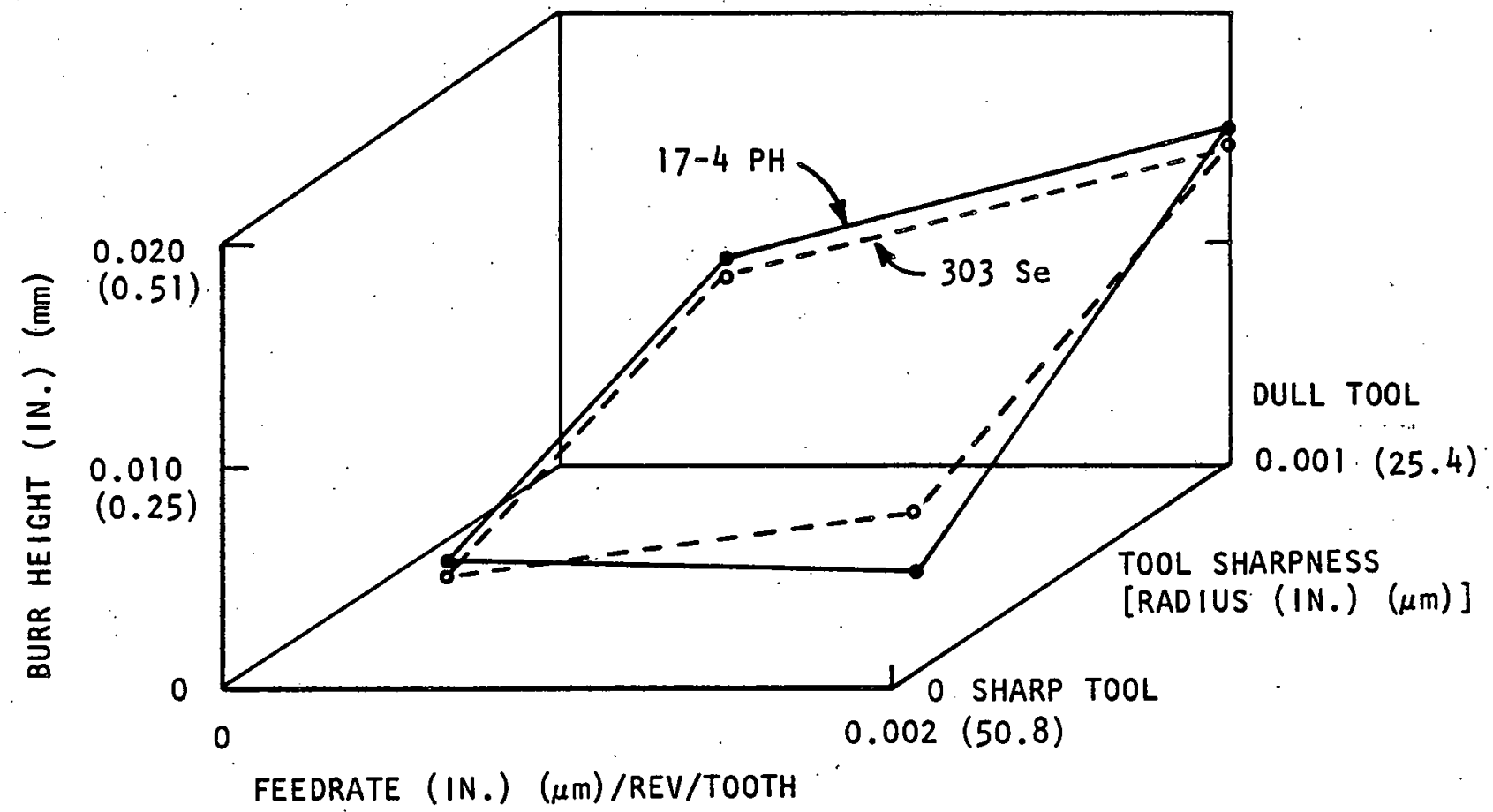

Figure 23. Edge 1: Effect of Feedrate and Tool Sharpness on Burr Height

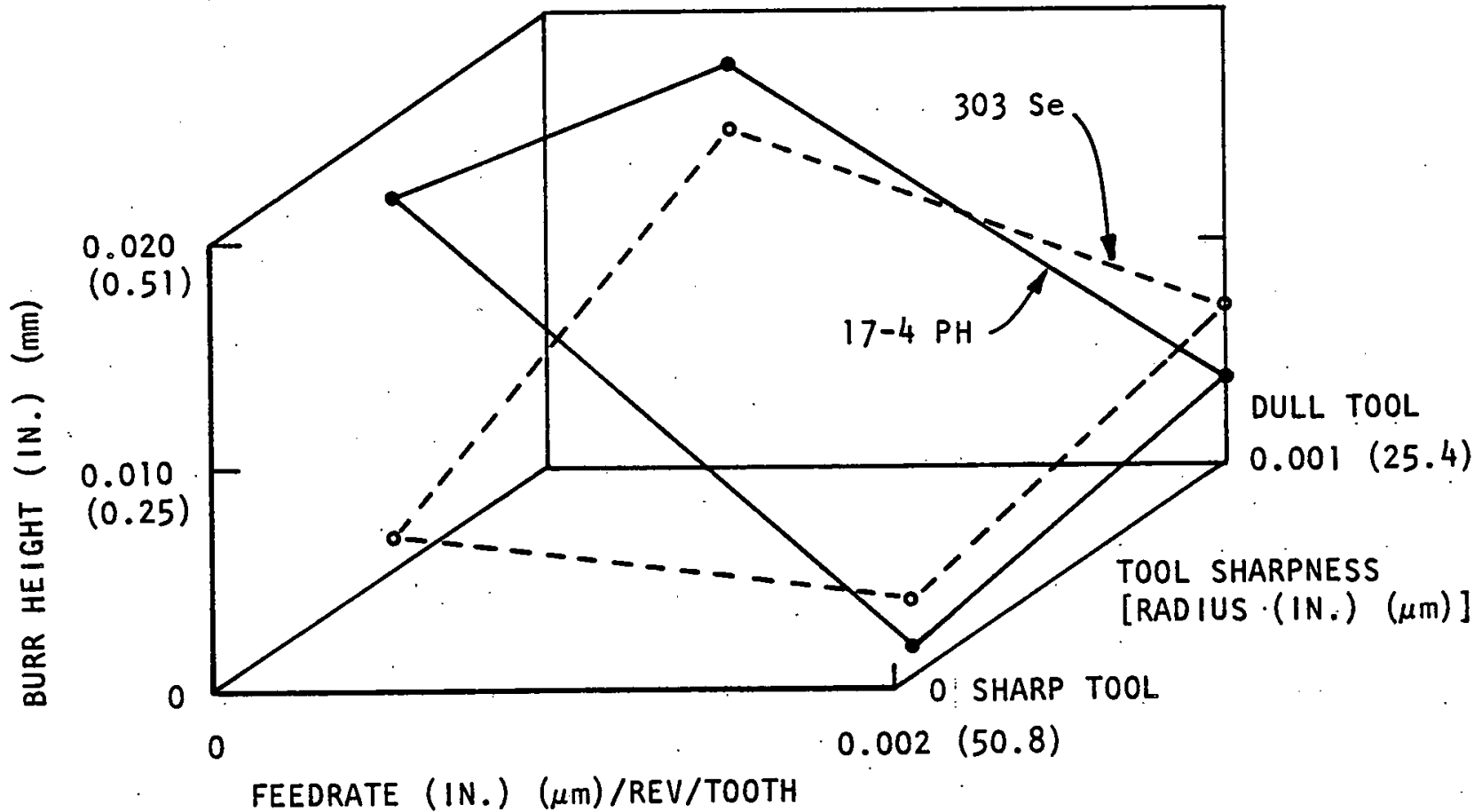

Figure 24. Edge 2: Effect of Feedrate and Tool Sharpness on Burr Height 


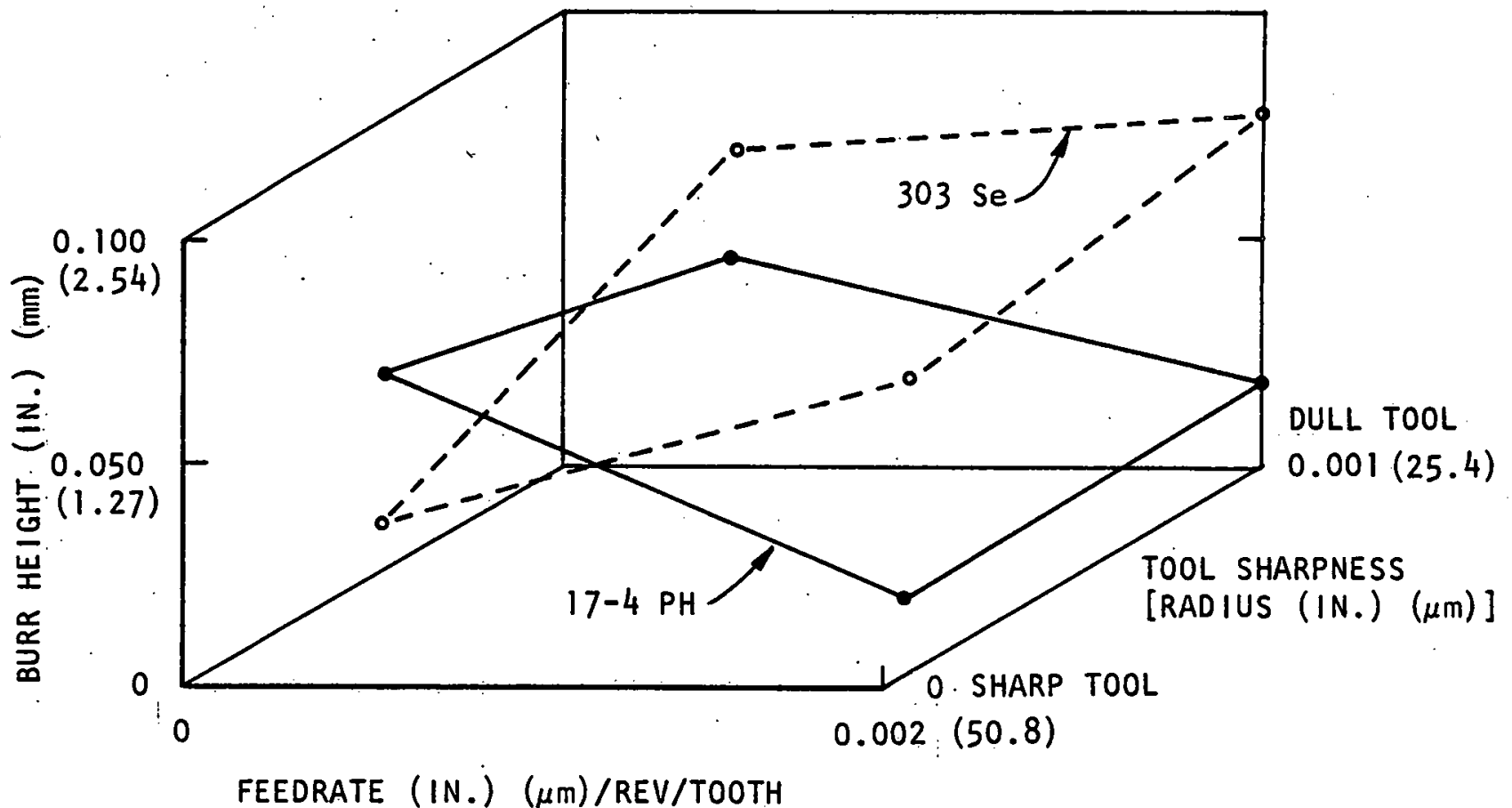

Figure 25. Edge 3: Effect of Feedrate and Tool Sharpness on Burr Height

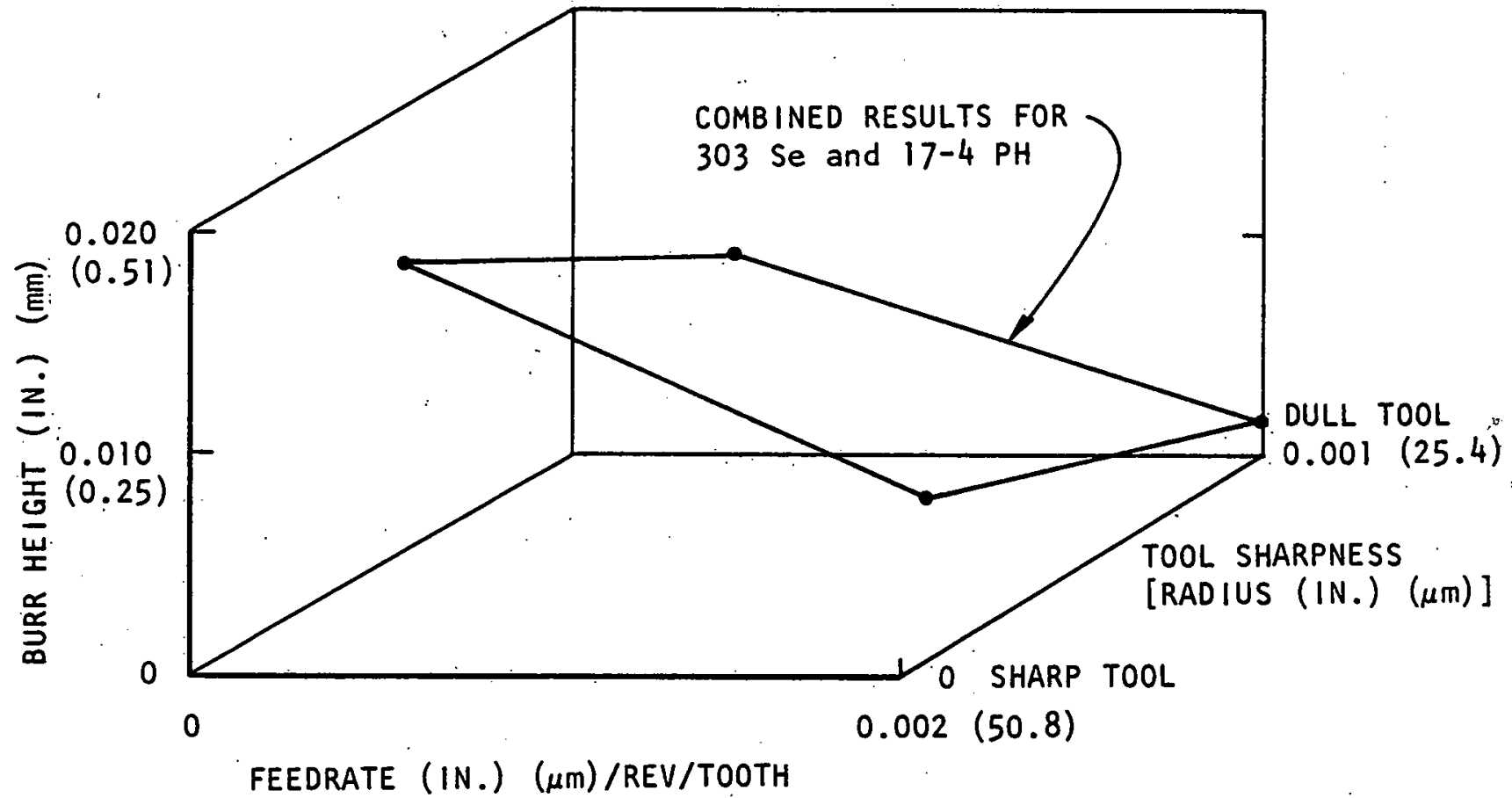

Figure 26. Edge 4: Effect of Feedrate and Tool Sharpness on Burr Height 


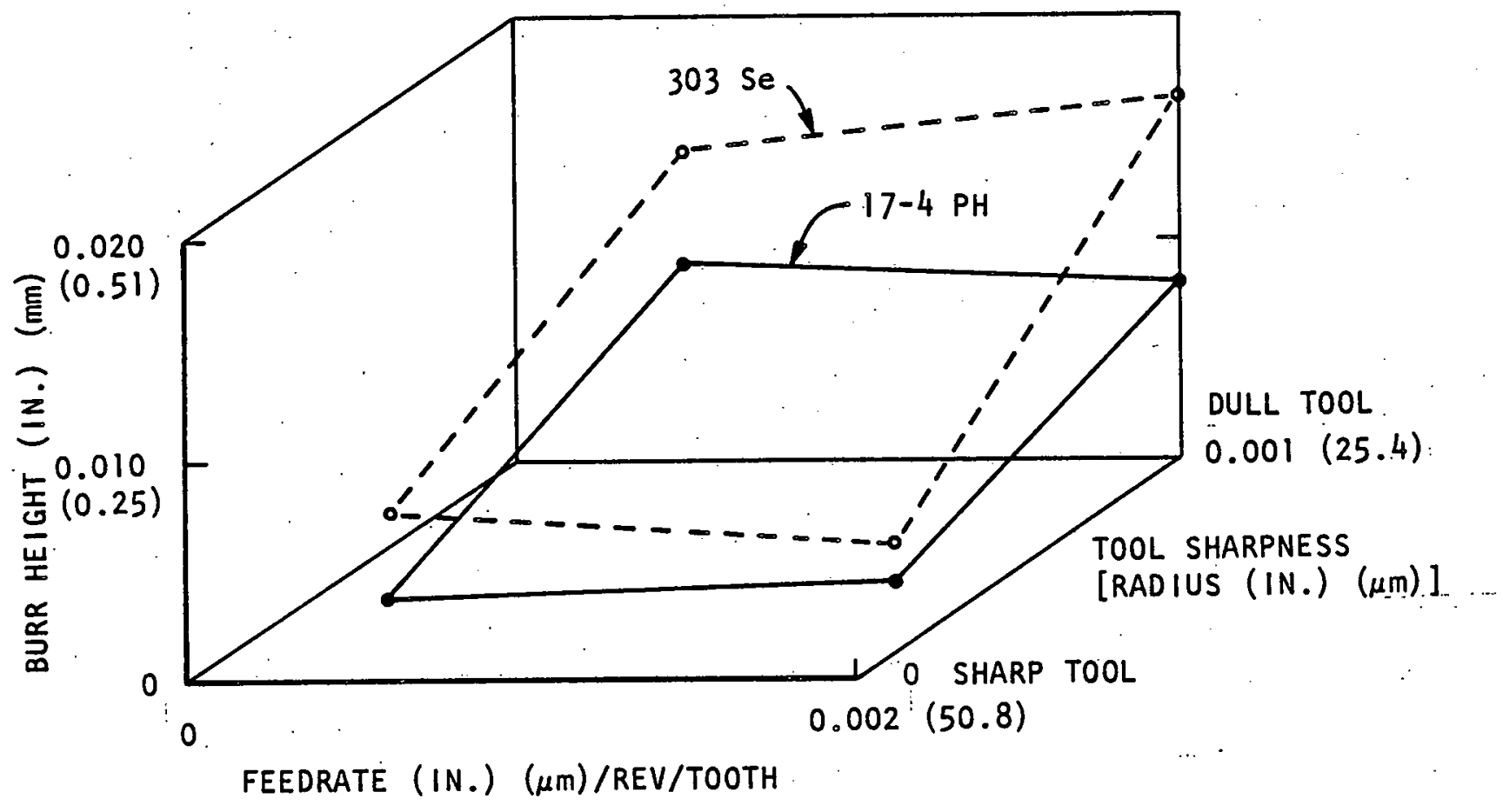

Figure 27. Edge 5: Effect of Feedrate and Tool Sharpness on

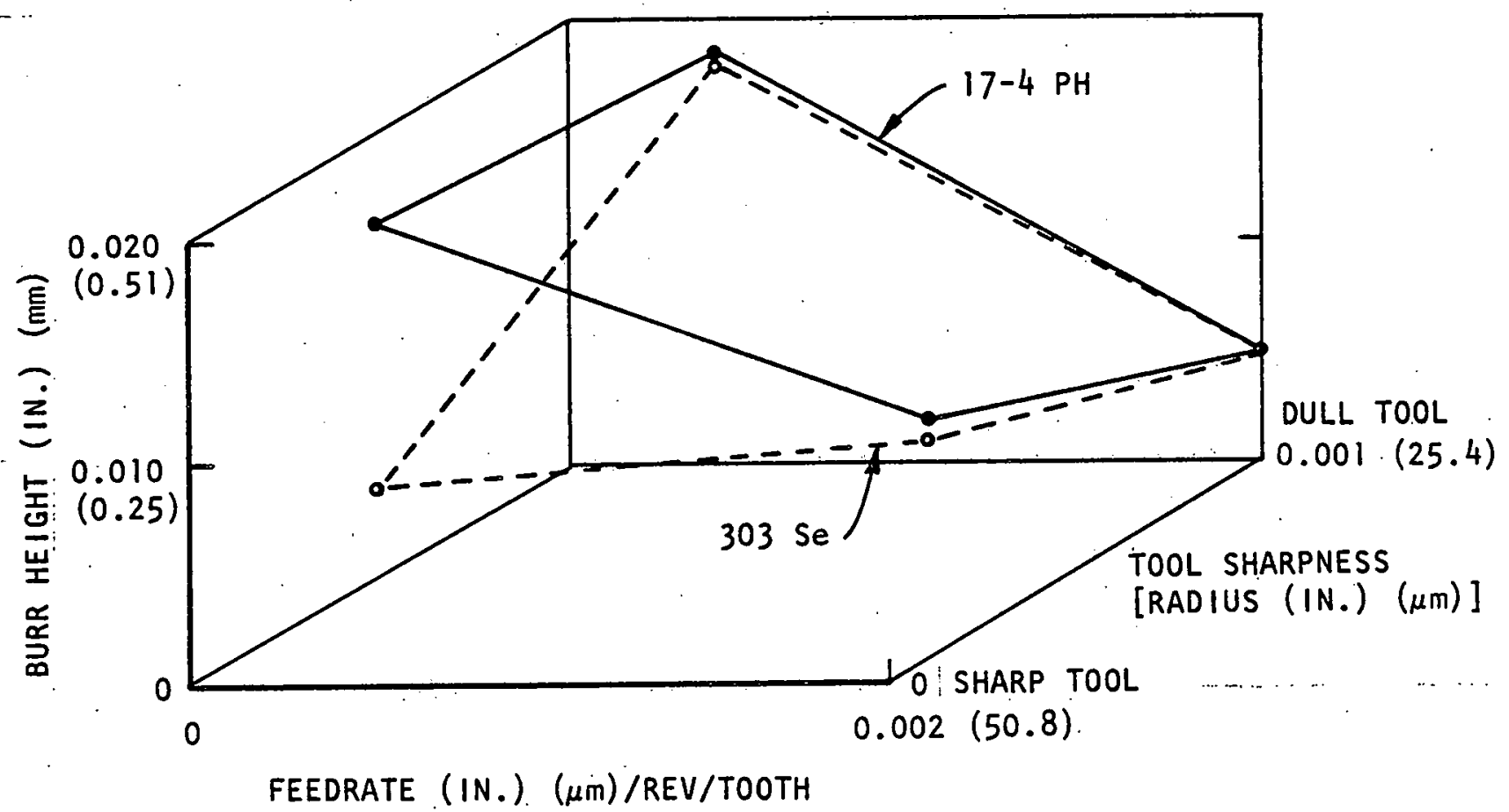

Figure 28. Edge 6: Effect of Feedrate and Tool Sharpness on Burr Height 


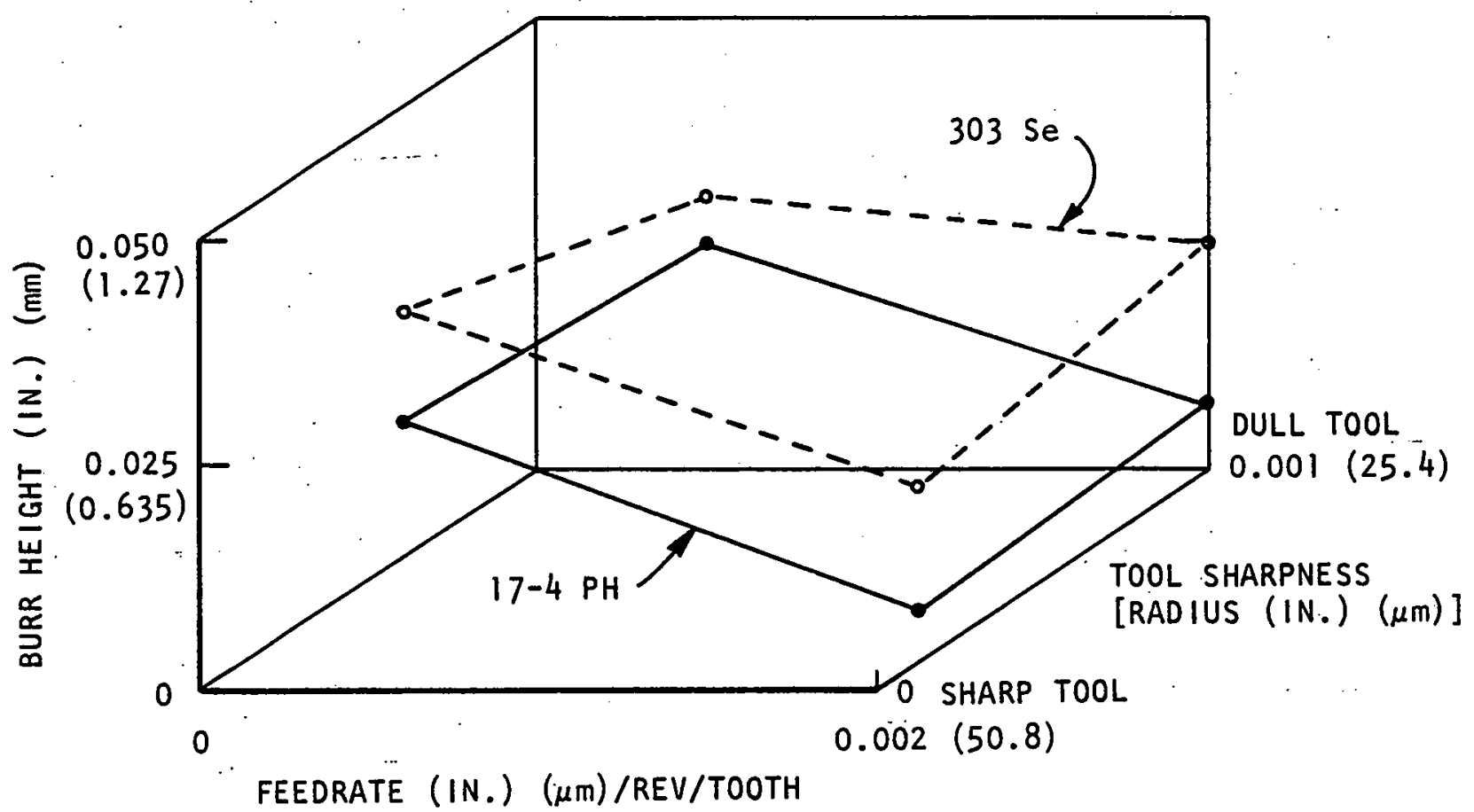

Figure 29. Edge 7: Effect of Feedrate and Tool Sharpness on Burr Height

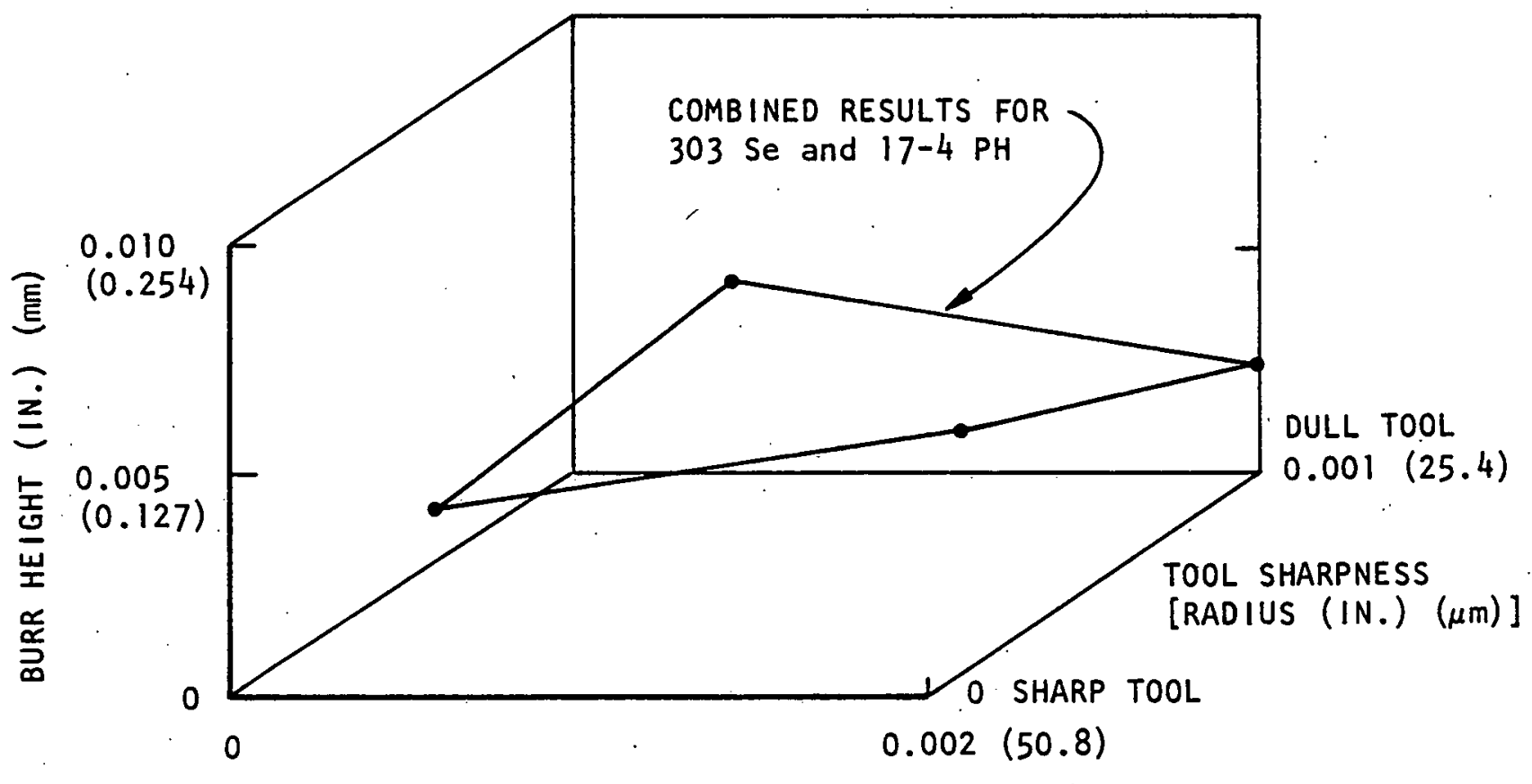

FEEDRATE (IN.) $(\mu \mathrm{m}) / \mathrm{REV} / \mathrm{TOOTH}$

Figure 30. Edge 8: Effect of Feedrate and Tool Sharpness on Burr Height 


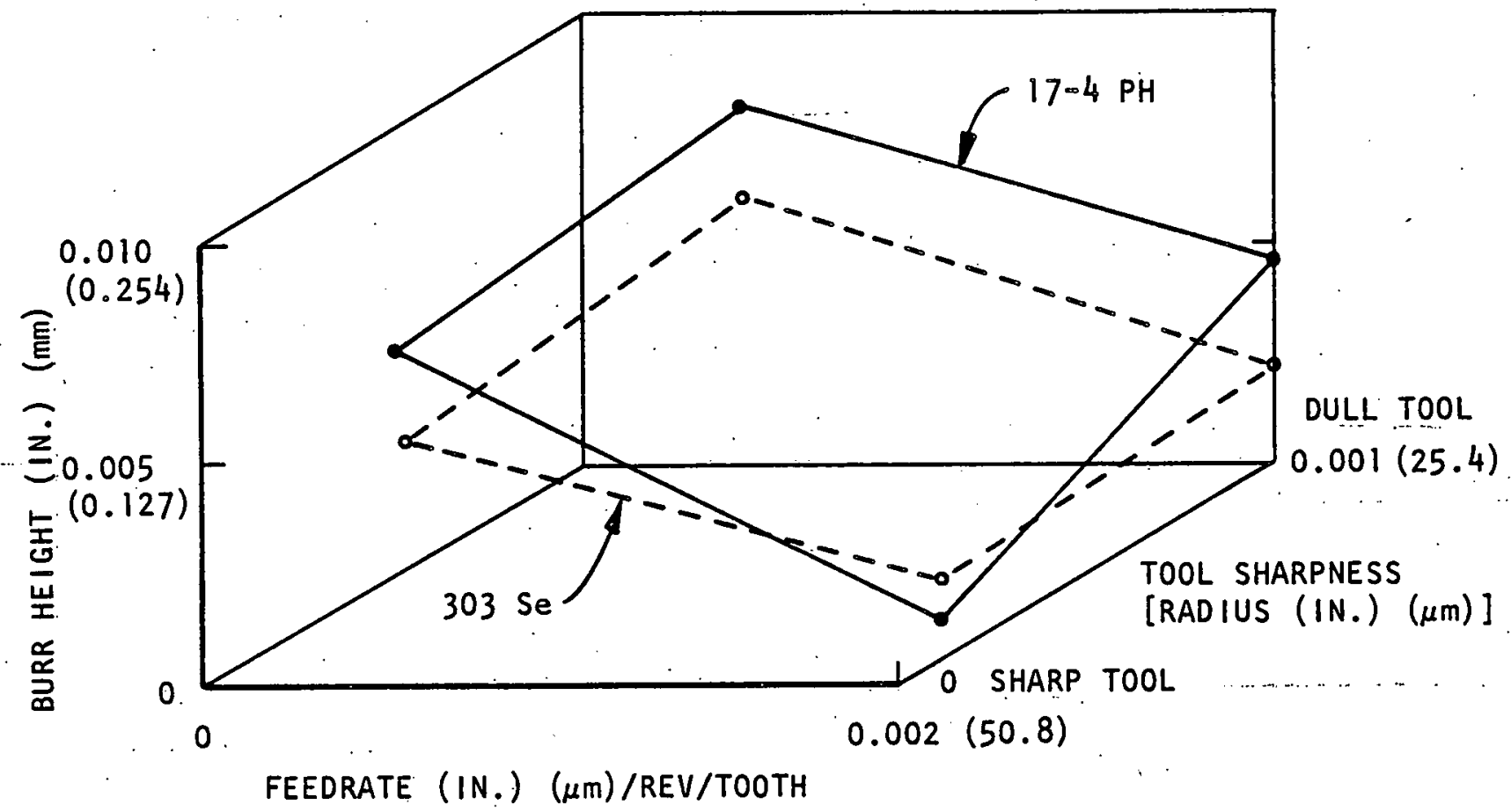

Figure 31. Edge 9: Effect of Feedrate and Tool Sharpness on Burr Height

CUTTER DIAMETER $(\mathrm{mm})$

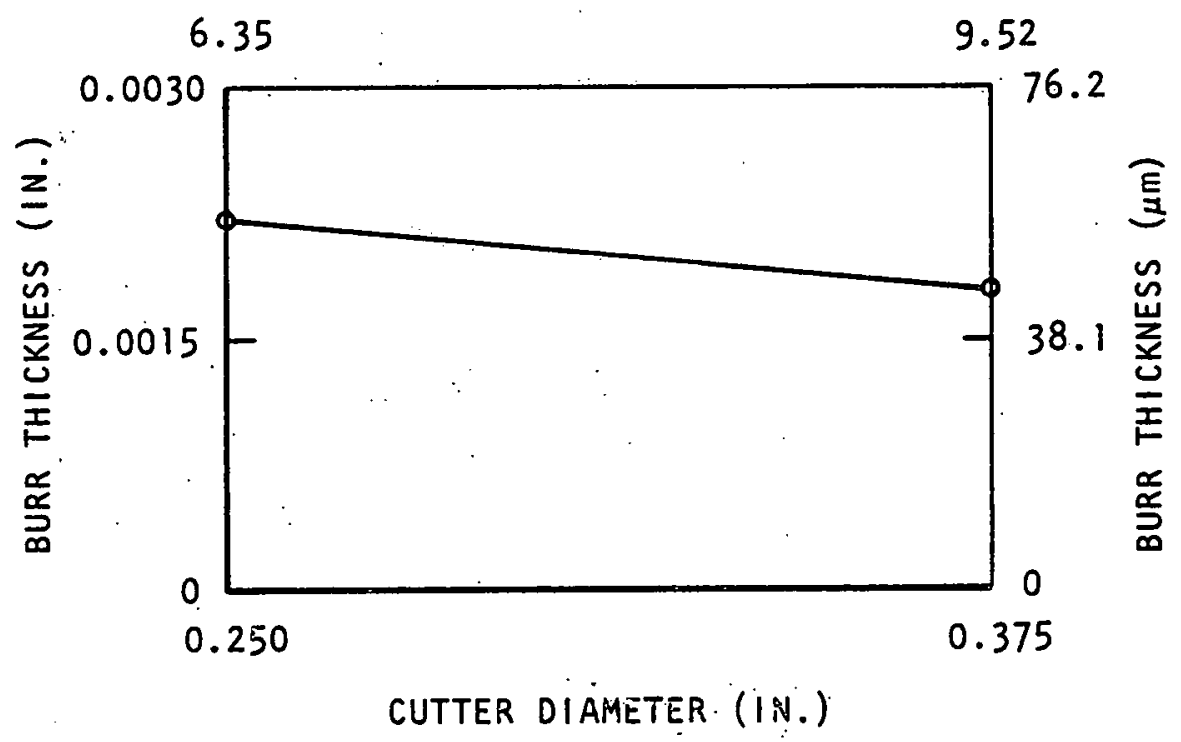

Figure 32. Edge 1: Effect of Cutter Diameter and Burr Thickness 


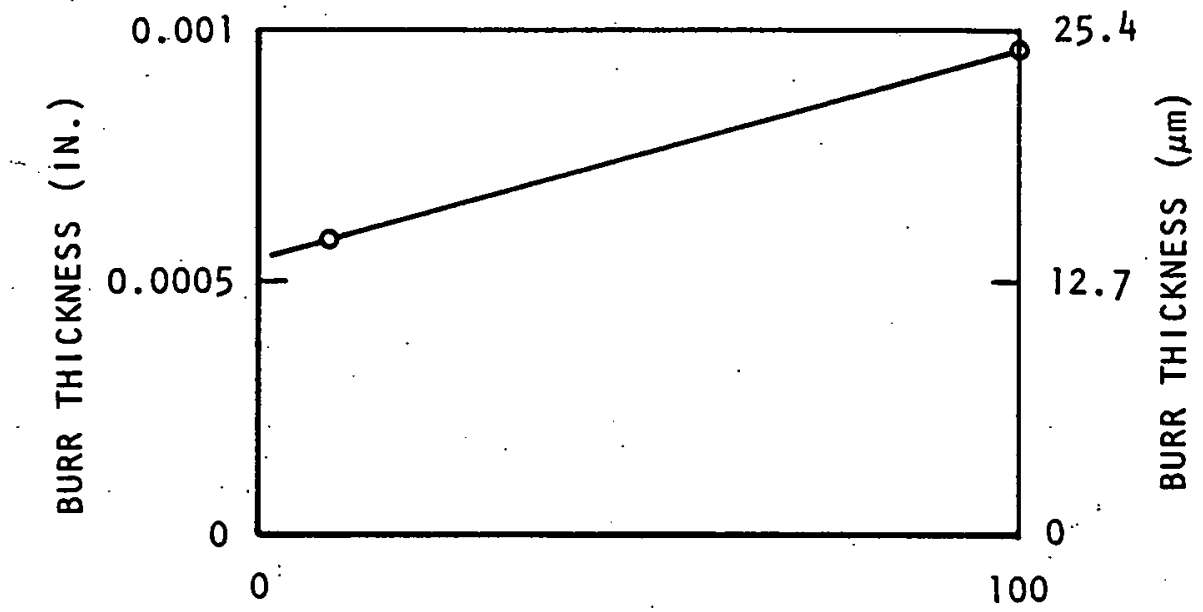

RADIAL DEPTH (PERGENT OF DIAMETER)

Figure 33. Edge 6: Effect of Radial Depth of Cut on Burr Thickness

FEEDRATE $(\mu \mathrm{m} /$ REV/TOOTH)

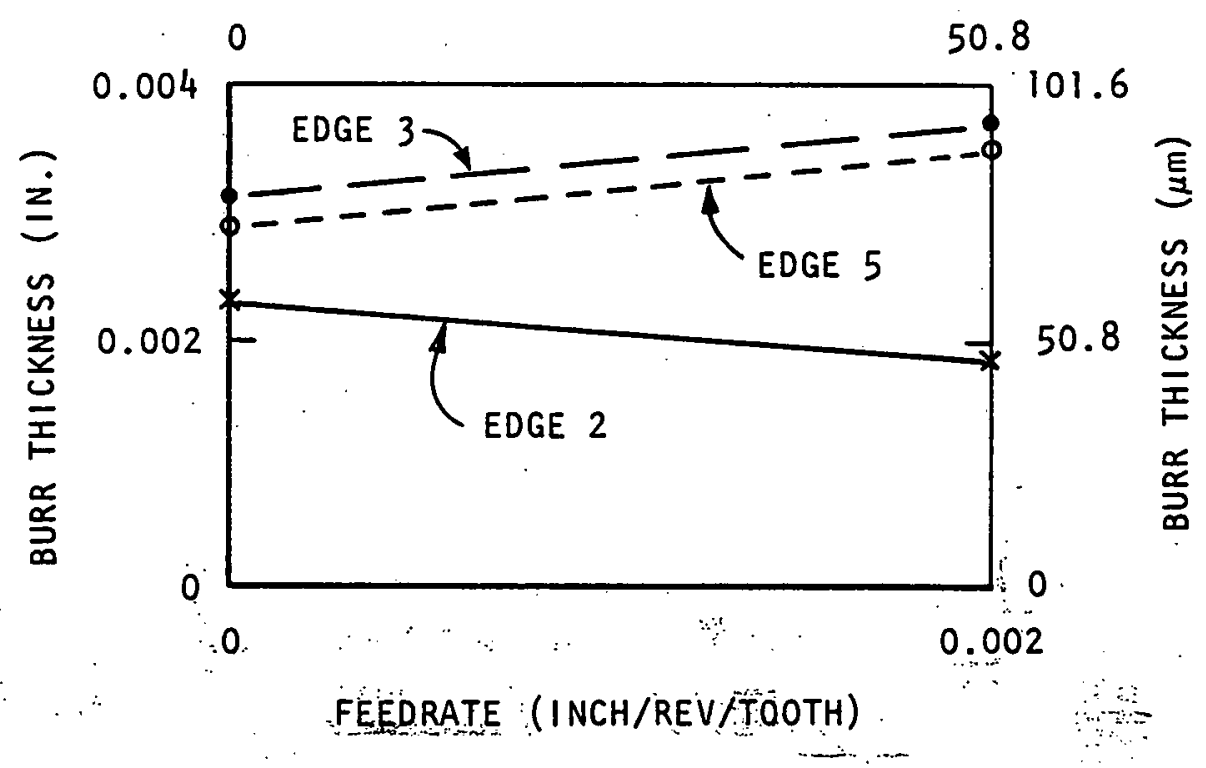

Figure 34. Effect of Feedrate of Burr Thickness at Edges 2,. 3, and 5 


\section{TOOL SHARPNESS $(\mu \mathrm{m})$}

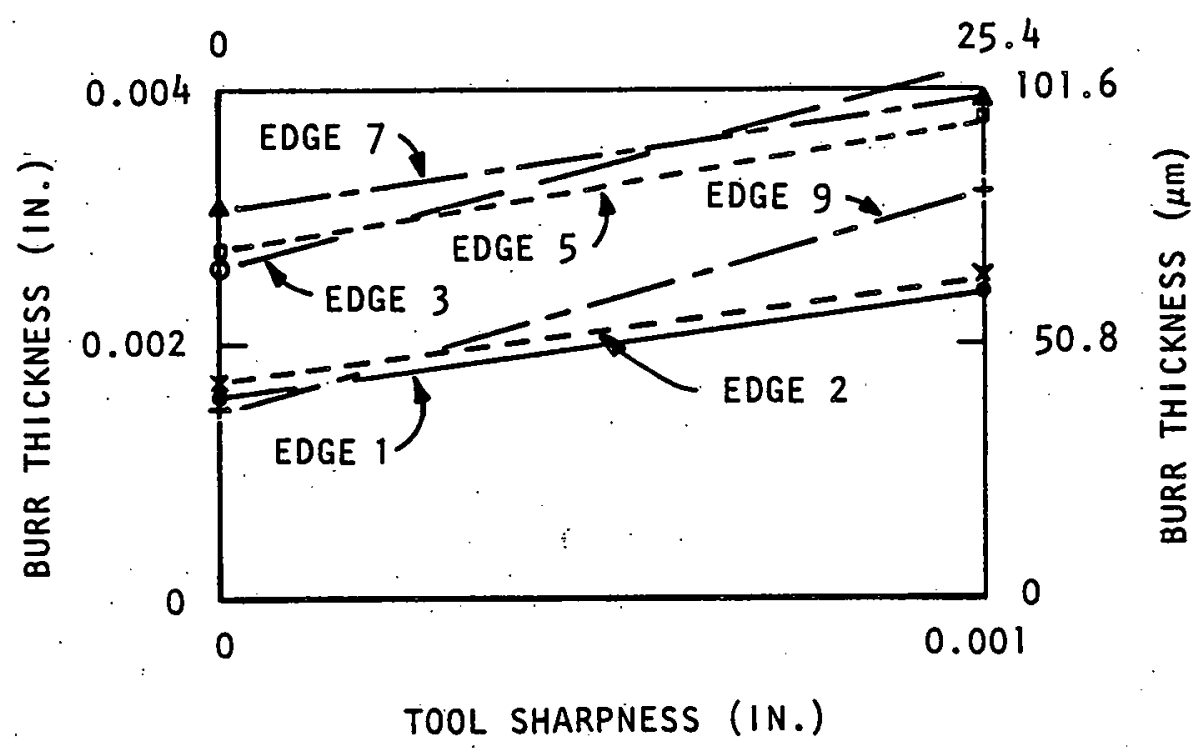

Figure 35. Effect of Tool Sharpness on Burr Thickness

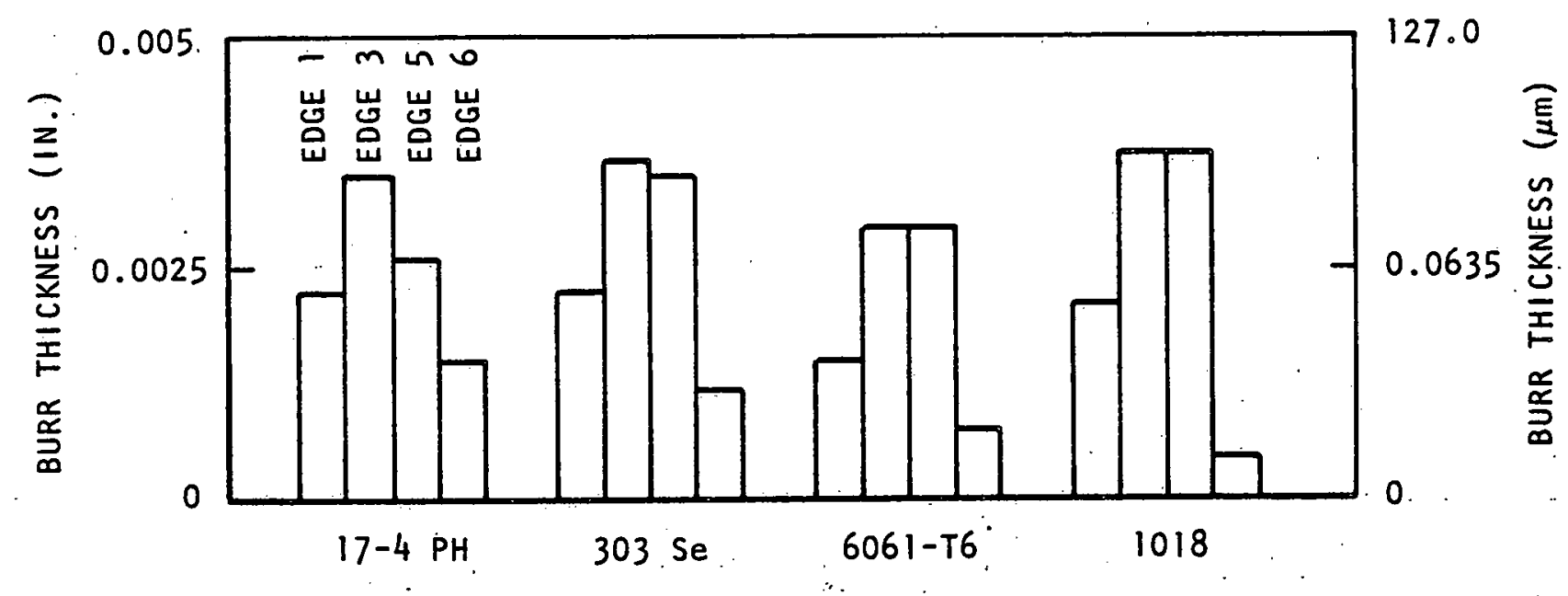

Figure 36. Effect of Workpiece Material on Burr Thickness 


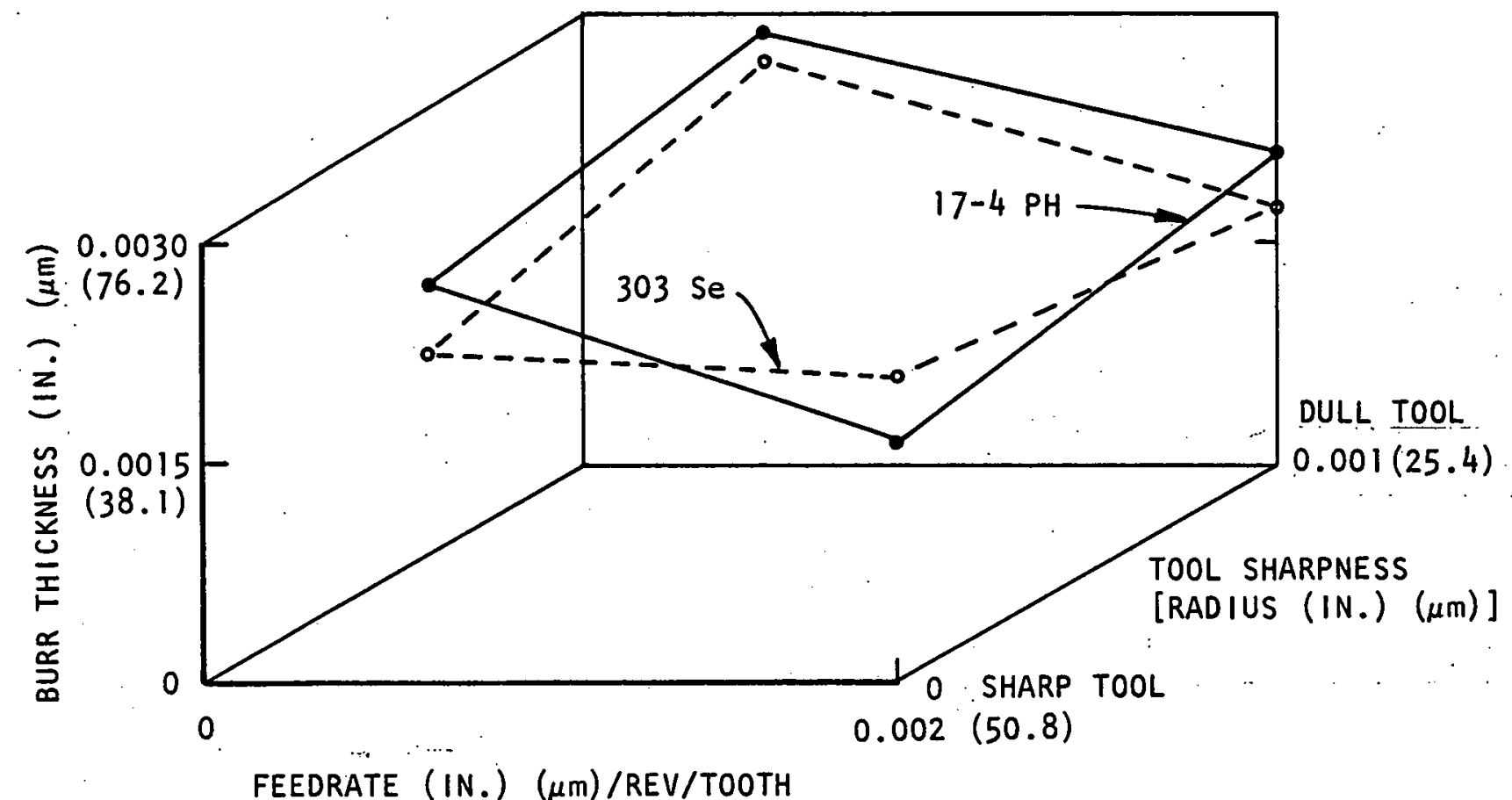

Figure 37. Edge 1: Effect of Feedrate and Tool Sharpness on Burr Thickness

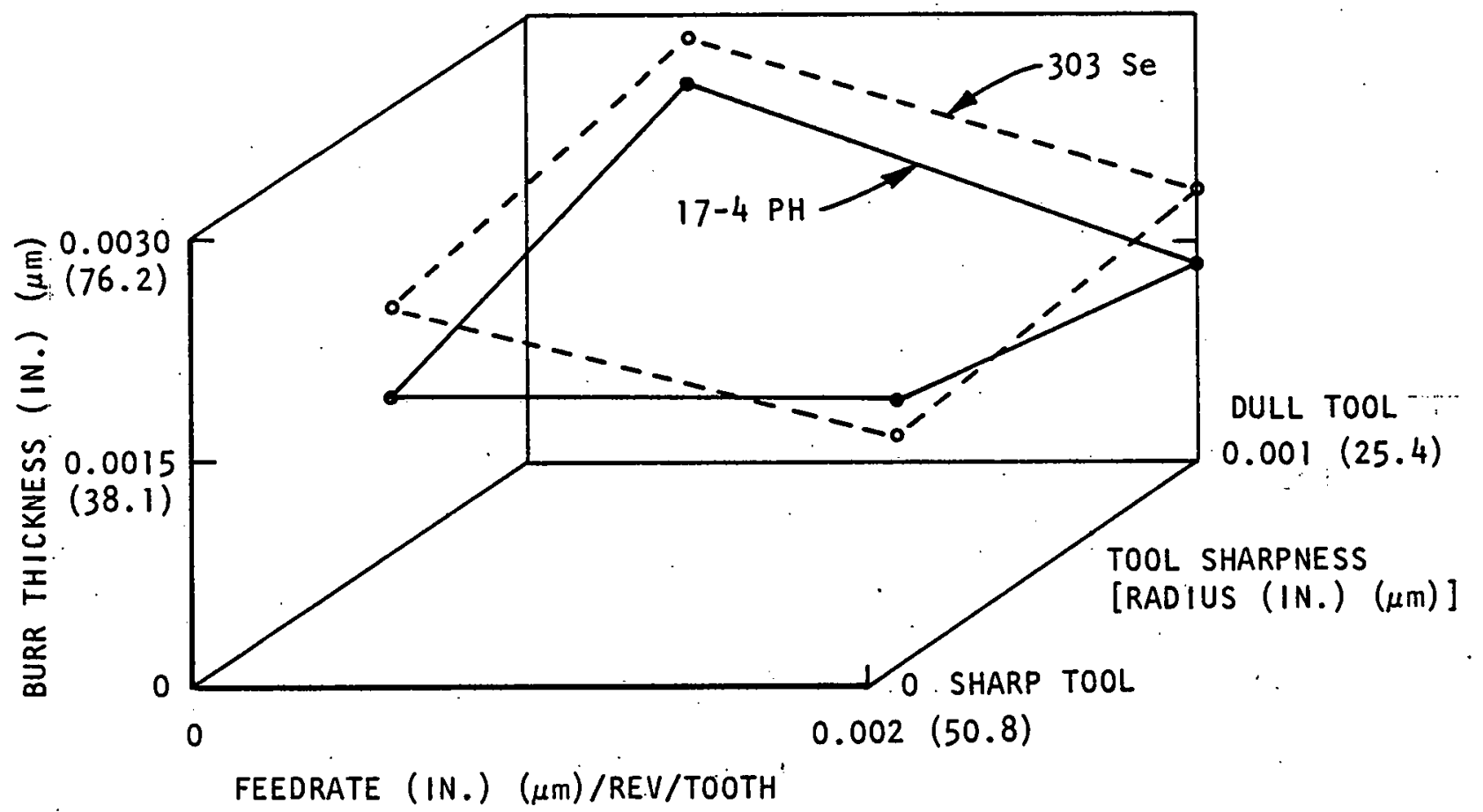

Figure 38. Edge 2: Effect of Feedrate and Tool Sharpness on Burr Thickness 


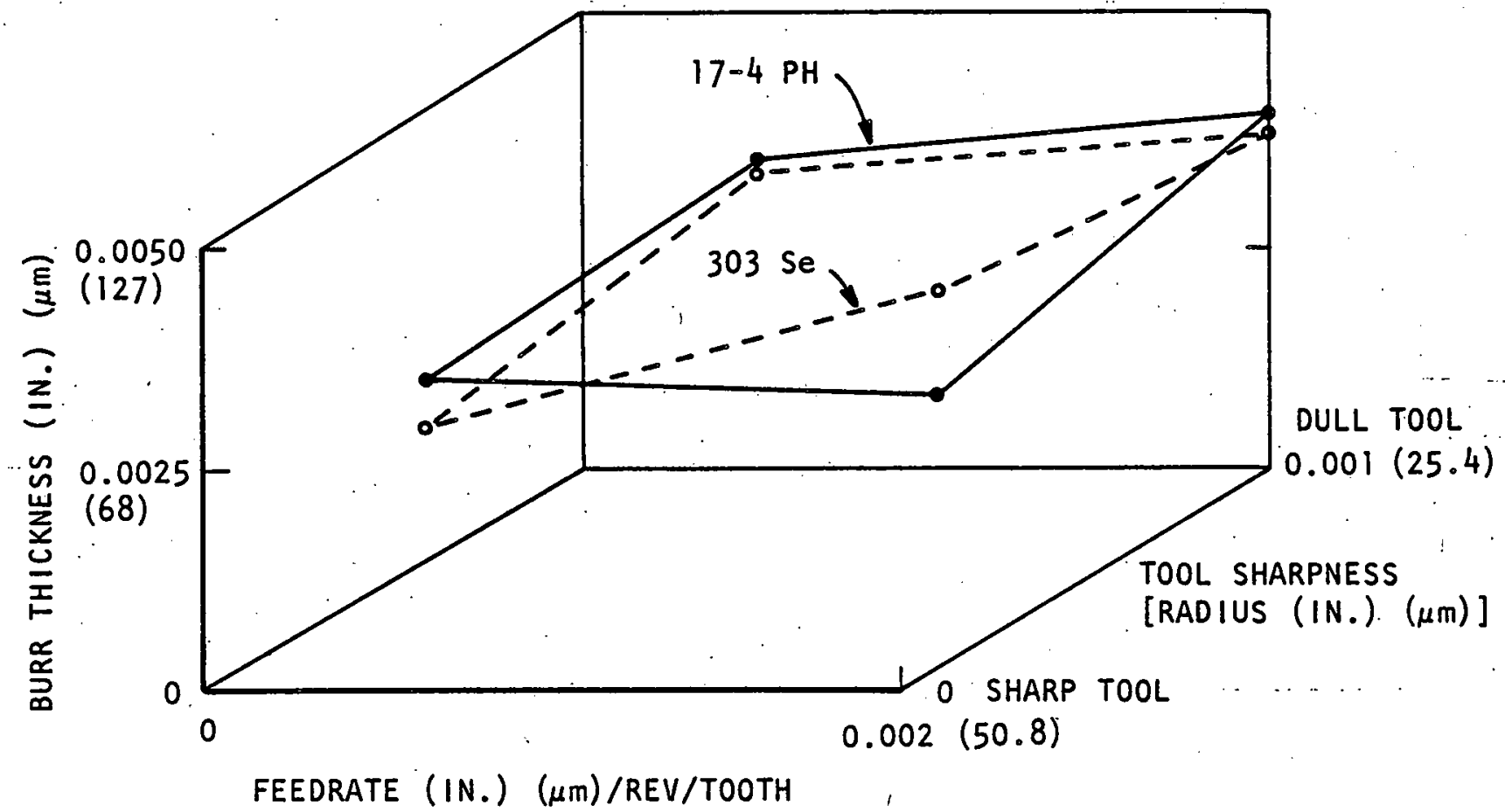

Figure 39. Edge 3: Effect of Feedrate and Tool Sharpness on Burr Thickness

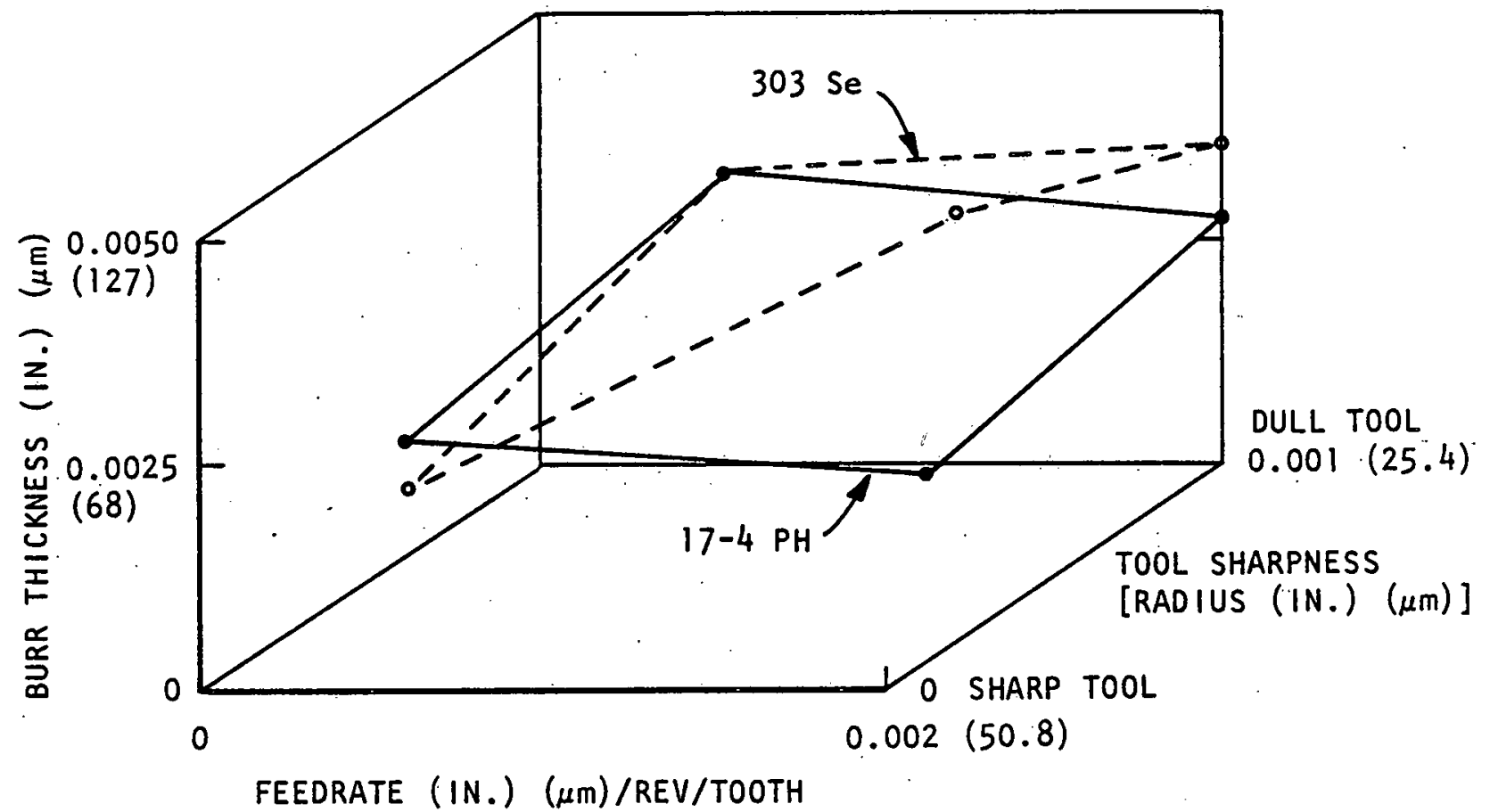

Figure 40. Edge 5: . Effect of Feedrate and Tool Sharpness on Burr Thickness 


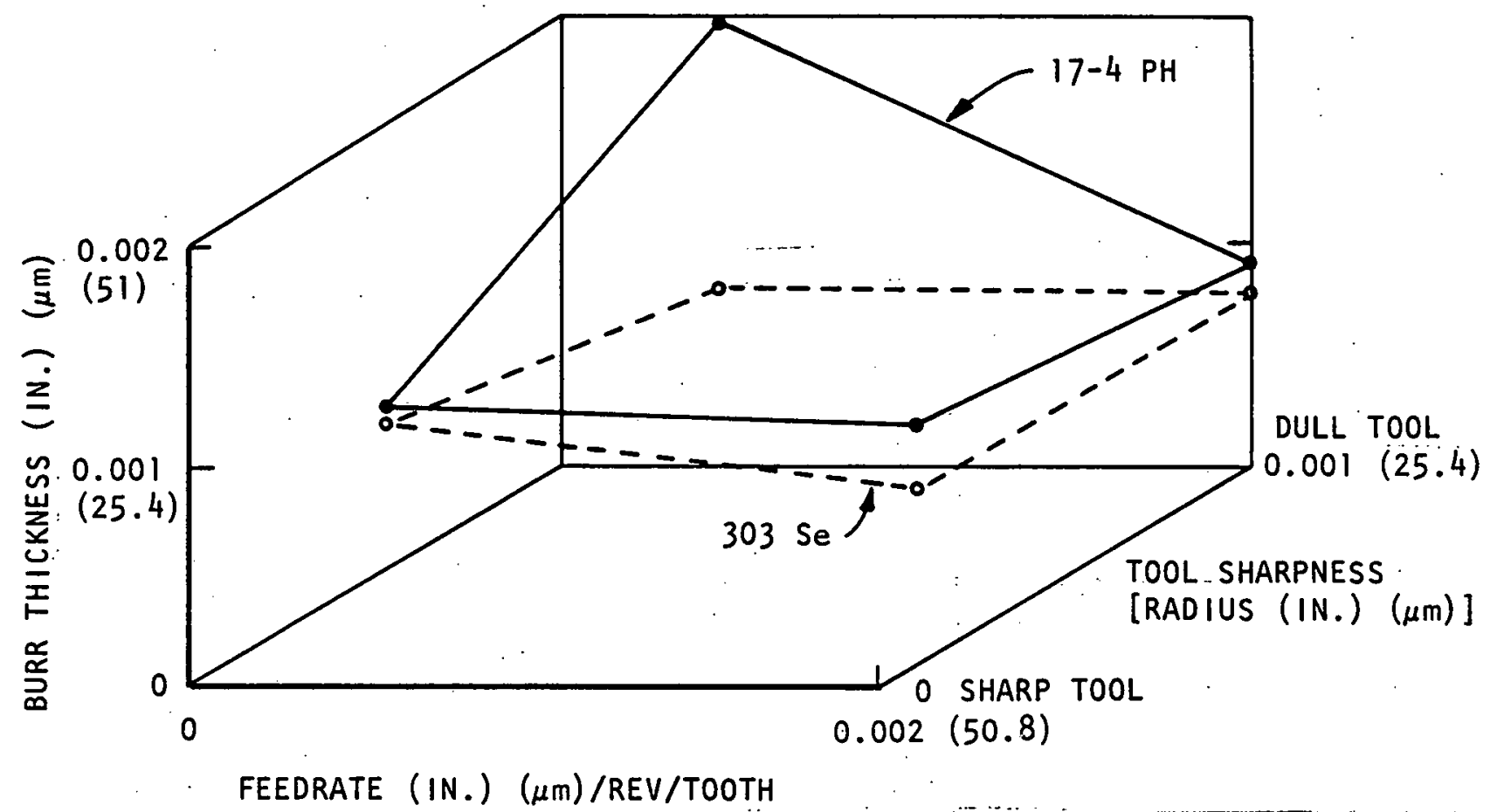

Figure 41. Edge 6: Effect of Feedrate and Tool Sharpness on Burr Thickness

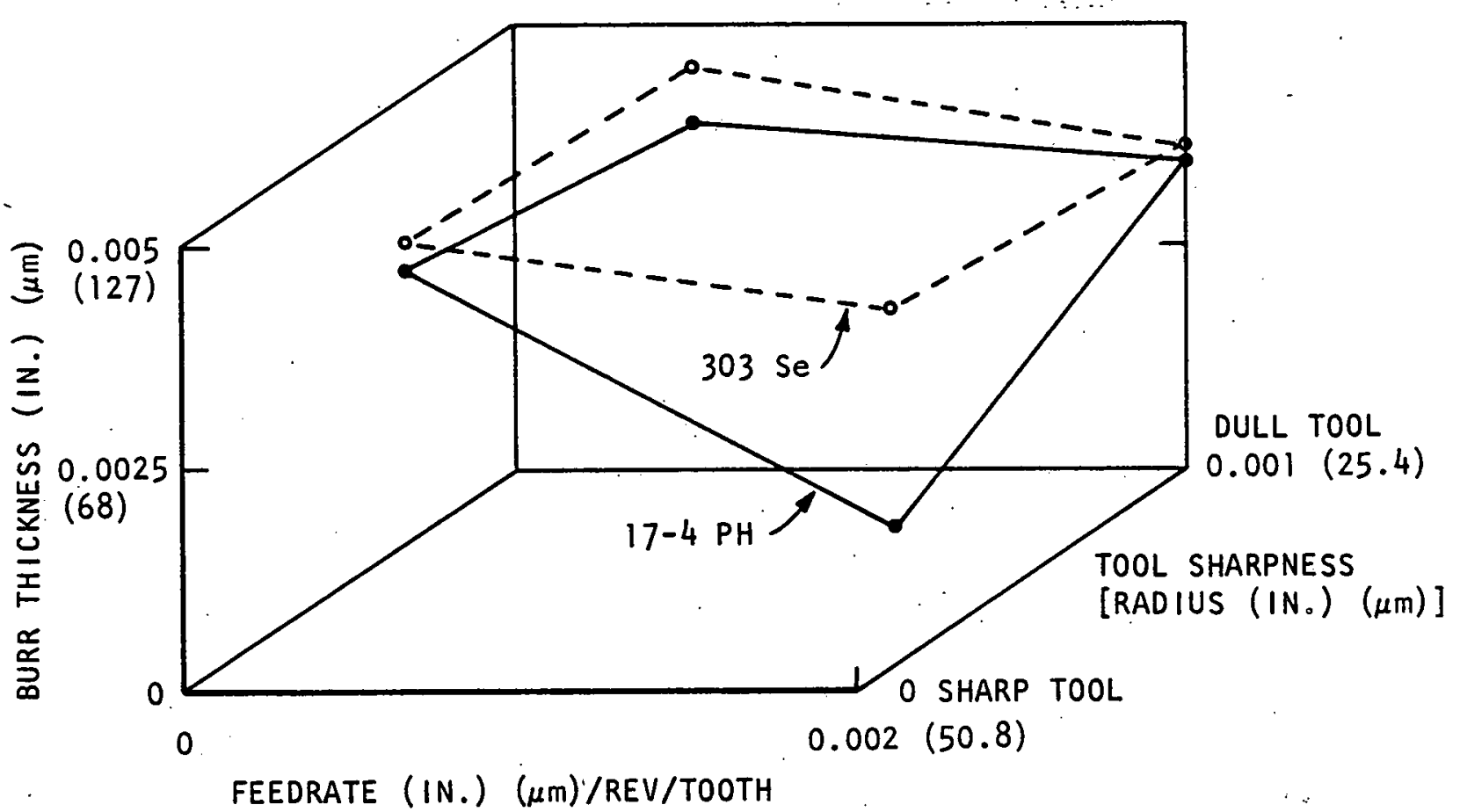

Figure 42. Edge 7: Effect of Feedrate and Tool Sharpness on Burr Thickness 


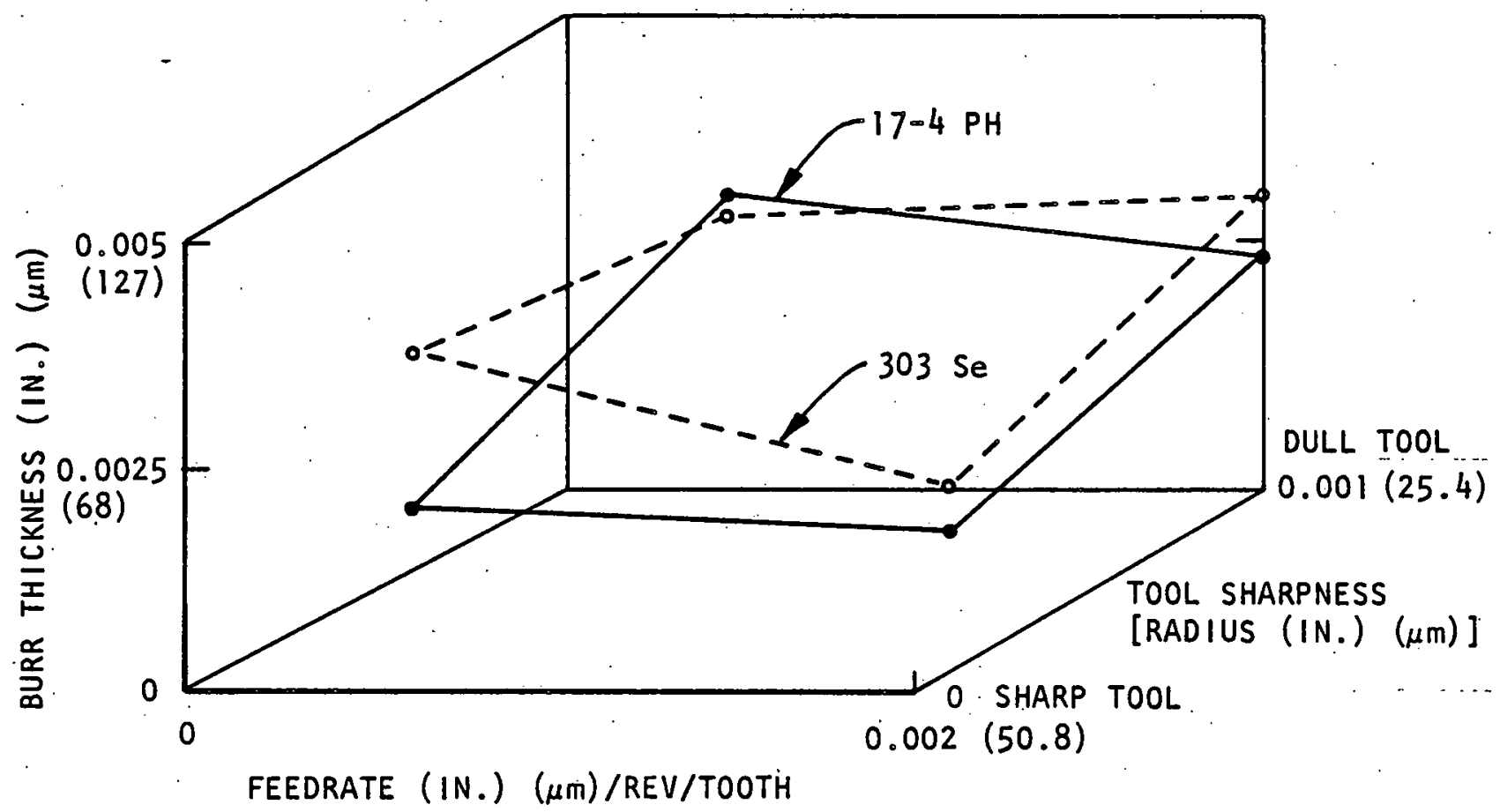

Figure 43. Edge 9: Effect of Feedrate and Tool Sharpness on Burr Thickness

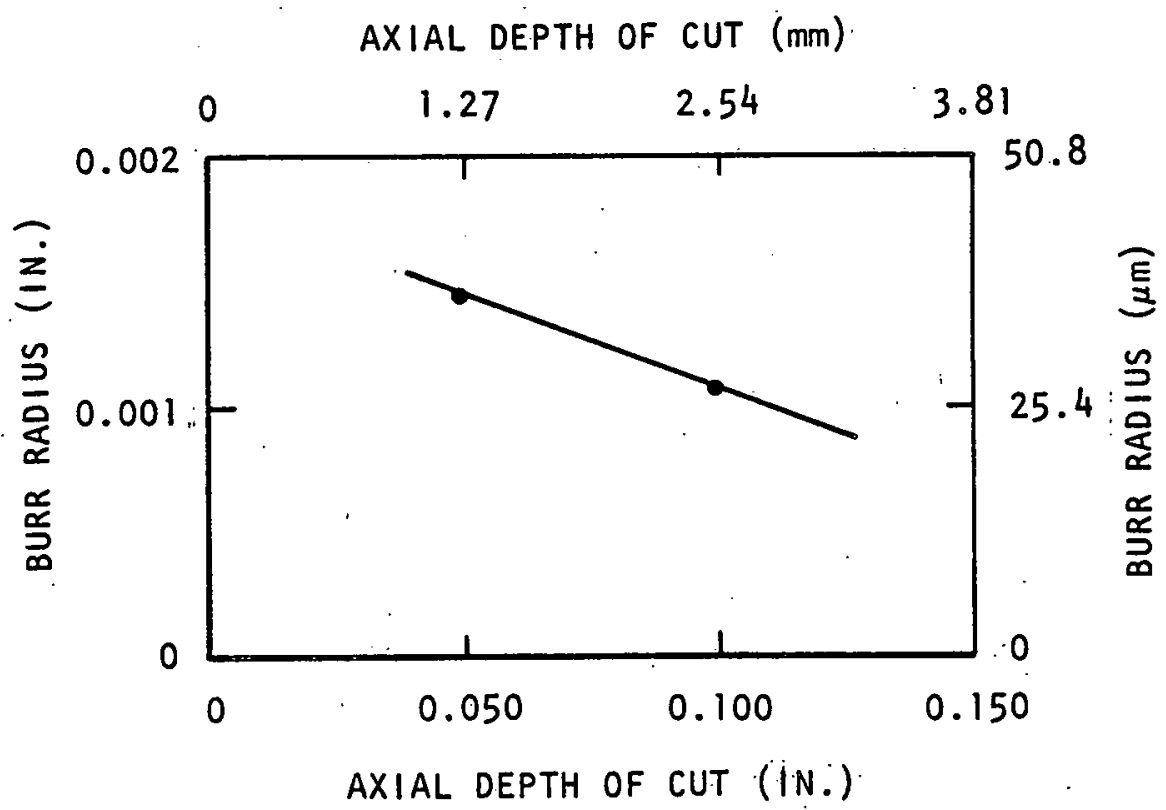

Figure 44. Edge 1: Effect of Axial Depth of Cut on Burr Ratius 
burrs while high feedrates with sharp tools produced the thinnest burrs. For the conditions tested, the worst burrs were twice as thick as those produced under the best conditions.

Burr Radius

As indicated in Table 4, no single variable affected the radius on the backside of the burr on all edges. The tool diameter did not influence the burr radius on any edge.

Deeper cuts produced small burr radii on edge 1 , (Figure 44). Dull tools increased the burr radius on edges 1 and 2 (Figure 45), but not elsewhere. Increasing radial depth of cut increased the burr radius on edge 3 (Figure 46). Increasing the feedrate increased the burr radius of the roll-over burrs on edges 3 and 5 (Figure 47). As a general rule, the smallest burr radii occurred in 6061 aluminum and the largest in 303 se stainless steel (Figure 48). This result, which corresponds with the strainhardening exponents, implies that materials with high strain-hardening exponents tend to develop large burr radii.

On edges 1 and 2 , the burr radii for the two stainless steel materials were nearly identical (Figures 49 and 50). High feedrates and sharp tools produced the smallest burr radii. on the other edges, a notable difference existed between the two materials (Figures 51 to 54 ).

\section{Effects of Tool Wear on Burr Properties}

The second test was a study of how burr properties vary with end-mill wear. A high-speed steel, four-flute, end mill was used to mill a 0.200 -inch-deep $(50.8 \mathrm{~mm})$ full-diameter slot in 303 Se stainless steel. A spindle speed of $845 \mathrm{rpm}$ and a feed of $0.0005 \mathrm{IPR} / \mathrm{t}(12.7 \mu \mathrm{m} / \mathrm{rev} / \mathrm{tooth})$ was used. A watersoluble spray mist coolant was used throughout the cuts. Burrs on edges 1 and 2 were measured at various points throughout the cut. A total of 261 inches of cut were made in this study. Burr height was measured optically after machining. Both height and thickness were also measured subsequently from metallurgical mounts.

An analysis of burr height variations as a function of length of cut traversed indicated that no real correlation existed. The data from this study are presented in Appendix A, Table A-2. Linear regressions of the data could only account for 4 percent of the data scatter. The average height of burrs at location 1 was 0.0062 inch $(157.5 \mu \mathrm{m})$. At location 2, the average burr height was 0.0033 inch $(83.8 \mu \mathrm{m})$. The standard deviation of the data was 0.0034 and 0.0027 inch ( 84 and $69 \mu \mathrm{m}$ ), respectively. The typical wide variation in height results are shown in Figure 55 . 


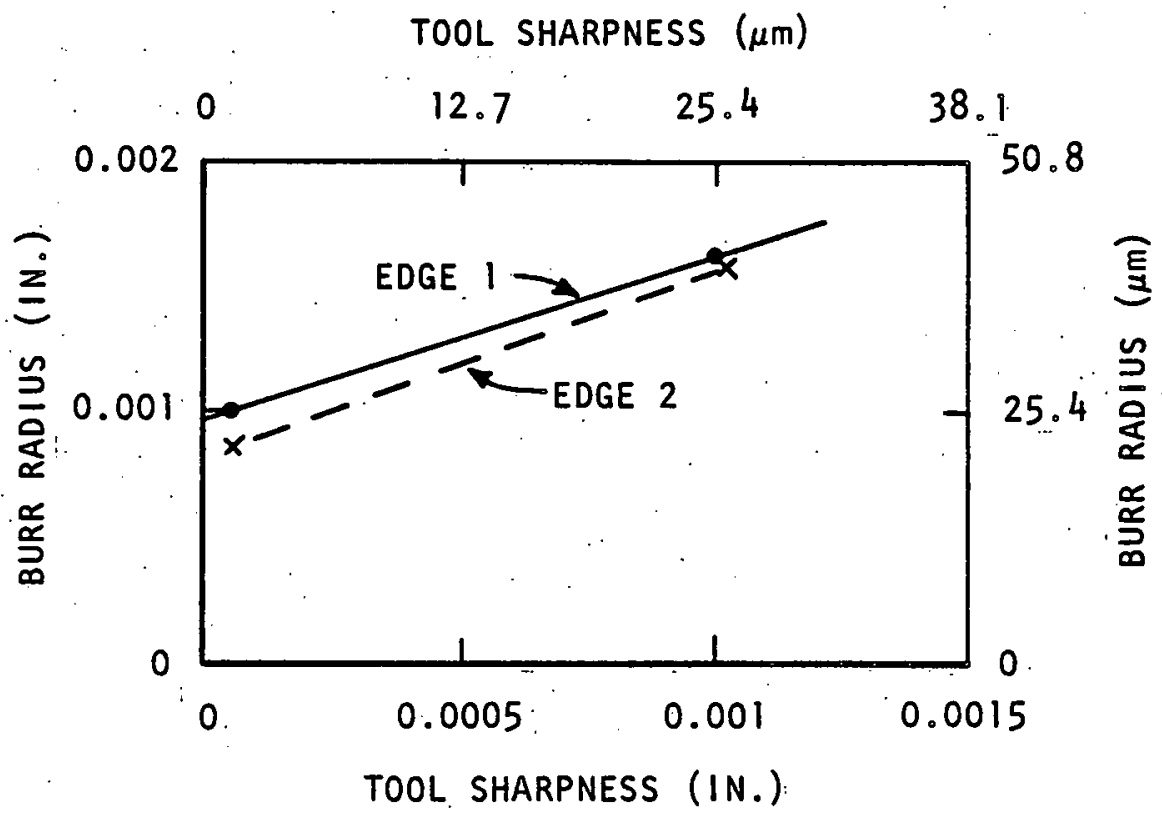

Figure 45. Edges 1 and 2: Effect of Tool Sharpness on Burr Radius

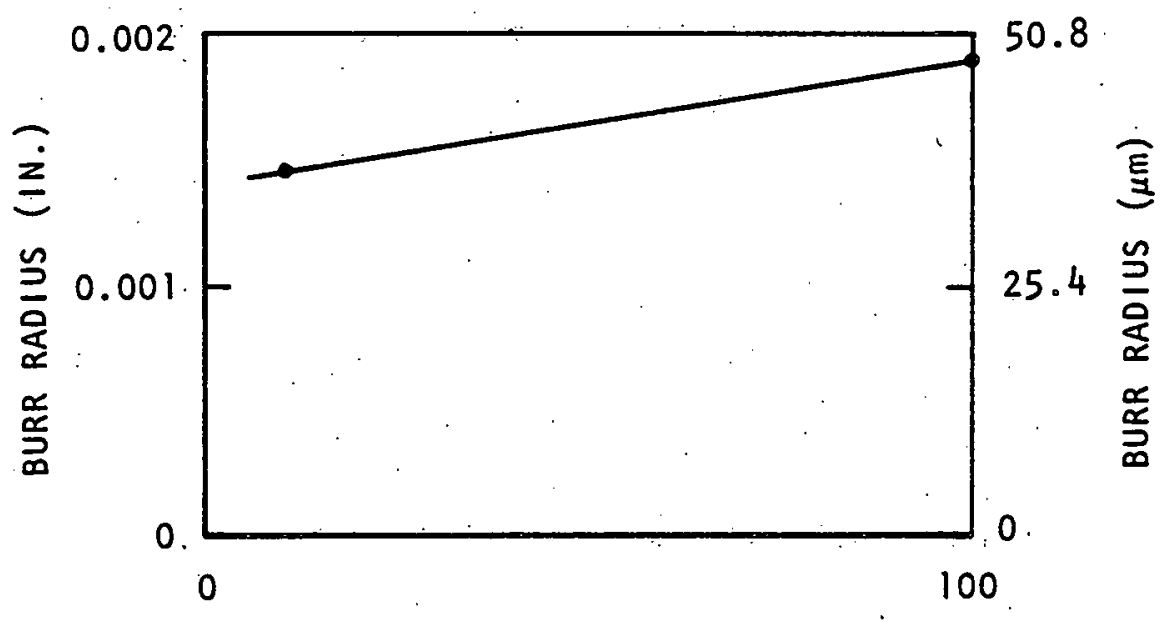

RADIAL DEPTH OF CUT (PERCENT OF DIAMETER)

Figure 46. Edge 3: Effect of Radial Depth of Cut on Burr Radius 


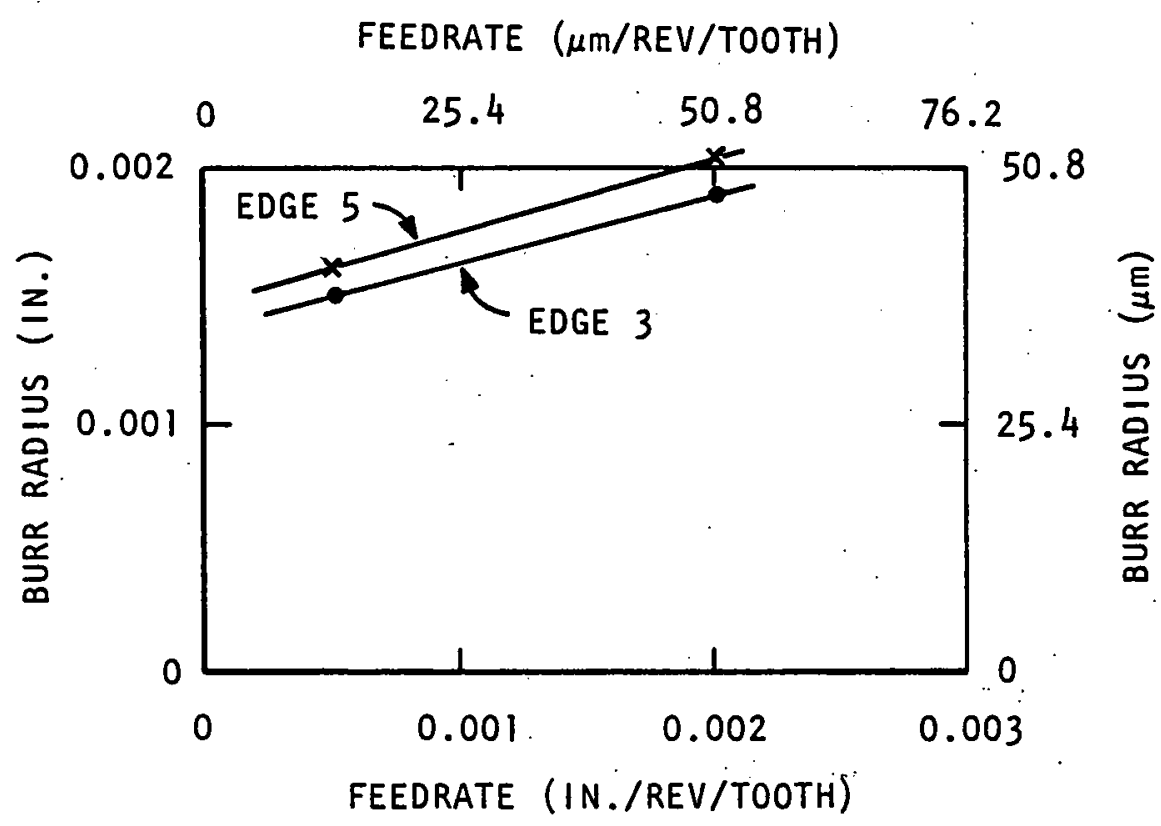

Figure 47. Edges 3 and 5: Effect of Feedrate on Burr Radius

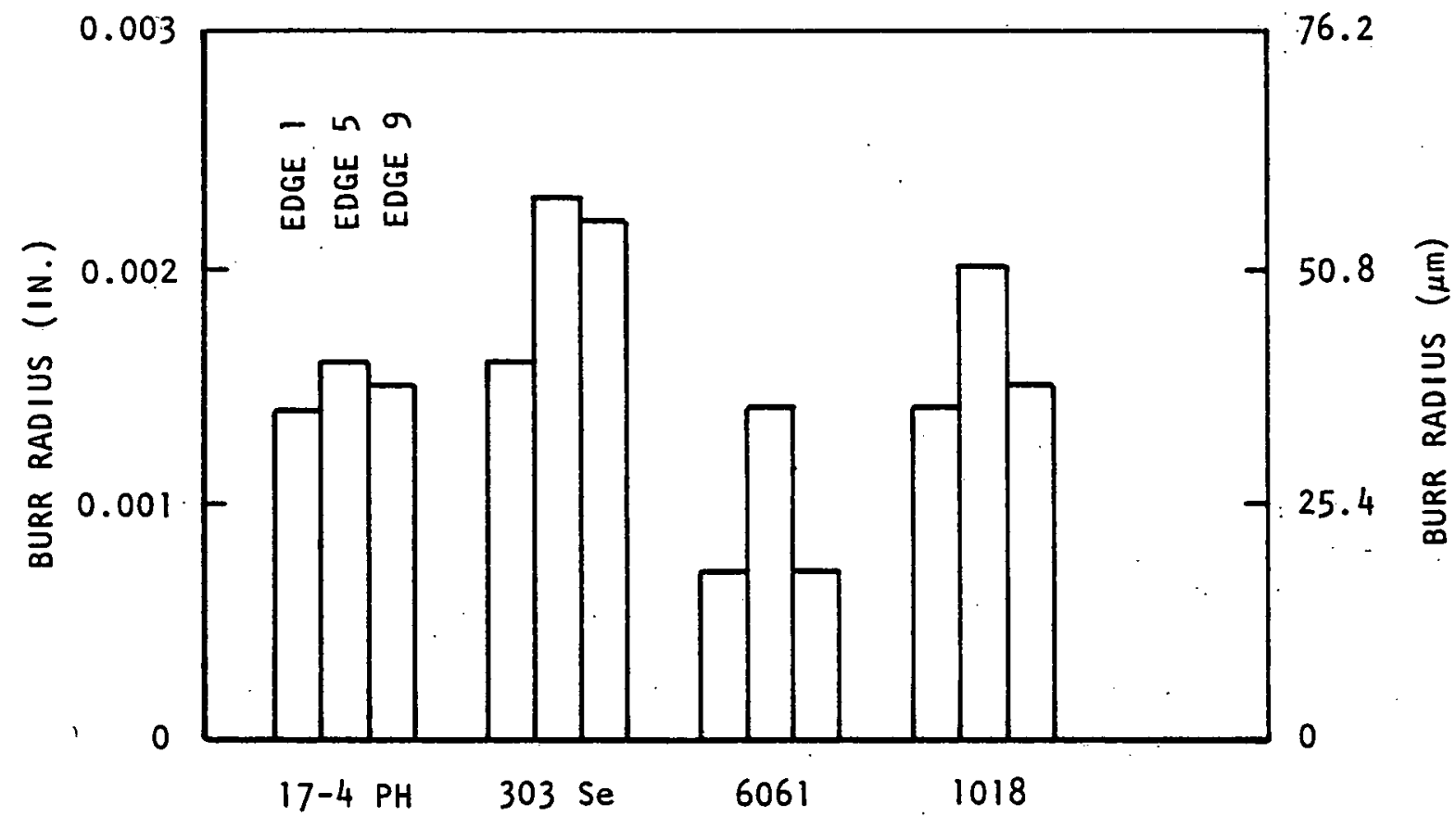

Figure 48. Edges 1, 5, and 9: Effect of Workpiece Material on Burr Radius 


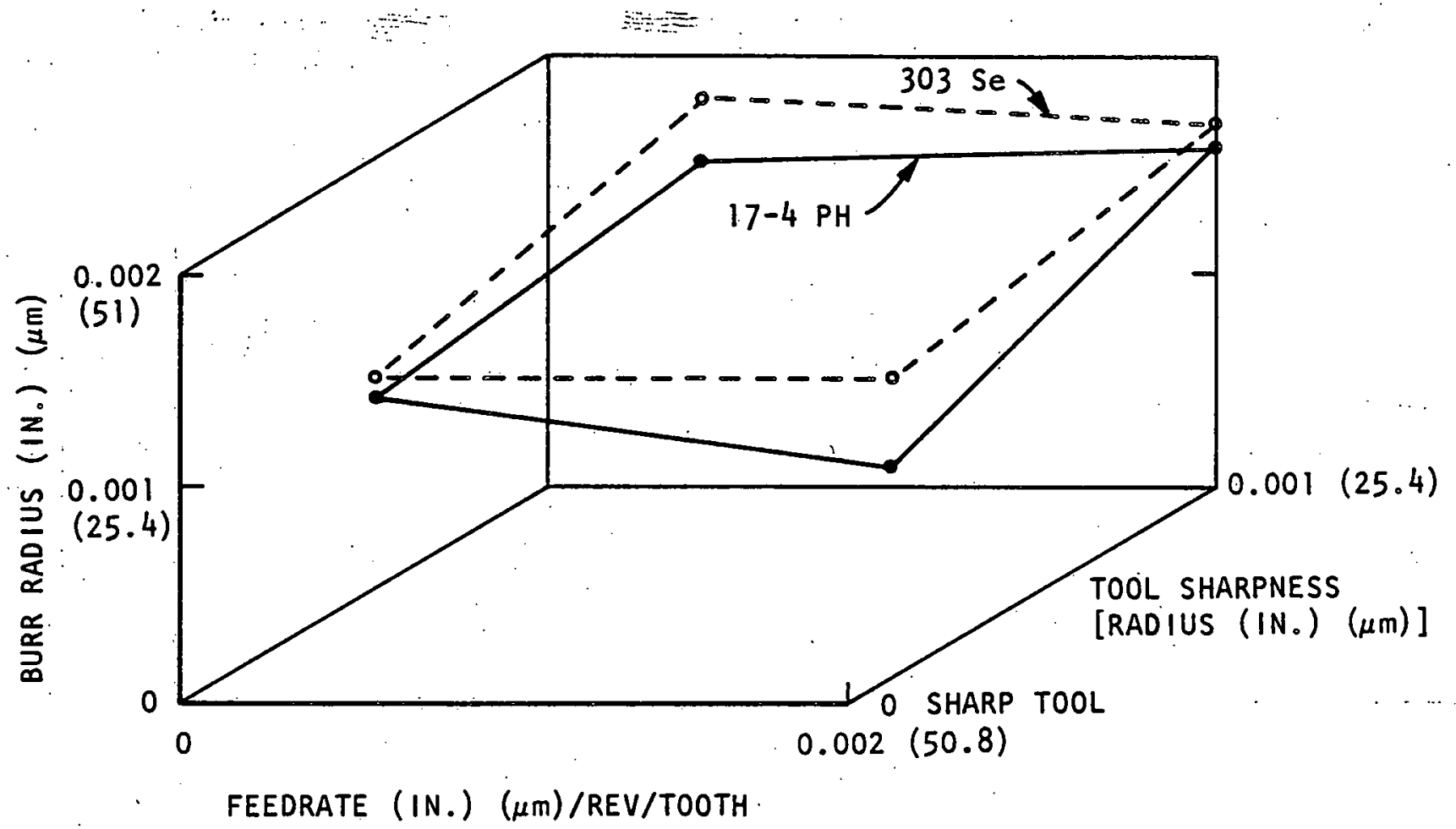

Figure 49. Edge 1: Effect of Feedrate and Tool Sharpness on Burr Radius

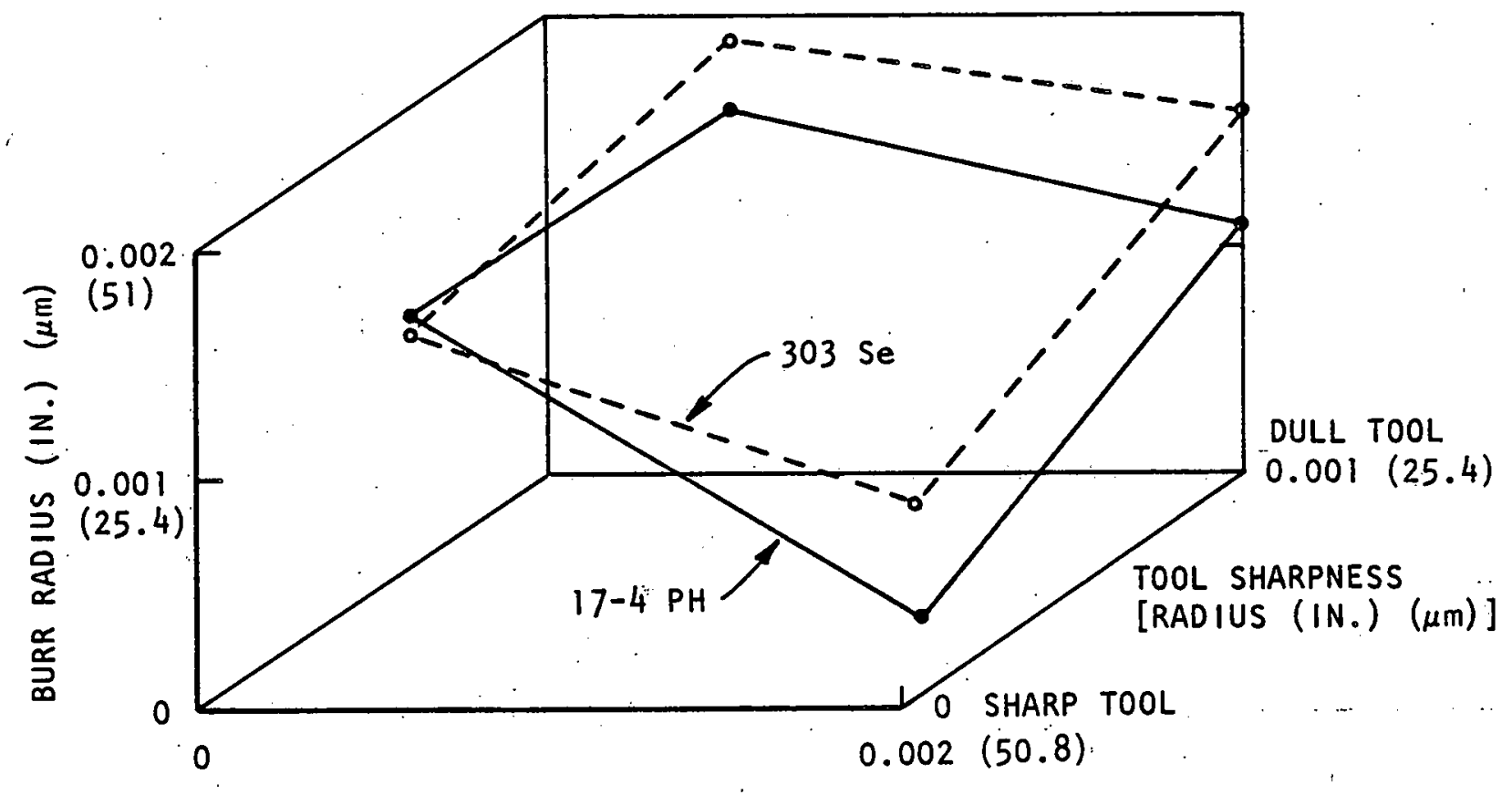

FEEDRATE (IN.) $(\mu \mathrm{m}) /$ REV/TOOTH

Figure 50. Edge 2: Effect of Feedrate and Tool Sharpness on Burr Radius 


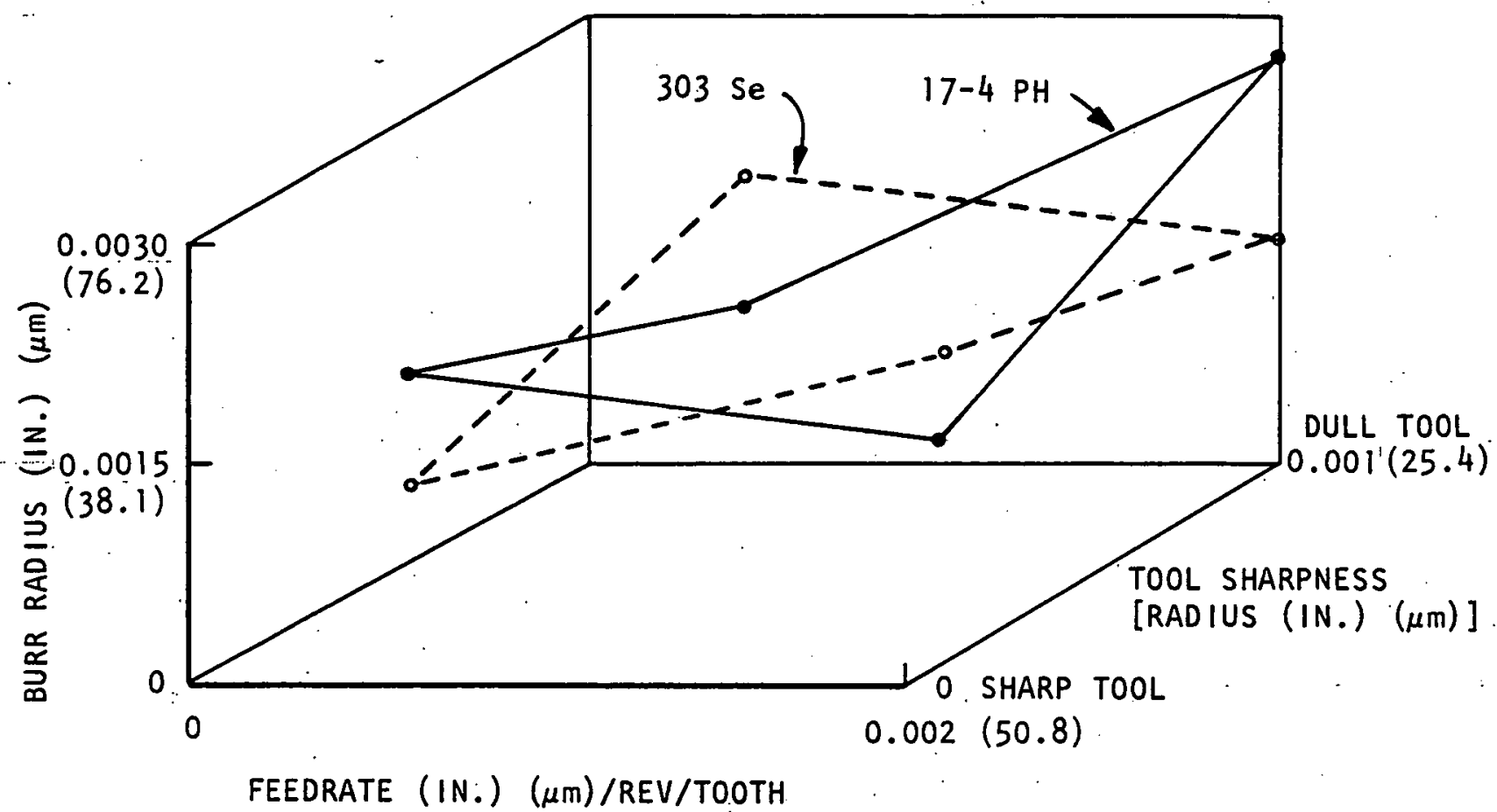

Figure 51. Edge 3: Effect of Feedrate and Tool Sharpness on Burr Radius

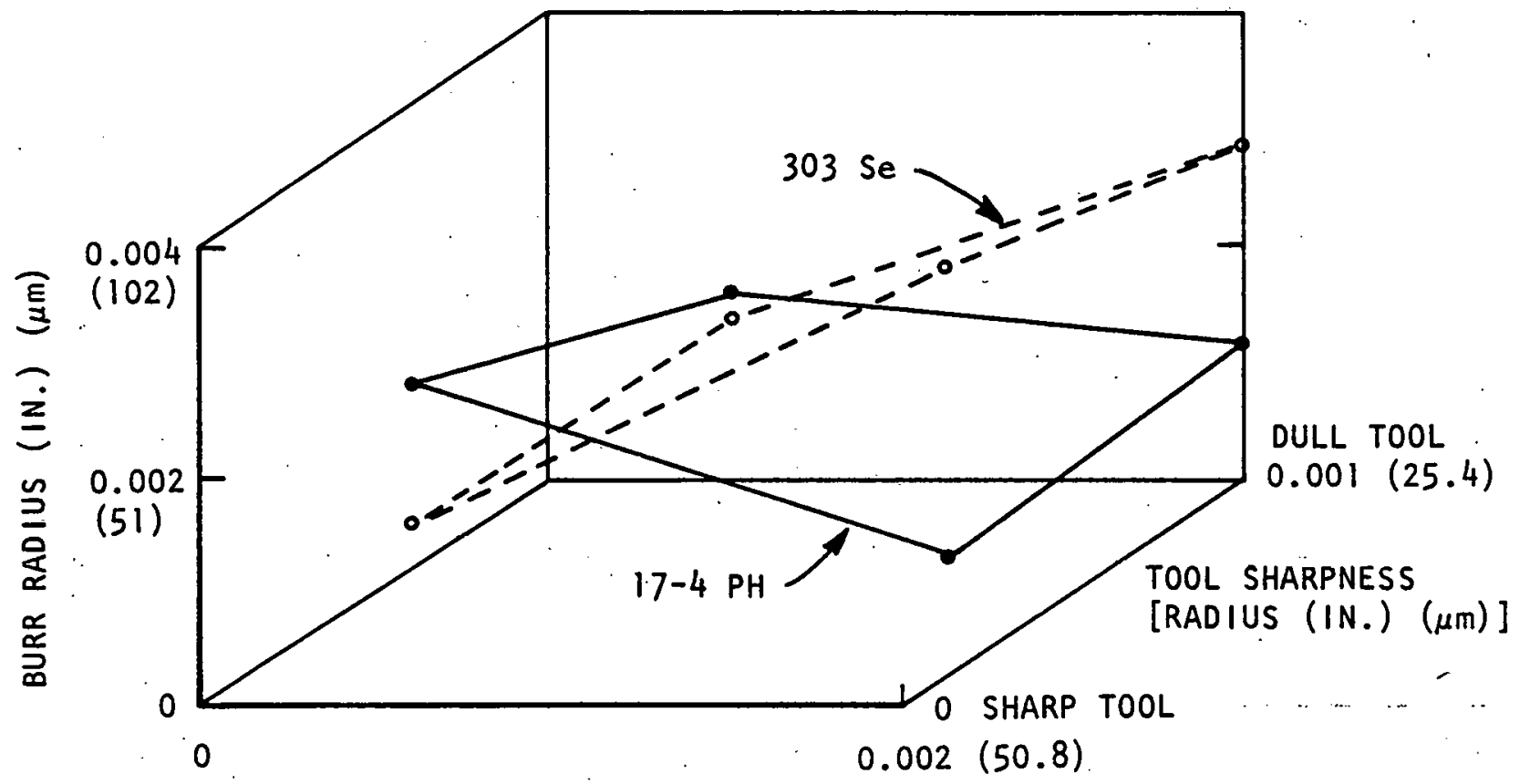

FEEDRATE (IN.) $(\mu \mathrm{m}) /$ REV/TOOTH

Figure 52. Edge 5: Effect of Feedrate and Tool Sharpness on Burr Radius 


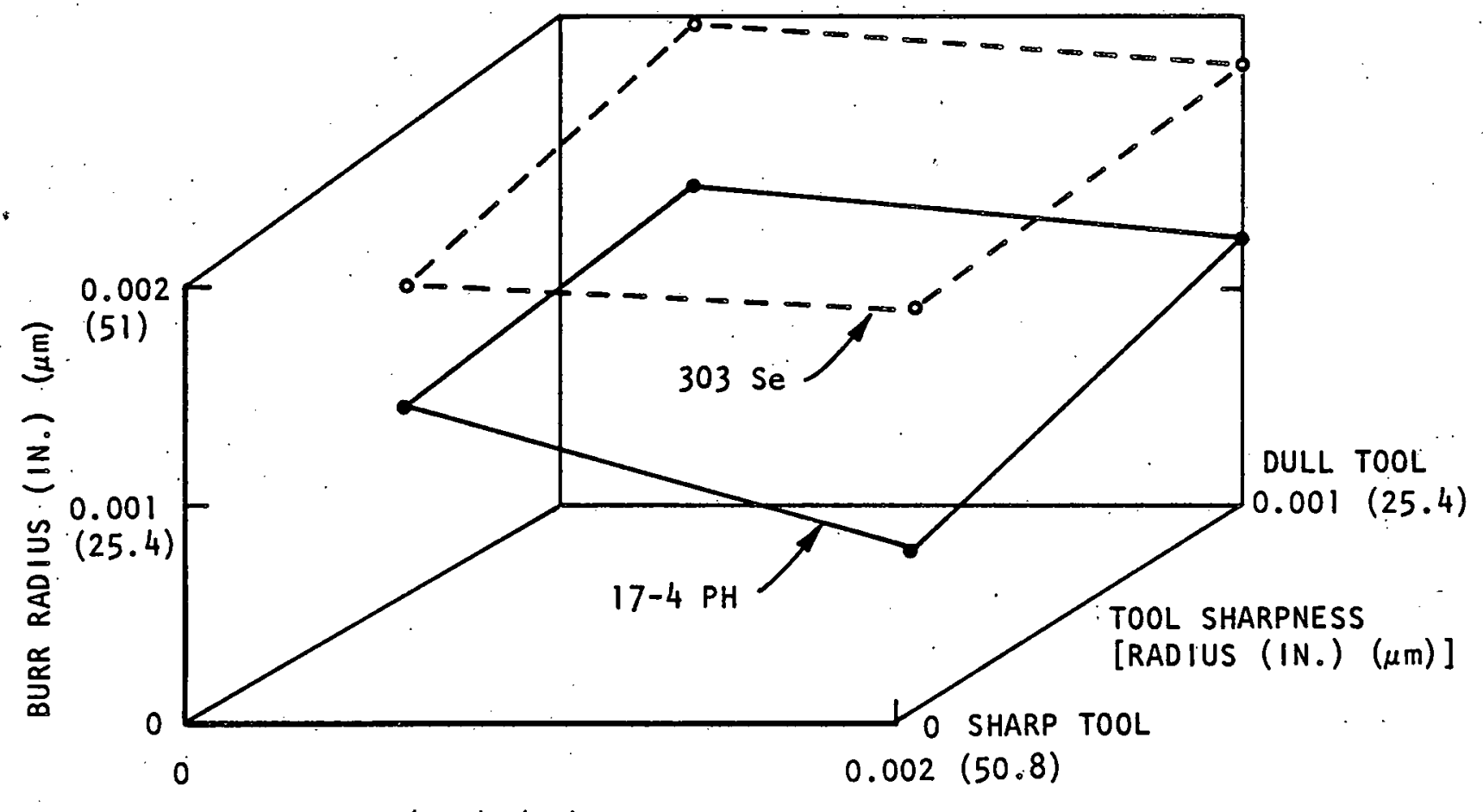

FEEDRATE (IN.) $(\mu \mathrm{m}) /$ REV/TOOTH

Figure 53. Edge 7: Effect of Feedrate and Tool Sharpness on Burr Radius

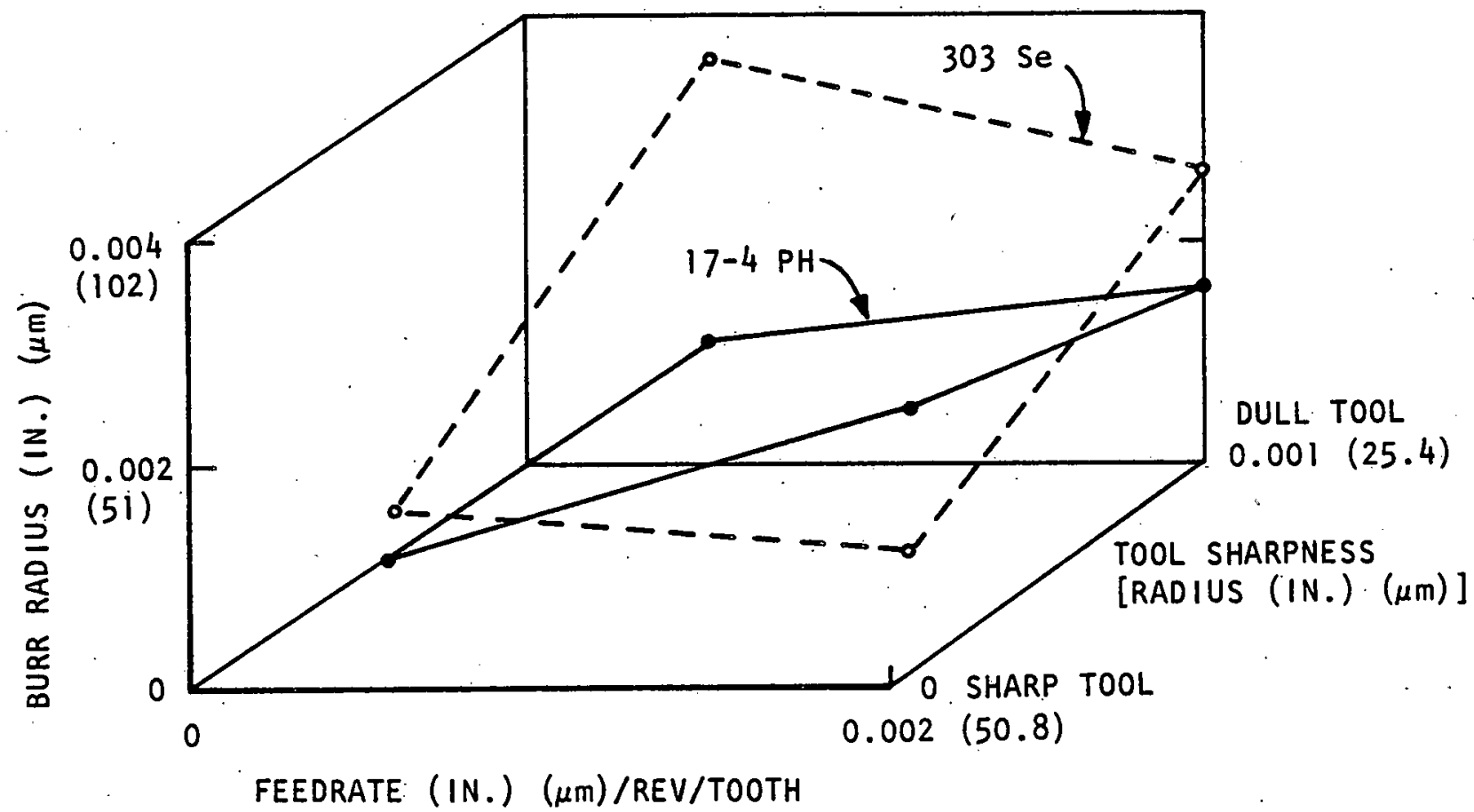

Figure 54. Edge 9: Effect of Feedrate and Tool Sharpness on Burr Radius 


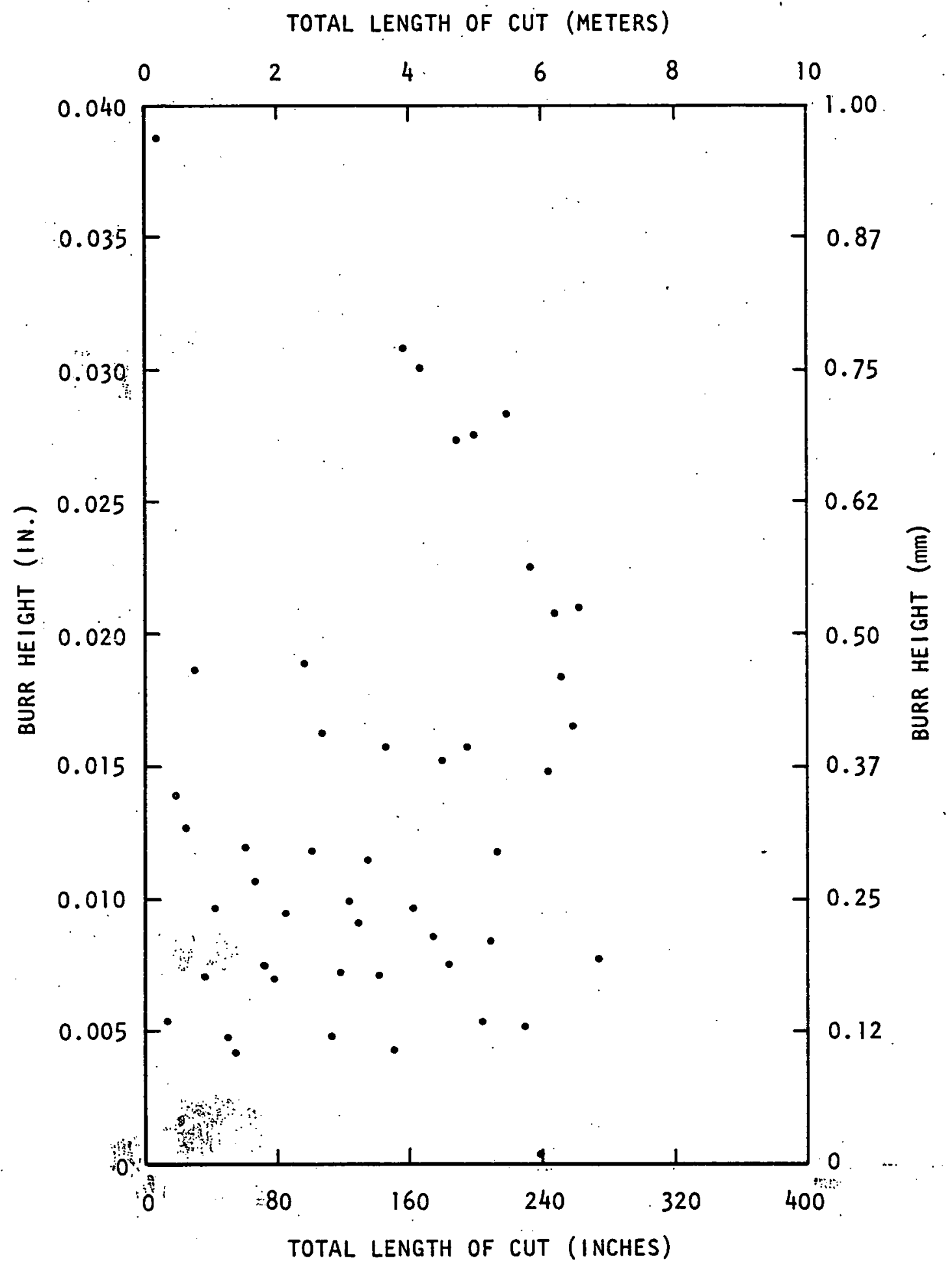

Figure 55. Burr Height at Edge 1 as a Function of Length of Cut 
Similar wide data scatter was observed for burr thickness and radius. No correlation was observed between these properties and length of cut or between the various burr properties. The average burr thickness was 0.0032 inch $(81 \mu \mathrm{m})$ at edge 1 , and $0.0013(33.0 \mu \mathrm{m})$ at edge 2 . The standard deviation of these measurements was 0.0019 and 0.0009 inch $(48.3$ and $22.9 \mu \mathrm{m})$, respectively. The average burr radii were 0.0008 inch $(20.3 \mu \mathrm{m})$ at edge 1 and 0.0026 inch $(66.0 \mu \mathrm{m})$ at edge 2 . The standard deviation of these measurements was 0.0010 and 0.0024 inch ( 25.4 and $61.0 \mu \mathrm{m})$, respectively.

End Milling Hiperco 50

While in general it is true that large burrs do not occur in brittle materials, there are some notable exceptions. Hiperco 50 which, with an elongation of less than 0.5 percent, in a 2 -inch ( $50.8 \mathrm{~mm}$ ) gage length, is considered a brittle material, is one of these exceptions.

Finish pass profiling cuts of 0.002 - to $0.003-i n c h$ radial depth $(50.8$ to $76.2 \mu \mathrm{m})$ were taken on a slotted cylinder (Figure 56). These cuts were made with a high-speed, steel, four-flute end $\mathrm{mill}$ at $0.00011 \mathrm{inch} / \mathrm{rev} /$ tooth $(2.79 \mu \mathrm{m} / \mathrm{rev} /$ tooth $)$ at $4500 \mathrm{rpm}$ with a water-soluble coolant. The axial depth of cut was 0.080 inch $(2.03 \mathrm{~mm})$. As shown in Table 6, burr thicknesses were typically 0.0021 inch $(53.3 \mu \mathrm{m})$, and burr heights ranged from 0.0058 to 0.0201 inch $(147.3$ to $510.5 \mu \mathrm{m})$. Although the machining conditions are sufficiently different to prevent direct comparison with the previous data, it is instructive to note that these burrs are roughly half the size of those produced in the ductile materials. The hardness of the burrs averaged $R_{c} 52$, while the parent material was only $R_{c} 30$.

The largest single factor in the size of these burrs must be the rubbing which occurs when low feedrates are used. The material gets hot, then softens when rubbing occurs, and becomes a plastic rather than a brittle material in the area where the burr is produced. While the obvious solution to minimize this problem is to increase the feedrate, this is not always possible because feedrate increases can raise cutting forces which distort thin walls. As a general rule; however, increasing feedrates up to 0.001 inch/rev/tooth $(25.4 \mu \mathrm{m} / \mathrm{rev} /$ tooth $)$ reduces cutting forces.

\section{Effect of Helix Angle}

The effect of the helix angle on burr size was briefly studied in one test. In this study, a full-diameter slot was produced in the end of a 303 Se stainless steel bar, at a feedrate of $0.0011 \mathrm{inch} / \mathrm{rev} /$ tooth $(27.9 \mu \mathrm{m} / \mathrm{rev} /$ tooth $)$ and a spindle speed of $1750 \mathrm{rpm}$. Cutter diameters varied from 0.250 to 0.375 inch 


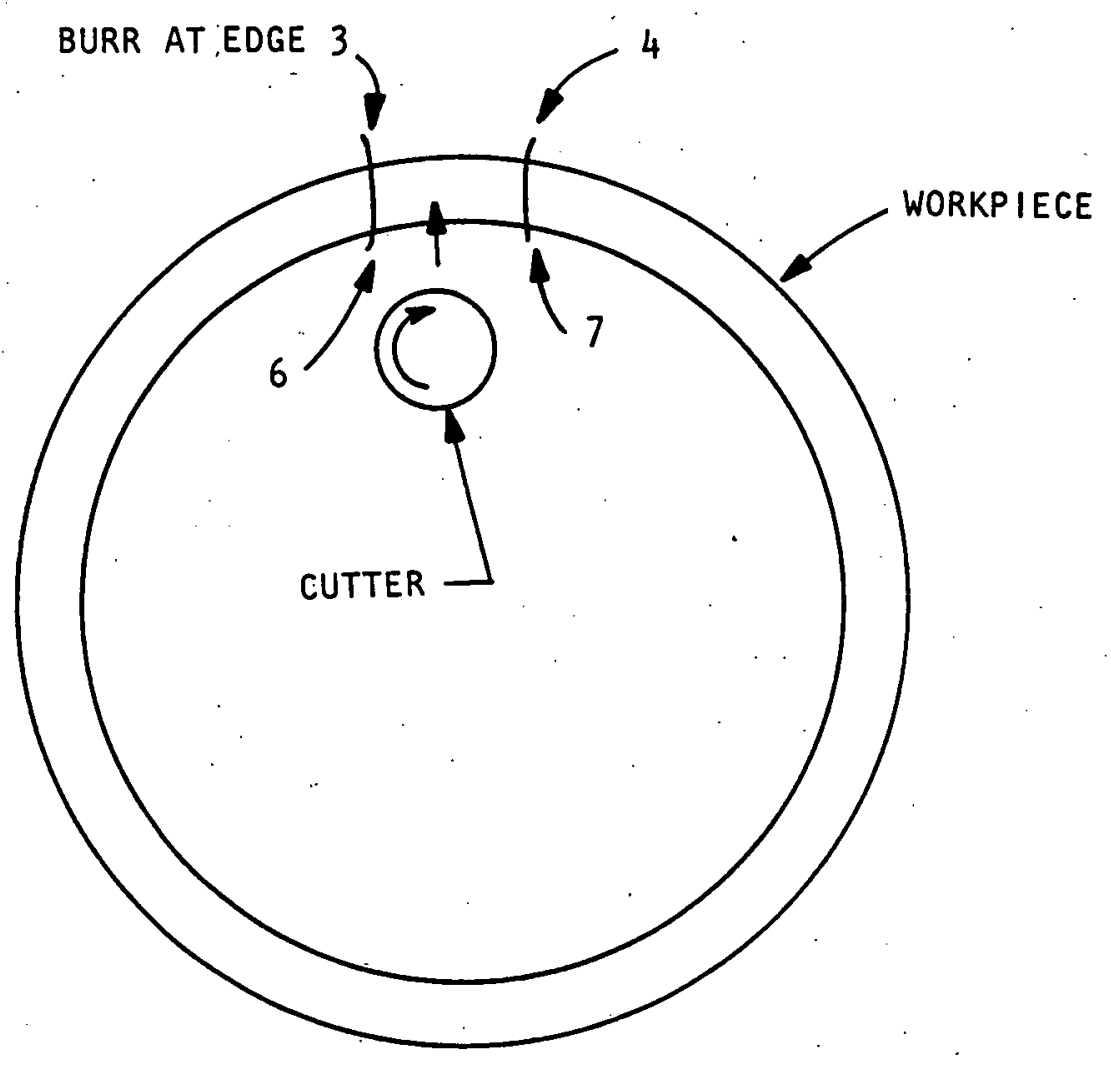

Figure 56. Specimen Used in Hiperco 50 End-Milling Study

( 6.35 to $9.53 \mathrm{~mm}$ ). The helix angles used included 32,0 , and -13 degrees where a negative angle implies a left-hand spiral right-hand cut.

While the left-hand spiral cutter produced slightly shorter burrs on edges 1 and 2 than did the conventional cutter, it did not eliminate the burr (Table 7 ). This is consistent with the theory of burr formation when a large roll-over burr does not occur on these edges. The reverse helix tool produced a much longer burr at edge 7 than did the other cutters. The zero degree helix tool produced much higher burrs on edges 1 and 2 than did the standard or the reverse helix, which was unexpected.

The Appearance of Milling Burrs

Burrs exist in many forms. For example, if entrance burrs exist at edge 6 they are small mounds of material. The roll-over burrs are long flaps of material having a rectangular cross section. The burrs on edges 1 and 2 can be a short, uniform, triangular 
Table 6. Properties of Burrs Produced by End Milling Hiperco 50

\begin{tabular}{lllll}
\hline & \multicolumn{4}{l}{ Burr Size (in.)* } \\
\cline { 2 - 5 } Property & \multicolumn{3}{l}{ Edge Location } \\
\cline { 2 - 5 } Height & 0.0201 & 0.0065 & 0.0058 & 0.0179 \\
Thickness & 0.0020 & 0.0021 & 0.0008 & 0.0022 \\
\hline * 0.001 inch equals $25.4 \mu \mathrm{m})$ & & \\
\hline
\end{tabular}

spike, as shown in Figure 16, or they can have a loose, feathery appearance, as shown in Figure 57. On some parts, only one or two strands are evident, while on other the entire edge is covered with these feathery burrs. Although these projections are easily wiped off, the root of the burr, in the form of a triangular spike, is still present.

The burrs illustrated in Figures 58 and 59 were produced by slotting a hollow cylinder at $0.00005 /$ inch $/ \mathrm{rev} /$ tooth $(1.27 \mathrm{~m} / \mathrm{rev} /$ tooth) and $2720 \mathrm{rpm}$. The four-flute, solid-carbide cutter was 0.069 inch $(1.75 \mathrm{~mm})$ in diameter and had a 30-degree helix. The workpiece material was in the H900 condition.

The appearance of the burr on edge 1 can be significantly different from that on edge 2 , as shown in Figures 58 and 59. Figure 58 is a photograph of the burr on edge 1, in 17-4 PH stainless steel. The burr on edge 2 in this slotting application is obviously much larger and stiffer. In both cases, the obvious part of the burr is formed by chip roll-over. The fingers projecting from both are the result of tears occurring in the chip. All burrs produced with a dull tool at these edges had the feathery appearance. Although the burrs produced by the sharp tools also had some of this appearance, it was very minute. Figures 60,61 , and 62 provide some additional comparisons of burrs at these edges.

The burrs on edges 5,8 , and 9 assume at least two forms. Figure 63 illustrates the scallop nature of burrs produced at edge 9 by a face mill. In this type of application, burr height is a function of cutter diameter and location relative to the edge of the part, in addition to the parameters already indicated. In general, the burrs on these edges are not as regular, as shown in Figure 60 .

Text continued on page 86: 
Table 7. Effect of Helix. Angle on Burr Size

\begin{tabular}{|c|c|c|c|c|c|c|c|c|c|}
\hline \multirow{3}{*}{$\begin{array}{l}\text { Diameter } \\
(\text { in. })^{*}\end{array}$} & \multirow{3}{*}{$\begin{array}{l}\text { Helix } \\
\text { Angle } \\
\text { (Degrees) }\end{array}$} & \multicolumn{8}{|l|}{ Location } \\
\hline & & $\cdot$ & 2 & 3 & 4 & 5 & 6 & 7 & 8 \\
\hline & & \multicolumn{8}{|c|}{ Burr Height (in.) } \\
\hline 0.265 & 32 & 0.0030 & $0.0045 \dagger$ & 0.200 & 0 & $\begin{array}{l}0.0026 \\
\max \end{array}$ & 0 & 0.0280 & $\begin{array}{l}0.0015 \\
\max \end{array}$ \\
\hline 0.250 & 0 & 0.0350 & $0.0157 \dagger \dagger$ & $* *$ & 0 & $\begin{array}{l}0.0060 \\
\max \end{array}$ & 0.0020 & 0.0220 & $\begin{array}{l}0.0055 \\
\max \end{array}$ \\
\hline \multirow[t]{2}{*}{0.375} & -12 & 0.0024 & 0.0013 & 0.325 & 0 & $\begin{array}{l}0.0060 \\
\max \end{array}$ & 0 & 0.1000 & $\begin{array}{l}0.0020 \\
\max \end{array}$ \\
\hline & & \multicolumn{8}{|c|}{ Burr Thickness (in.) } \\
\hline 0.265 & 32 & $* * *$ & 0.0015 & 0.0010 & 0 & 0.0030 & 0 & 0.0070 & 0.0010 \\
\hline 0.250 & 0 & 0.0023 & 0.0010 & 0.0020 & 0 & 0.0025 & 0.0080 & 0.0060 & 0.0020 \\
\hline 0.375 & -12 & 0.0020 & 0.0015 & $0.0030 * *$ & 0 & 0.0018 & 0 & 0.0050 & 0.0016 \\
\hline \multicolumn{10}{|c|}{$\begin{array}{l}\text { *0.001 inch equals } 25.4 \mu \mathrm{m} \text {. } \\
\text { **The large portion of this burr broke loose in ha } \\
\text { ***Not accurately determined. } \\
\quad \nmid \text { Individual fragments are up to } 0.060 \text { inch long. } \\
\text { † Individual fragments are up to } 0.150 \text { inch long. }\end{array}$} \\
\hline
\end{tabular}




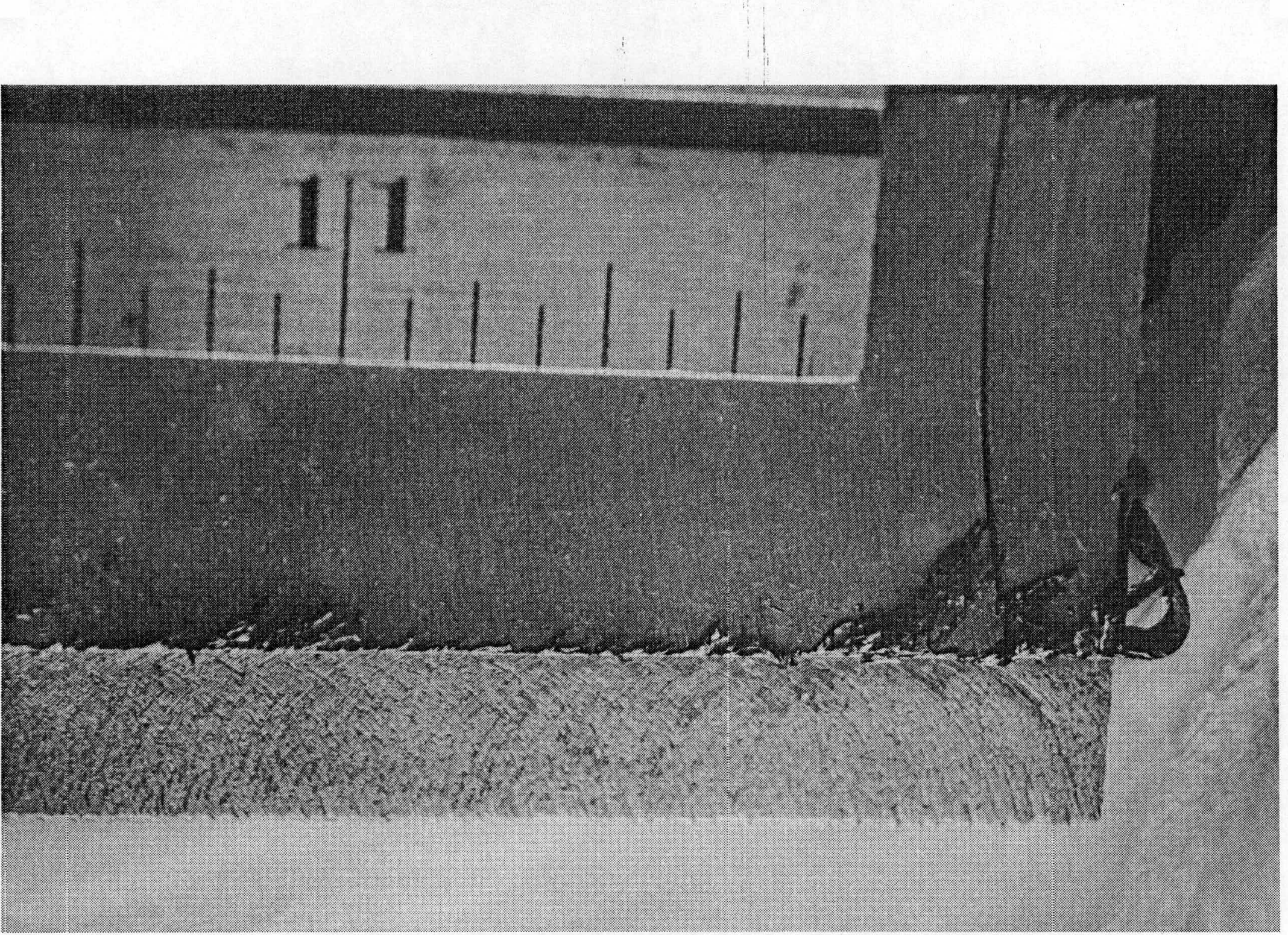

Figure 57. Feathery Burr on Edge 1, Produced by Face-Milling Low-Carbon Steel 


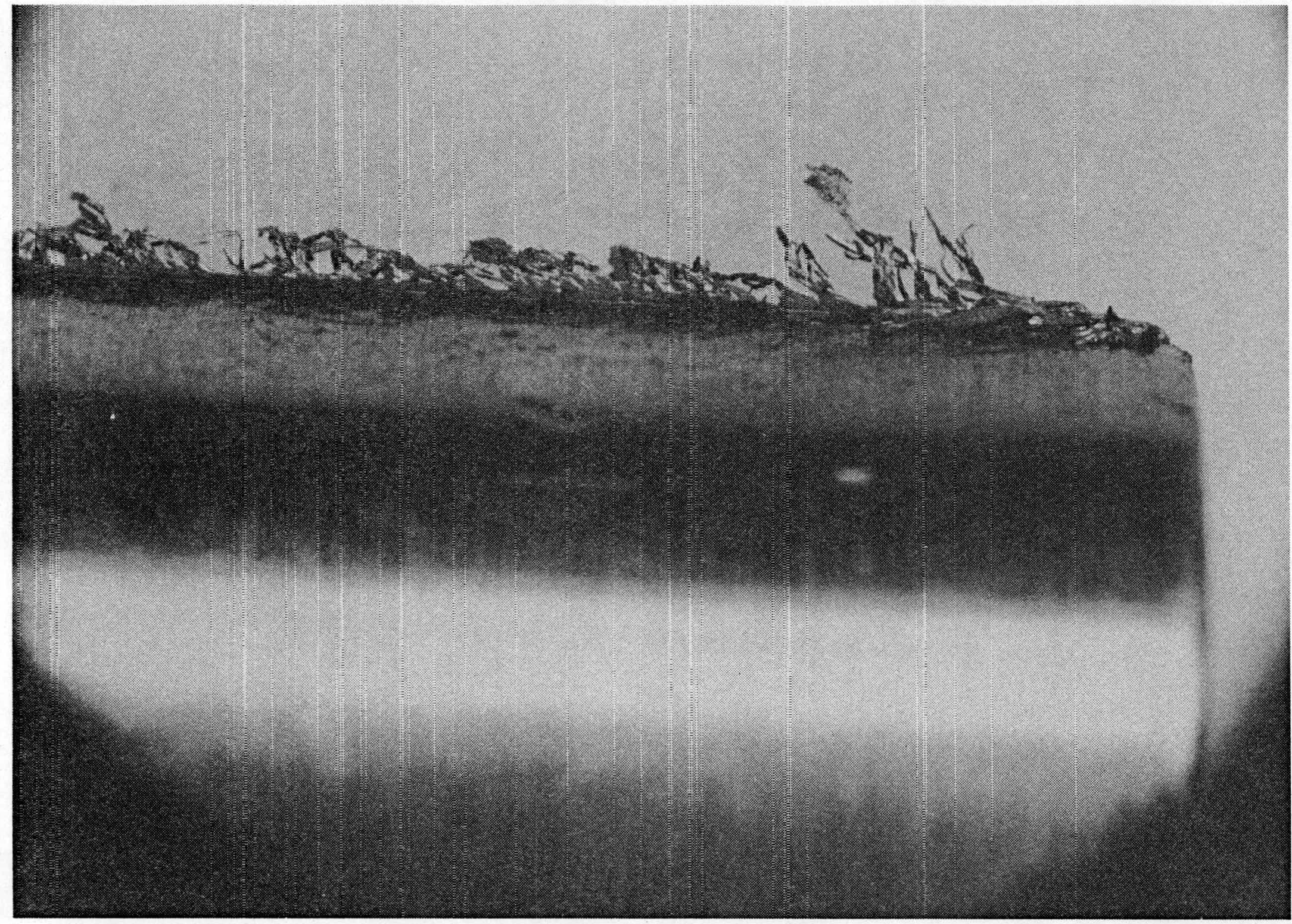

Iigure 58. Feathery Burr on Edge 1, Produced by Slotting 17-4 PH Stainless Steel 


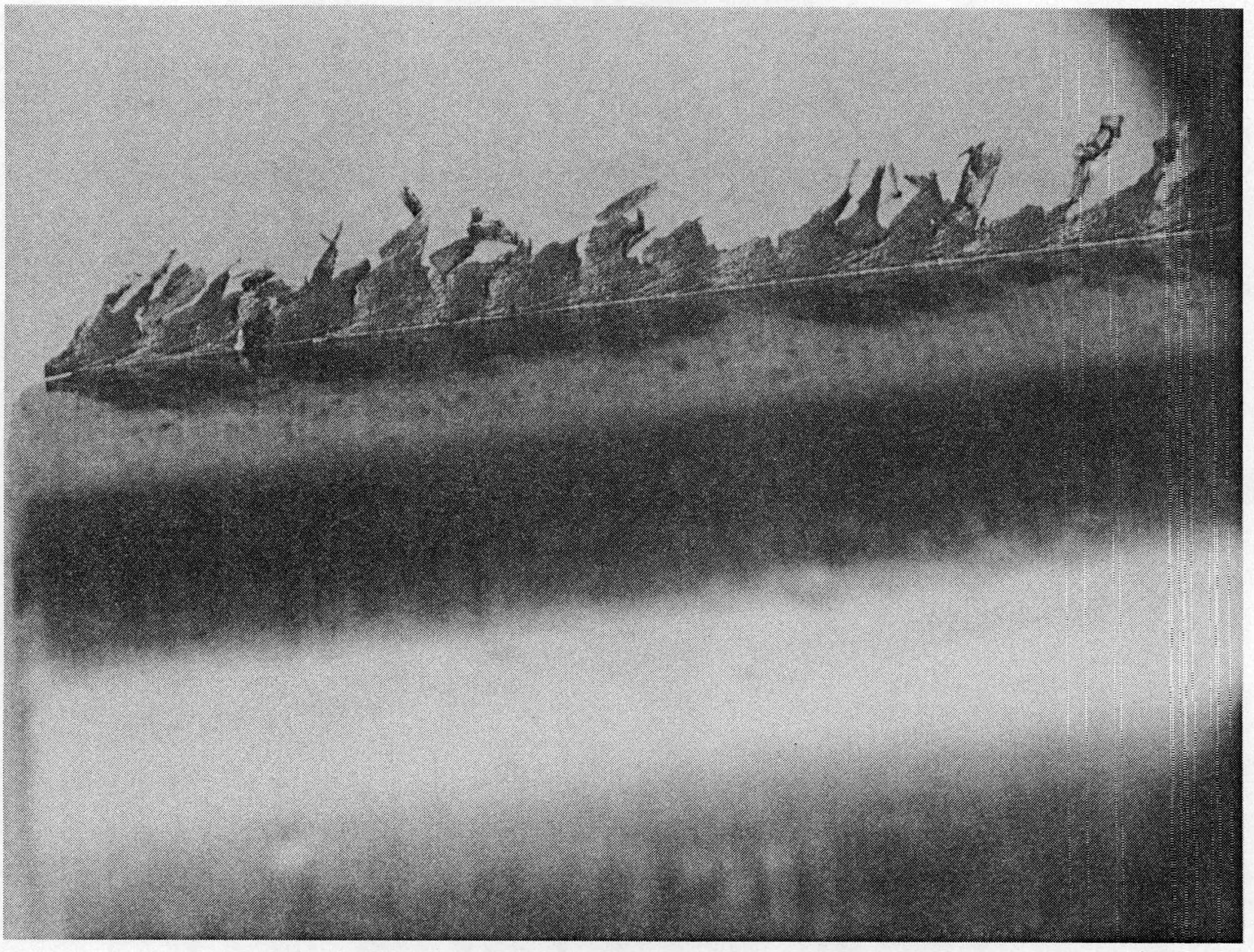

Figure 59. Feathery Burr on Edge 2, Produced by Slotting 17-4 PH Stainless Steel 


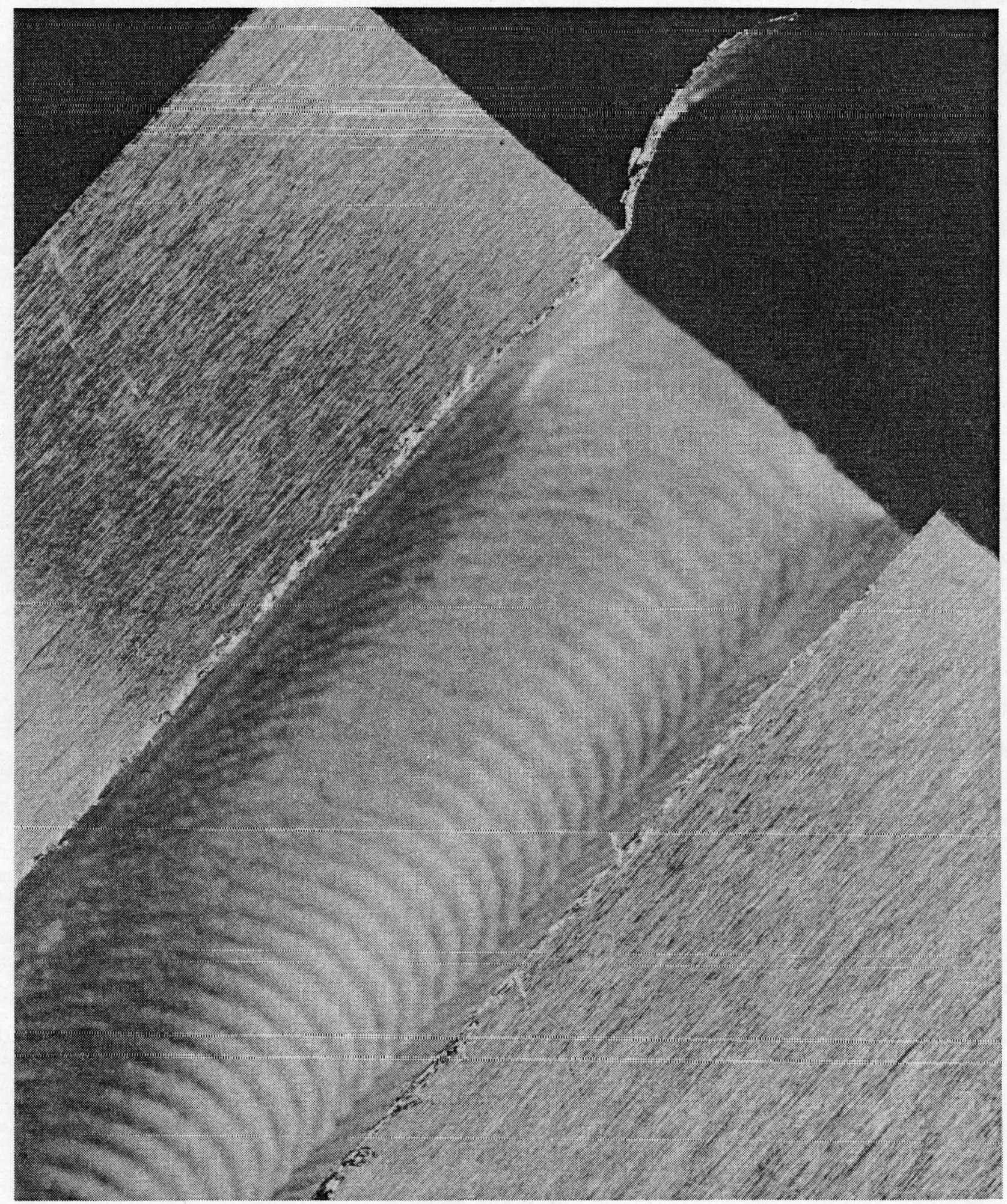

Figure 60. Small Burrs Produced on Edge 1 With Sharp End Mill in 1018 Steel ( $\left.R_{c} 20\right)$ 


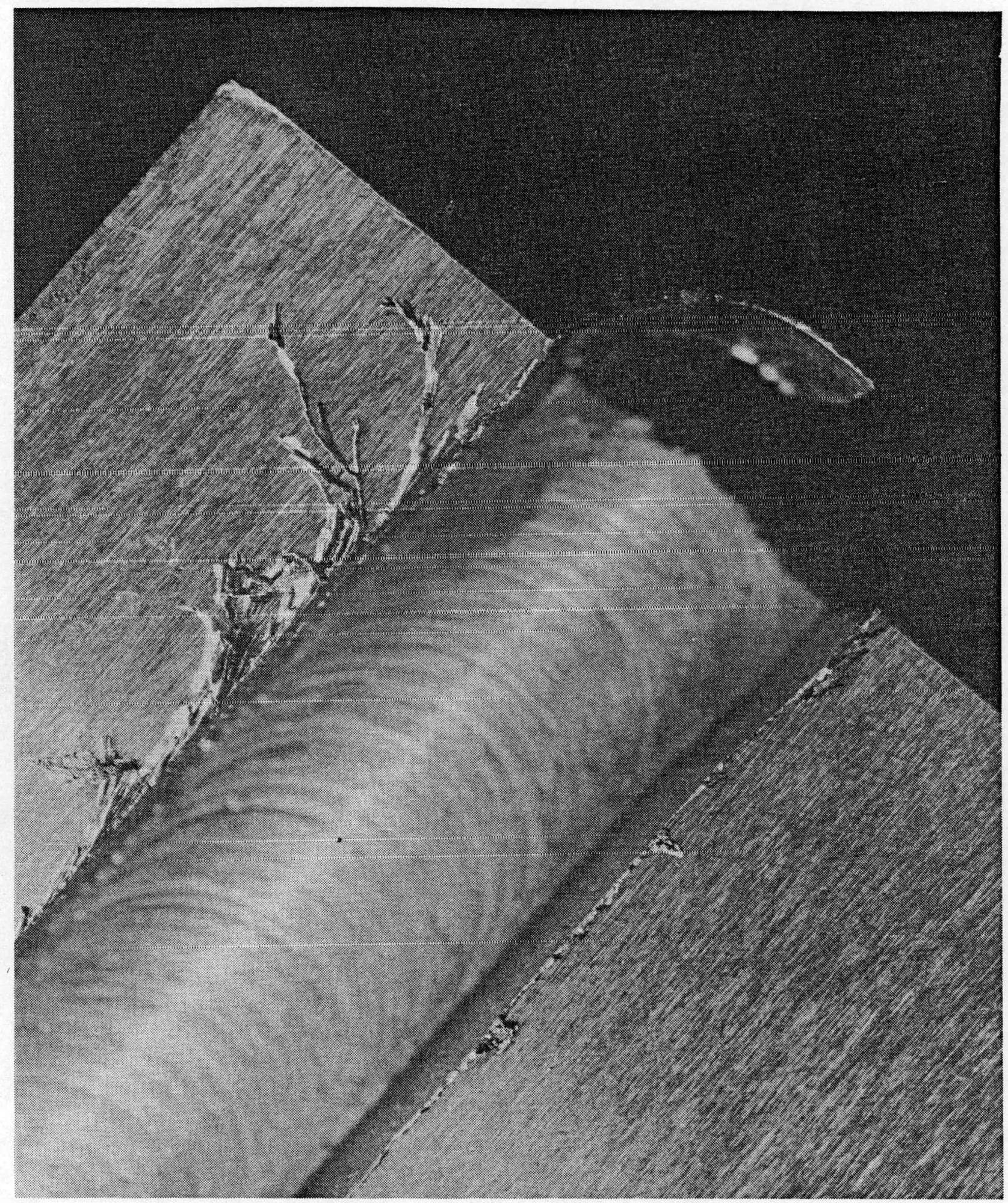

Figure 61. Feathery Burr on Edge 1, Produced by Dull End Mill in 1018 Steel $\left(R_{c} 20\right)$ 


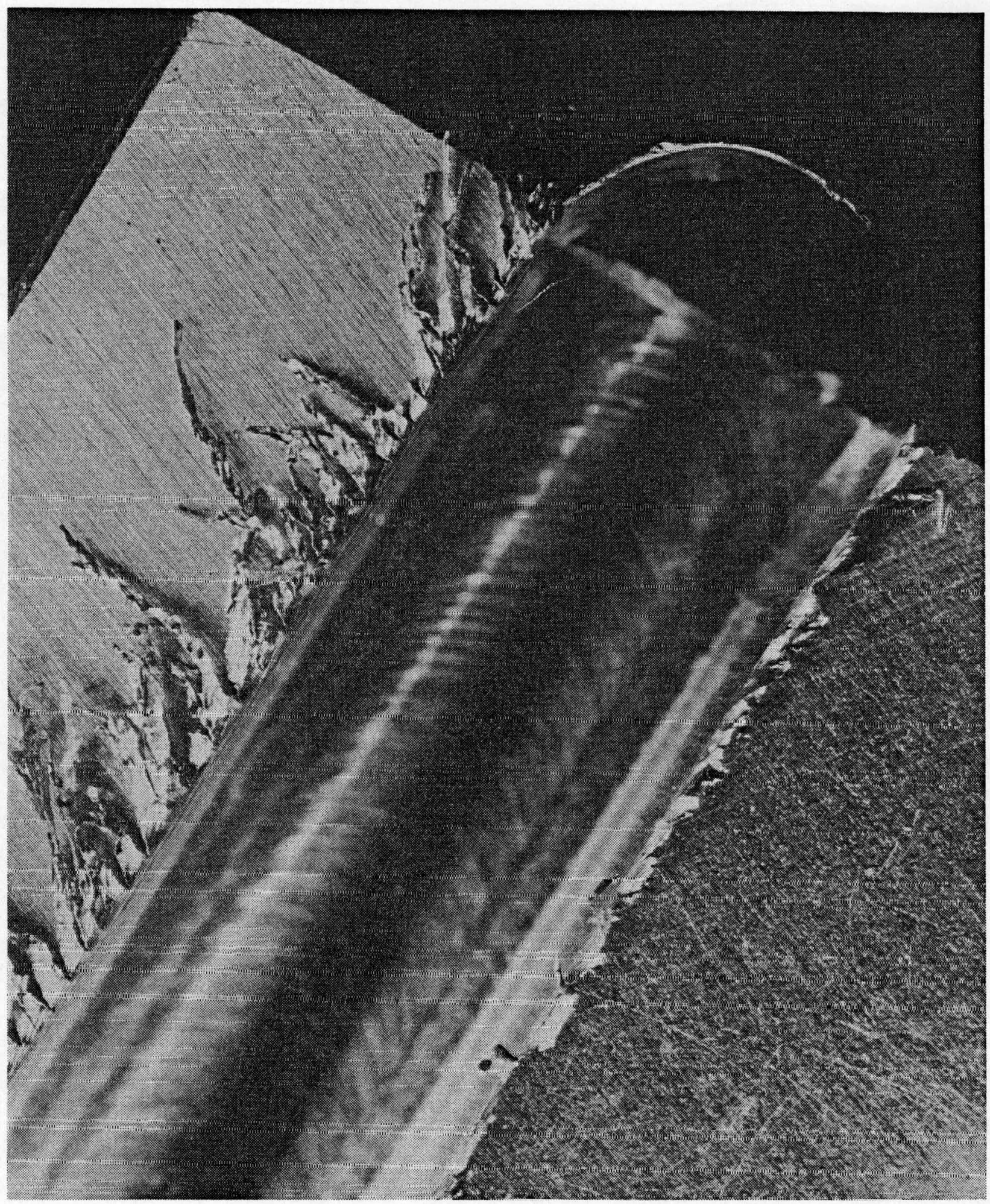

Figure 62. Feathery Burr on Edge 1, Produced by End Milling 6061-T6 Aluminum 


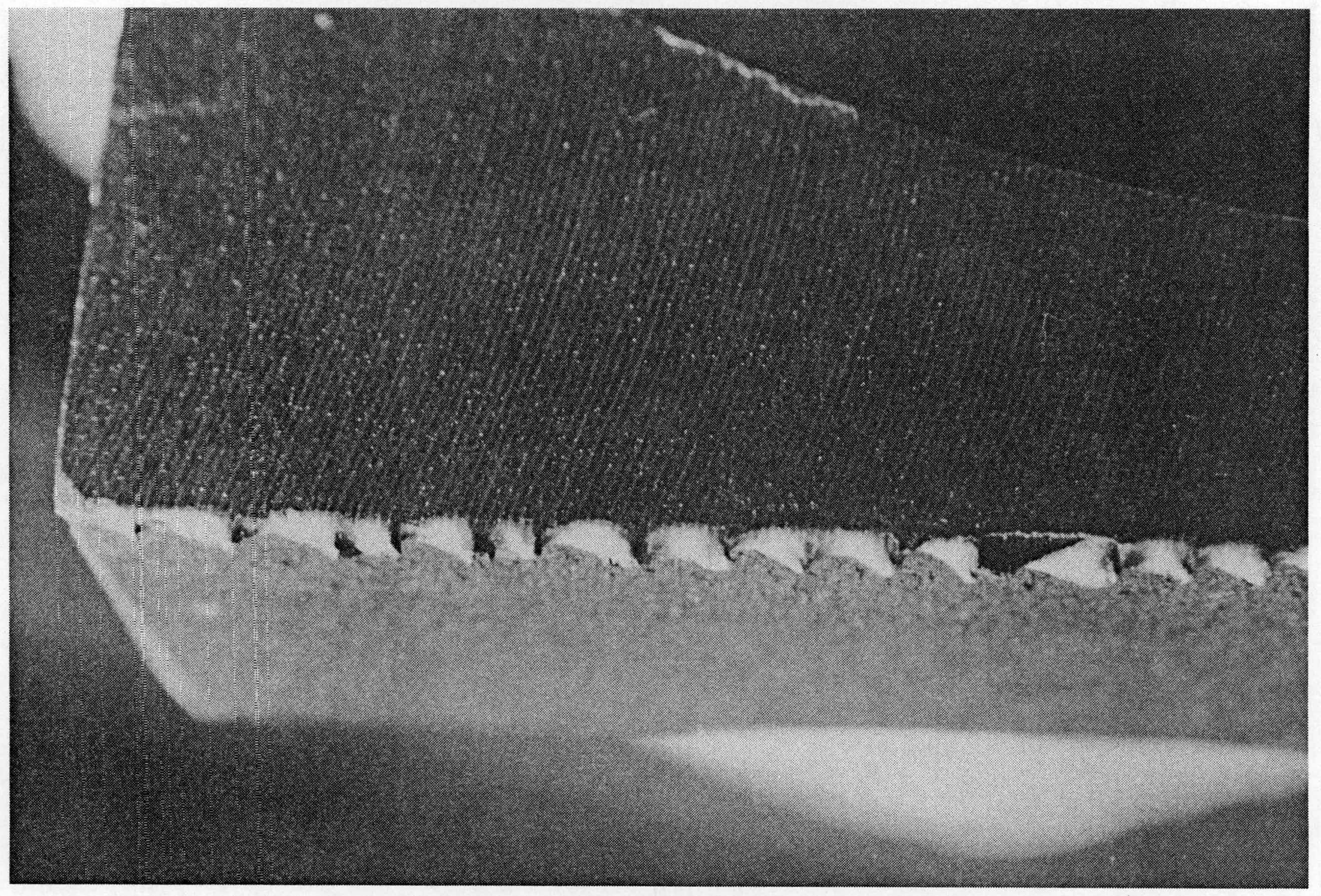

Figure 63. Uniform Burr Formed on Edge 9, Produced by a Face Mill in 1018 Steel 


\section{Effects of Measurement Approaches}

Data on burr properties are dependent upon the technique used to measure the burrs. ${ }^{28}$ Measurement of the burrs on edges 1 and 2 , in particular, are susceptible to the technique used. As an example, Table 8 presents the results of optically measuring the burrs from the end-mill wear test prior to mounting and after encapsulation. As shown, the measurements made from metallurgical mounts are much smaller than those made prior to mounting. The standard deviation of the data is also much smaller for the mounted specimen.- The reason for this can be appreciated by analyzing the previous photographs. Defining the average burr height is very difficult when one has an edge to evaluate like that of Figure 57 . By cross sectioning and mounting this edge, one has only a single projection to view, which simplified the measurement. At the same time, however, it is apparent that the height data will depend upon where the cross section is made (Figure 57). If the burr were more uniform, the difference between techniques would be less noticeable. Unfortunately, on many edges burr height varies considerably.

Another decision which has to be made is whether to measure the height of the individual projections or the height of the basic group the projections are in. Figure 64 illustrates the difference in these two approaches. Based on the mechanism by which the burrs form, the group height is a more meaningful measurement. If the tears did not occur, the group height would be the only burr height (Figure 59).

From a theoretical standpoint, the burrs on edge 5 should be similar to those shown in Figures $65 \mathrm{~A}$ or $65 \mathrm{~B}$. While most were similar to these two, a burr was often observed on the right-hand side of the edge as shown in Figures 65C and 65D. Similar although smaller effects were observed on edge 8 .

In the first study, an ANOVA was prepared for the measured data, then samples were ground down, and a second set of data was obtained. An ANOVA was then performed on the combined two sets of data. No significant differences were observed between the two ANOVAs, although more interactions appeared significant on the data set with repeated data. This indicates that repeated measurements are not necessary in a study of this magnitude and nature. As previously indicated, 27 this is not always the case.

\section{Analysis of Previously Published Data}

Only two reports have been published on the burrs produced by end milling. In the first report, ${ }^{l}$ the effects of helix angle and feedrate on burr thickness, height, and hardness were briefly studied. Beryllium copper and 303 Se stainless steel were used 
Table 8. Influence of Measuring Technique on Observed Burr Length

\begin{tabular}{|c|c|c|c|c|}
\hline \multirow[b]{4}{*}{ Feature } & \multicolumn{4}{|c|}{ Burr Height (in..)* } \\
\hline & \multicolumn{4}{|c|}{ Edge Number } \\
\hline & \multicolumn{2}{|l|}{1} & \multicolumn{2}{|l|}{2} \\
\hline & Optically & Mount & Optically & Mount \\
\hline $\begin{array}{l}\text { Average } \\
\text { Value }\end{array}$ & 0.0135 & 0.0062 & 0.0196 & 0.0033 \\
\hline $\begin{array}{l}\text { Standard } \\
\text { Deviation }\end{array}$ & 0.0083 & 0.0034 & 0.0098 & 0.0027 \\
\hline
\end{tabular}

$* 0.001$ inch equals $25.4 \mu \mathrm{m}$. )

in this study, and burrs were monitored on edges 1 and 9 . Feedrates varied from 0.0008 to 0.0015 inch/rev/tooth ( 20.3 to $38.1 \mu \mathrm{m} / \mathrm{rev} /$ tooth).

The helix angle did not affect the height or thickness of the burrs. Low helix angles appeared to result in softer burrs on edge 9 in beryllium copper. Slow feedrates tended to increase burr height on both edges in beryllium copper, but they did not influence the results in 303 Se stainless steel. Slow feedrates did increase the hardness of burrs in the stainless steel workpieces. At slow feeds, burr hardness was roughly five $R_{c}$ points higher than the original workpiece hardness, while the increase was roughly one point at the faster feedrate.

The fact that these results are not entirely consistent with the results of the current study is due to the brevity of the previously reported study. Only eight samples were evaluated versus 128 in the current study. Helix angle effects do warrant additional study, however, even though the data reported to date does not show dramatic reductions.

In the second reported study ${ }^{2}$, the effects of cutter diameter, radial depth of cut, and feedrate on burr height were evaluated in 303 Se stainless steel. Thirty-six combinations were evaluated. Burr height was measured with mechanical height gage indicators. As a general rule, increasing feedrate lowered burr height or produced no change. Burr heights also tended to increase radial depth of cut. 


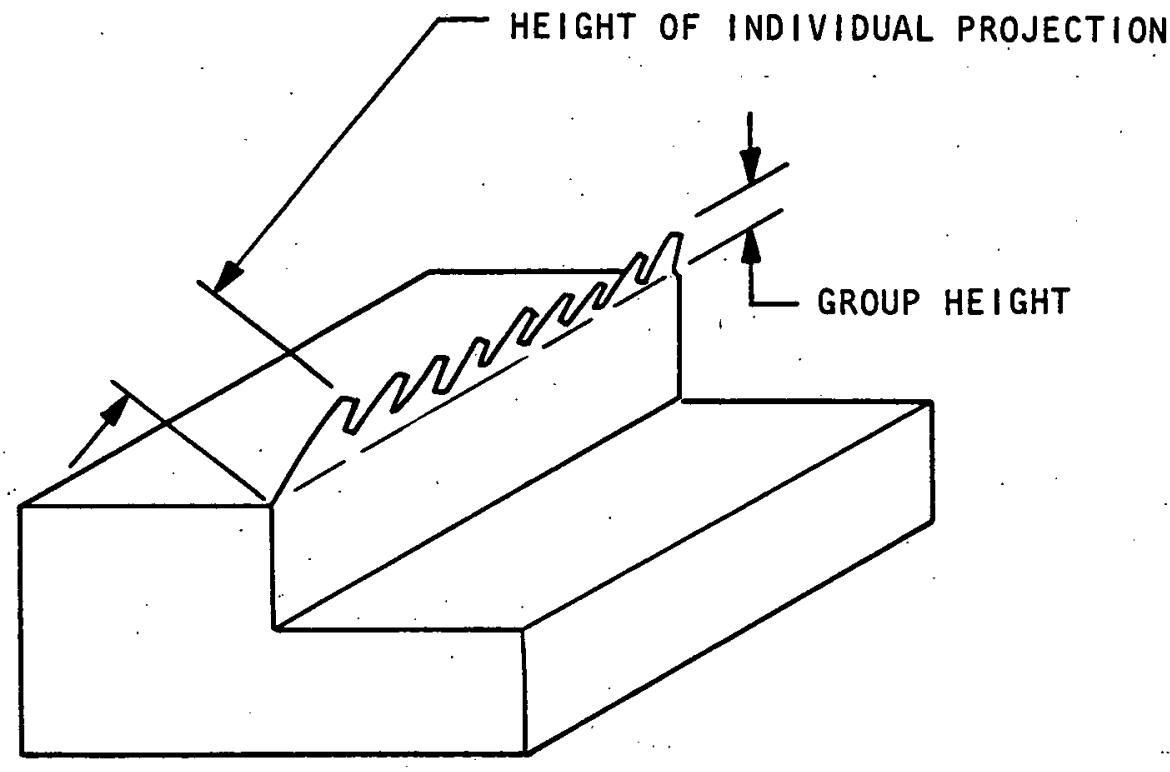

Figure 64. Possible Definitions of Burr Height for Feather-Like Burrs

Although radial depth of cut affected only the height of the burr on edge 3 in the current study (Table 2), it should be noted that Table 2 is based on the average results of four materials. A separate examination of the data for 303 Se stainless steel only indicates that burr height on edges 1,3 , and 6 increases by at least a factor of 2 when radial depths of cut increase from 10 to 100 percent of the cutter diameter. Increasing feedrates, as previously indicated, does lower burr height. As shown in Table 9 , the burr heights from the published study are considerably smaller than those from the current study, even though the same range of cutting conditions was used.

If feathery or flexible burrs are present, as in Figure 57, it is easy to see why mechanical indicators will not indicate the true burr height on some edges. These burrs simply bend over in such a way that the-true height is not recorded. From the standpoint of burr removal, however, readings from mechanical indicators may be more significant since they indicate the height of the tough portion of the burr.

\section{Production Implications}

The impetus for this study was a need to determine what could be done to minimize the size of milling burrs. Short, thin burrs can easily be removed by almost any deburring process without 
65A. TYPICAL BURR APPEARANCE (SPECIMEN 177).

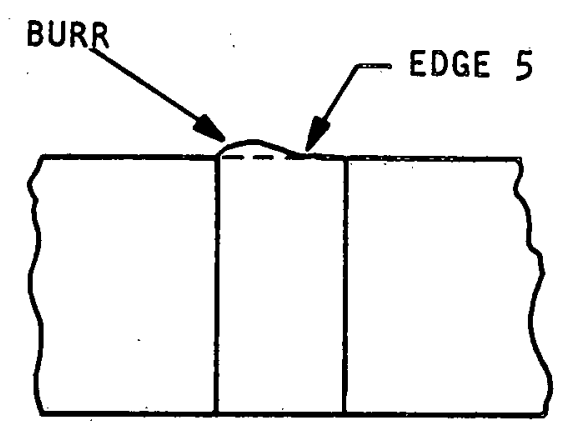

65B. BURR CONFIGURATION ON

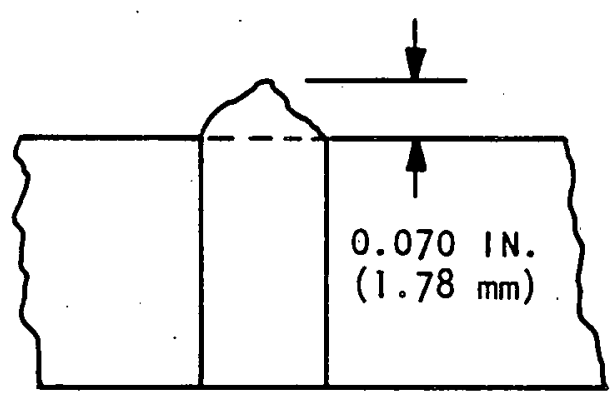
SPECIMEN 176

65C. BURR CONFIGURATION ON 0.085 I.N. $(2.16 \mathrm{~mm})$

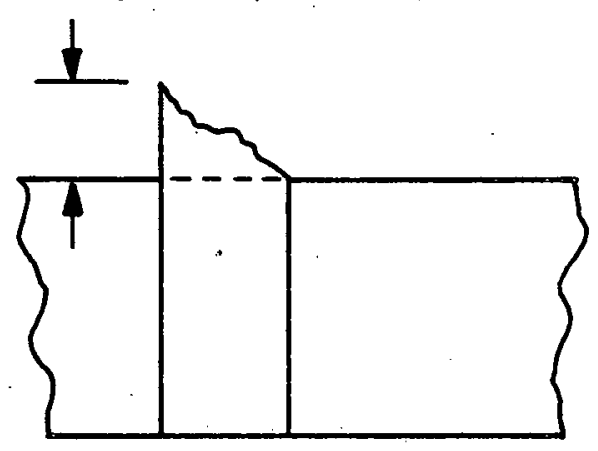
SPECIMEN 175

Figure 65. Shape of Burrs Observed on Edge 5 (Plan View) 
Table 9. Burr Heights Obtained in Two Similar Studies

\begin{tabular}{lll}
\hline & \multicolumn{2}{l}{ Burr Height (in.)* } \\
\cline { 2 - 3 } Burr & \multicolumn{2}{l}{ Method of Measurement } \\
\cline { 2 - 3 } Location & Mechanical Indicator** & Optical From Mounts*** \\
\hline 1 & 0.0010 & 0.0087 \\
2 & 0.0030 & 0.0084 \\
3 & 0.0850 & 0.0650 \\
4 & 0.0001 & $0.0121^{\cdots}$ \\
5 & 0.0024 & 0.0105 \\
6 & 0.0002 & 0.0010 \\
7 & 0.0600 & 0.0289 \\
8 & 0.0007 & 0.0048 \\
9 & 0.0029 & 0.0036 \\
10 & 0.0020 & $\dagger$ \\
\hline
\end{tabular}

$* 0.001$ inch equals $25.4 \mu \mathrm{m}$.

**From Reference 2.

***From Table 5 .

$\dagger$ Not measured.

noticeably affecting part dimensions. Burrs in the order of 0.004 inch thick $(101.6 \mu \mathrm{m})$, however, cannot be removed by most mechanized processes without at least 0.0002 inch $(5.08 \mu \mathrm{m})$ stock loss. On many precision miniature parts, such stock loss is not allowable.

Based on the studies described, burr size can be minimized by three basic approaches.

1. Use feedrates above $0.0005 \mathrm{inch} / \mathrm{rev} / \mathrm{tooth}(12.7 \mu \mathrm{m} / \mathrm{rev} / \mathrm{tooth})$. A feedrate of $\overline{0.002} \mathrm{inch} / \mathrm{rev} / \mathrm{tooth}(50.8 \mu \mathrm{m} / \mathrm{rev} / \mathrm{tooth})$ appears to be a reasonable optimum rate.

2. Use sharp tools. Dull tools double burr height and thickness.

3. Use the smallest radial depth of cut possible. 
While helix angles somewhat affect burr properties straight flute or reverse spiral cutters do not prevent burr formation.

The fact that eight burrs, each having a different thickness, height, and hardness, are produced in a single cut is of major significance in precision deburring efforts. In a mechanized process, each edge will respond differently because of burr size variations. Vibratory deburring a sharp edge, for example, may produce a $0.005-$ inch $(127 \mu \mathrm{m})$ radius, while a burr 0.004 inch thick by 0.020 inch high $(101.6$ by $500 \mu \mathrm{m})$ still remains attached to the part. Under such conditions, it is not possible to produce burr-free edges having 0.002 inch $(50.8 \mu \mathrm{m})$ maximum edge radii without reverting to manual techniques. Despite popular opinion to the contrary, burrs can form on the edge produced as the cutter enters the workpiece. However, when they occur, these burrs are small.

Burr properties are not very consistent. On a single edge, burr height can vary from 0.001 to 0.060 inch $(0.025$ to $1.500 \mathrm{~mm})$. Burr thickness and radii also vary significantly, although the actual magnitudes are much smaller. The standard deviation of burr property measurements is often the same order of magnitude as the average value. As an example, the average burr height on edge 1 , in the tool wear test, was 0.0032 inch $(81.3 \mu \mathrm{m})$. The standard deviation of these measurements was 0.0019 inch

$(48.3 \mu \mathrm{m})$. Thus, 95 percent of the readings varied between zero and 0.0070 inch $(177.8 \mu \mathrm{m})$. Such wide variation along a single edge also affects precision deburring.

While changing machining parameters reduces the size of some burrs, it may increase the size of other burrs. Thus, while increasing feedrate reduces the size of most burrs, or the burrs of most interest, it will increase the size of some and result in no change in others.

Burrs are harder than the parent material in any strain-hardening material. In 303 Se stainless steel, this increase varies from 2 to $10 R_{c}$ points.

\section{ACCOMPLISHMENTS}

Feedrate and tool sharpness have been shown to be the two most significant variables affecting the size of burrs produced by end milling. Slow feedrates and dull tools caused higher and thicker burrs. Increasing the radial depth of cut also has been shown to increase the size of some burrs.

The effects of feedrate, tool sharpness, axial depth of cut, radial depth of cut, and tool diameter were evaluated in 17-4 $\mathrm{PH}$ 
and 303 Se stainless steel, 1018 steel, and 6061-T6 aluminum. Burr size in 303 Se stainless steel was not affected by the tool wear resulting from producing 220 inches $(5.58 \mathrm{~m})$ of cut. Burr size did increase when tools developed a $0.001-i n c h(25.4 \mu \mathrm{m})$ radius on the cutting edge.

It was concluded that reverse helix tools do not prevent burrs, although they may reduce the size of some burrs.

The thickness, height, and radius on the backside of the burrs produced by end milling have been documented by 6000 measurements. Burrs were produced on up to eight different edges with a single cut, and the properties of each of these burrs were different. Burr properties have been shown to be highly variable.

Burrs have been shown to exist on all edges produced by a cutter. Conceptual and mathematical descriptions of burr formation have been described. Three distinct mechanisms were found responsible for the burrs produced by end mills.

\section{FUTURE WORK}

No additional work on end-milling burrs is planned, although additional information on helix-angle effects would be useful. Similarly, more detailed information on feedrate effects would be useful.

Additional tests are in progress to determine how machining variables affect the burrs produced by turning and drilling. An analysis will also be performed of economic trade-offs between machining and deburring costs. 


\section{REFERENCES}

${ }^{1}$ L. K. Gillespie, Vibratory Deburring (Topical Report). UNCLASSIFIED. Bendix Kansas City: BDX-613-735 (Rev), January, 1974. (Available from NTIS).

${ }^{2}$ L. K. Gillespie, "The Formation and Properties of Machining Burrs," M.S. Thesis, Utah State University: Logan, Utah, 1973.

${ }^{3}$ L. K. Gillespie, The Burrs Produced by Drizzing (Topical Report). UNCLASSIFIED. Bendix Kansas City: BDX-613-1248.

${ }^{4}$ L. K. Gillespie, The Effects of Reaming Variables on Burr Properties (Topical Report). UNCLASSIFIED. Bendix Kansas City: BDX-613-1083, April, 1974.

${ }^{5}$ L. K. Gillespie, Properties of Burrs Produced by Ball Broaching (Topical Report). UNCLASSIFIED. Bendix Kansas City: BDX-613-1084, Apri1, 1974.

${ }^{6} \mathrm{~L}$. K. Gillespie and P. T. Blotter, "The Formation and Properties of Machining Burrs," Transactions ASME (Series B), Journal of Engineering for Industry, February, 1976, pp 66-74.

${ }^{7}$ L. K. Gillespie, "The Effect of Cutting Edge Radius on Poisson Burr Properties," SME paper, MR 74-990, 1974.

${ }^{8}$ S. Zaima, A. Yuki, and S. Kamo, "Drilling of Aluminum Alloy Plates With Special Type Point Drill," Journal of Japan Institute of Light Metals, Volume 18, Number 5, May, 1968, pp 269-276; Volume 18, Number 6, June, 1968, pp 307-313.

${ }^{9}$ Clarence L. Bell and Blaine Kearsley, "The Effects of Drill Point Geometry, Feed and Speed on Cutting Forces and Burrs," unpublished report prepared for Utah State University, Department of Manufacturing Engineering, 1963.

${ }^{10} \mathrm{C}$. M. Fleming, Precision Hole Generation Methods, McDonnell Aircraft Company: AFML-TR-73-135, March, 1973.

${ }^{1}$ Saito, Zuzo, Kinji Sato, Tsuneo Saga, Makoto Ogawa, and Mizusawa Shozo, "Drilling Machinability for Aluminum Sheets," Journal of Japan Institute of Light Metals. (KEI Kinzoku), Volume 20, Number 2, February, 1970.

12 Shigeo Zaima, Masaji IIO, and Kenichi Shirakawa, "On the Effect of Cutting Fluid on Drilling Aluminum Alloy," Journal of Japan Institute of Light Metals, (KEI Kinzoku), Volume 19, Number 1, January, 1969, p 8. 
${ }^{13}$ Otto Kienzle and D. Werner Kienzle, "Tool Wear in the Cutting of Thin-Gauge Steel Sheets," ASTME Research Report Number 22, May 1, 1959. (Translation and discussion of article in Stahl und Eisen, Volume 78, Number 12, June 12, 1958, pp 820-828).

$14 \mathrm{John}$ E. Biegel and Robert E. Holmes, "Development of a Punchability Rating Method for Electrical Steels," ASTME Research Report Number 30, March 1, 1961.

${ }^{15}$ Hans Buhler and Fedor Pollmar, "The Formation of Burrs in the Cutting of Thin Sheet," Bander-Bleche-Rohre, Volume 12, Number 3, March, 1971, pp 105-111.

${ }^{16}$ Harding R. Hugo, "How to Improve Metal Stamping Die Performance," Sheet Metal Industries, February, 1971, pp 120-135.

${ }^{17}$ Frederico Strasser, "How Control of Burrs Aids Sheet Metal Stamping," The Iron Age, Volume 185, Number 3, January 21, 1960, pp 90-92.

${ }^{18} \mathrm{~K}$. K. Wang, Khalil Taraman, and S. M. Wu, "An Analysis of Punching Variables by Two-Level Fractional Factorial Design," ASME paper, 69-WA/Prod 27, 1969.

${ }^{19} \mathrm{C}$. S. Wukusik and R. S. Zeno, "Improving Punchability of Silicon Steel," Tool Engineer, Volume 41, Number 12, December, 1958, pp 63-70.

20 James Nielson McBride, "The Magnitude of Burrs Caused by Electrical-Discharge Machining." M.S. Thesis, Utah State University: Logan, Utah, 1969.

${ }^{21}$ L. K. Gillespie, "The Formation and Properties of Burrs," SME paper, MRR 75-03, 1975.

${ }^{22} \mathrm{~A}$. G. Atkins and R. M. Caddell, The Incorporation of Work Hardening and Redundant Work in Rod-Drawing Analyses," International Journal of Mechanical Sciences, Volume 10, 1968, pp 15-28.

${ }^{2}{ }^{3}$ M. E. Merchant, "Metal Cutting Research," pp 5-44 in Machining-Theory and Practice, American Society of Metals, Metals Park, Ohio, 1950, pp 5-44.

${ }^{24} \mathrm{~F}$. Schafer, "Product Design Influences on Deburring," $S M E$ paper, MR 75-483, 1975.

${ }^{25}$ Hugh 0 'Neill, The Hardness of Metals and Its Measurement. Cleveland: Sherwood Press, 1934. 
${ }^{26}$ M. C. Shaw and G. J. DeSalvo, "A New Approach to Plasticity and Its Application to Blunt Two-Dimensional Indenters, "ASME Transactions Journal of Engineering For Industry, May, 1970, pp 469-479.

${ }^{27}$ L. K. Gillespie, "Effects of Measurement Technique and Experimental Design in the Analysis of Burrs," SME paper, MR 75-985, 1975.

${ }^{28}$ L. K. Gillespie, "The Measurement of Burrs," SME paper, MR 74-993, 1974. 
THIS PAGE

\section{WAS INTENTIONALLY LEFT BLANK}


1

Appendix A

EFFECTS OF MACHINING AND END MILLING ON BURR MEASUREMENTS 
Table A-1. Effect of Machining Conditions on Burr Height

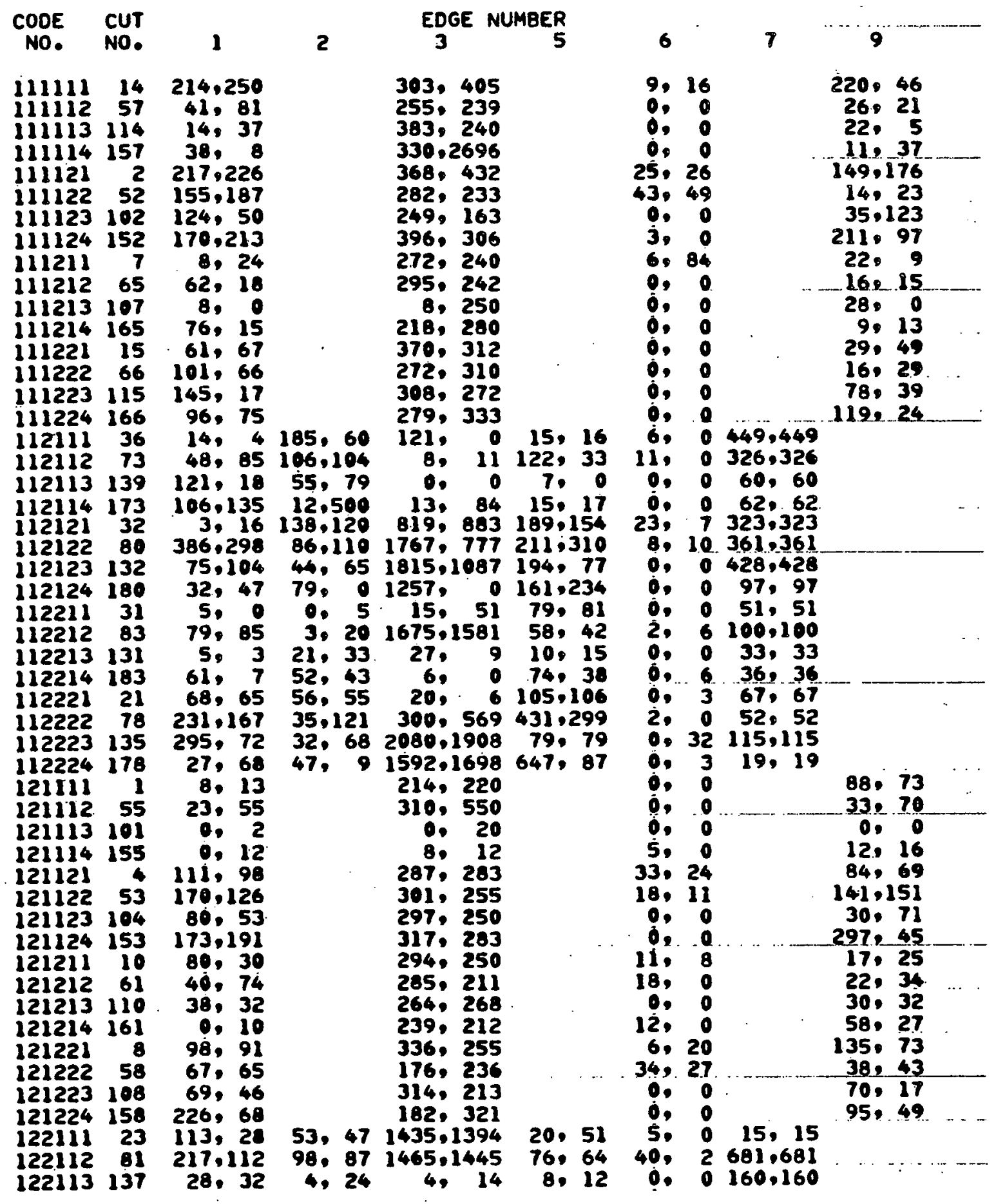

-VALUES SHOWN ARE IN 0.0001 INCH UNITS. 0.0001 INCH 2.54 MICROMETERS. TWO MEASUREMENTS WERE MAOE AT EACH COMBINATION OF VARIABLES - CODE NUMBERS ARE IOENTIFIED IN TABLE 4 IN THE MAIN BODY OF THIS REPORT 
Table A-1 Continued. Effect of Machining Conditions on Burr Height

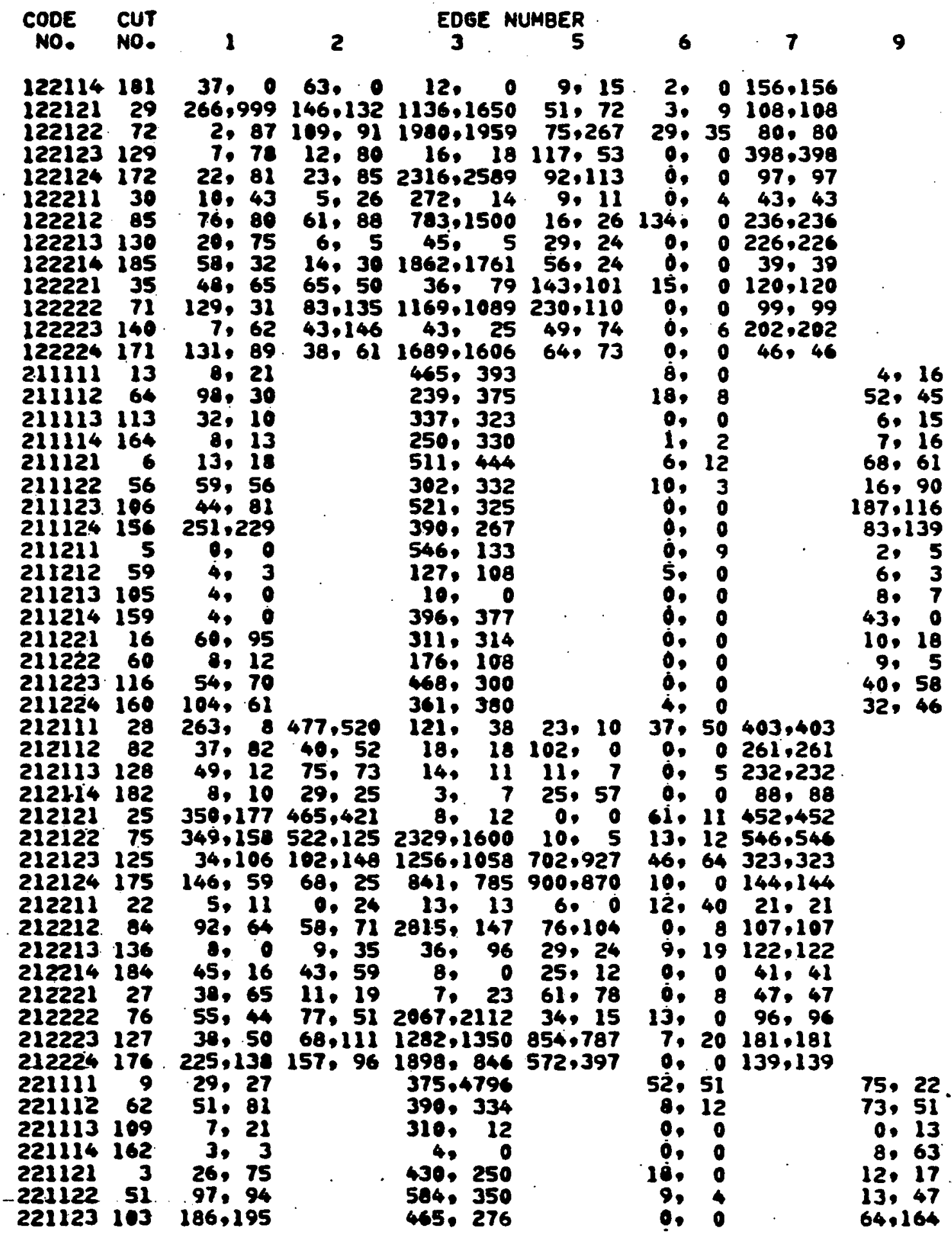

-VALUES SHOWN ARE IN 0.0001 INCH UNITS. 0.0001 INCH 2.54 MICROMETERS. THO MEASUREMENTS MERE MADE AT EACH COMBINATION OF VARIAOLES

- CODE MUMBERS ARE. IDENTIFIED IN TABLE \& IN THE MAIN BOOY_OF THIS REPORT 
Table A-1 Continued. Effect of Machining Conditions on Burr Height

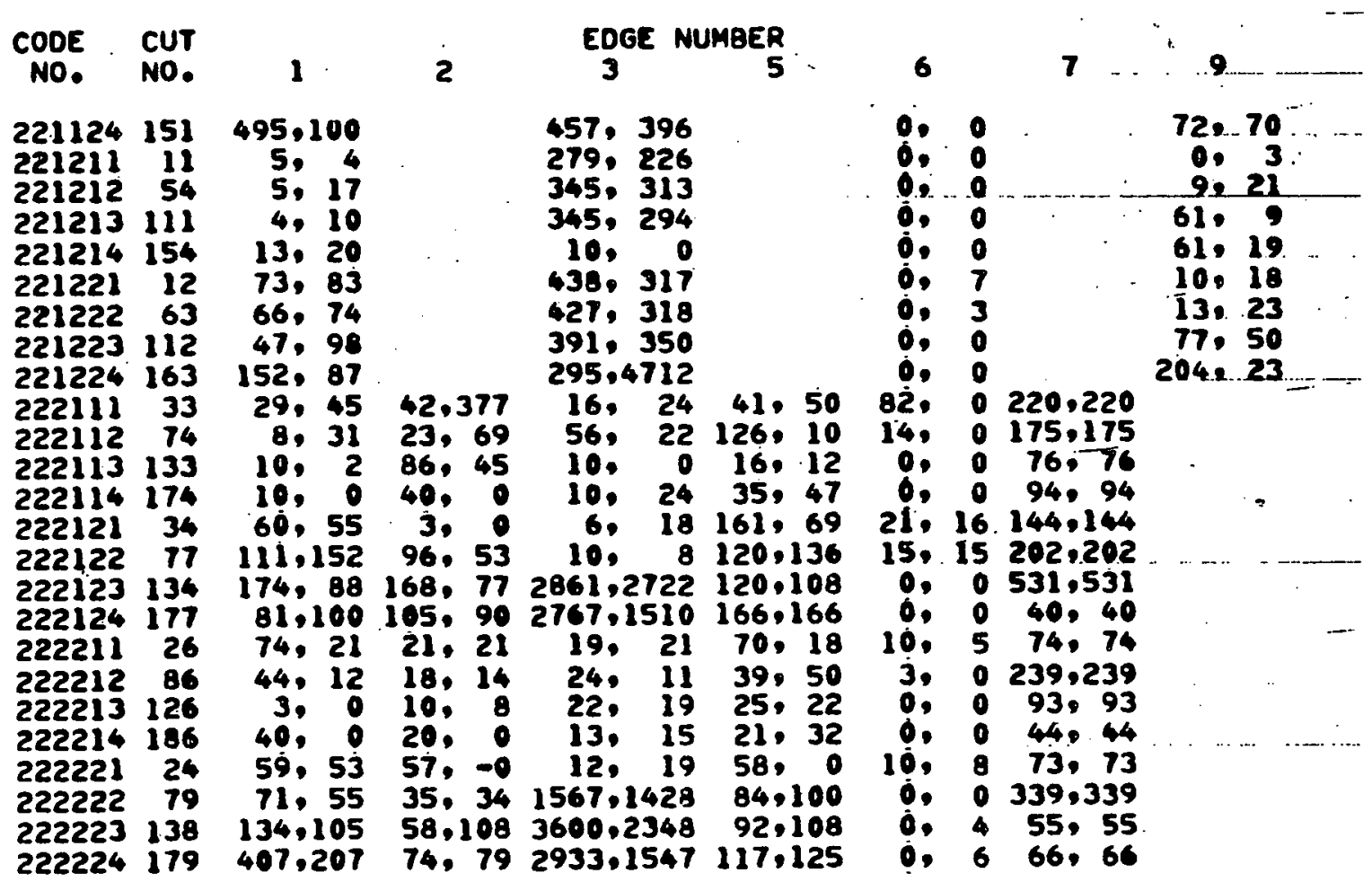

-VALUES SHOWN ARE IN 0.0001 INCH UNITS. 0.0001 INCH 2.54 MICROMETERS. TWO MEASUREMENTS WERE MADE AT EACH COMBINATION OF VARIABLES * CODE NUMBERS ARE IDENTIFIED IN TABLE \& IN THE MAIN BOOY OF THIS REPORT 


\section{THIS PAGE \\ WAS INTENTIONALLY \\ LEFT BLANK}


Table A-2. Effect of Machining Conditions on Burr Thickness

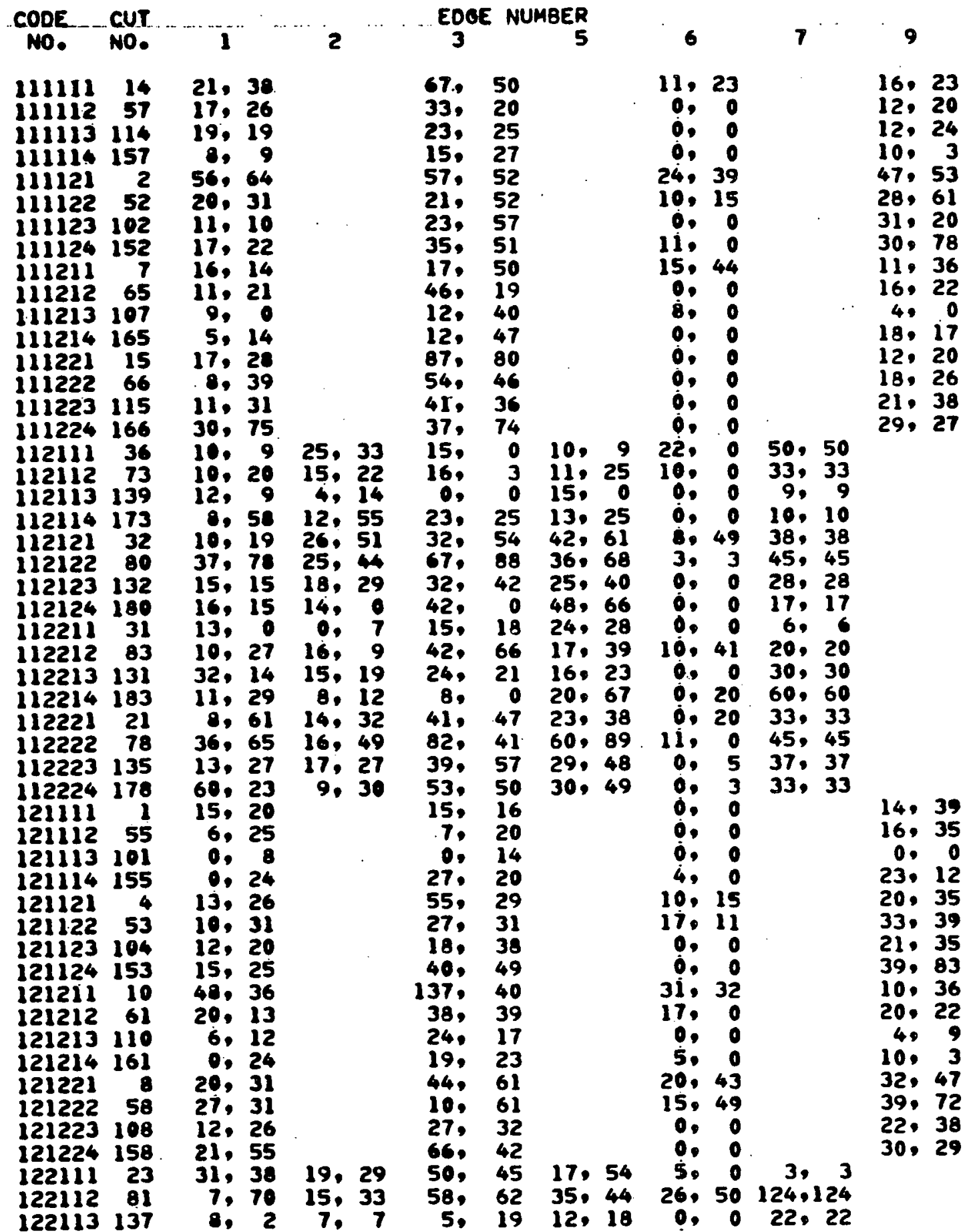

-VALUES SHOWN ARE IN 9.0001 INCH UNITS. 0.0001 INCH 2.54 MICROMETERS. TWO MEASUREMENTS WERE MADE AT EACH COMBINATION OF VARIABLES

- $C O D E$ NUMBERS ARE IDENTIFIED IN TABLE 4 IN THE MAIN BODY OF. THIS REPORT 
Table A-2 Continued. Effect of Machining Conditions on Burr Thickness

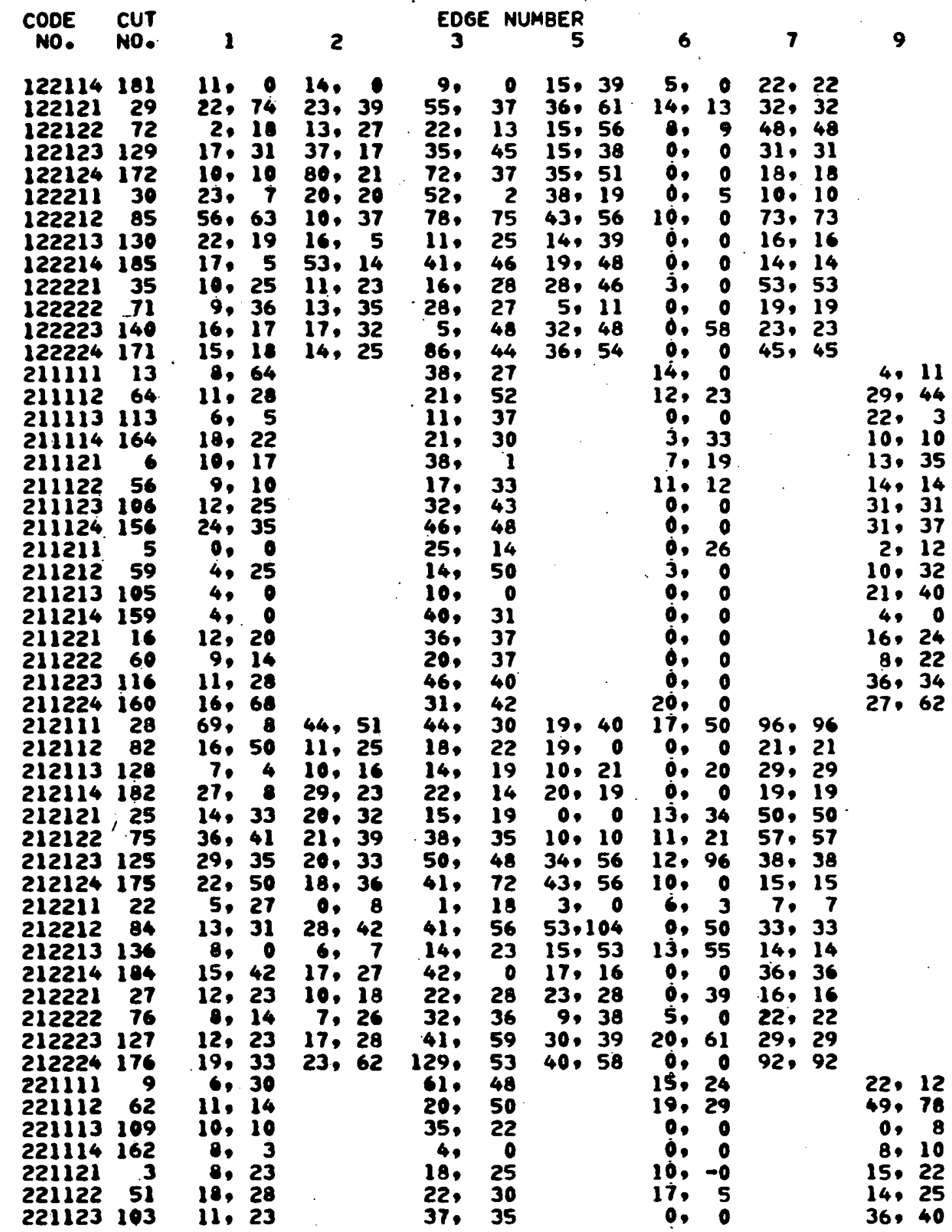

- VAlUes SHOWn ARE IN 0.0001 INCh UNITS. 0.0001 INCH 2.54 mICROMETERS. TWO MEASUREMENTS WERE MADE AT EACH COMBINATION OF VARIABLES

- CODE NUMBERS ARE IDENTIFIED. IN TABLE \& IN THE MAIN BODY OF THIS REPORT 
Table A-2 Continued. Effect of Machining Conditions on Burr Thickness

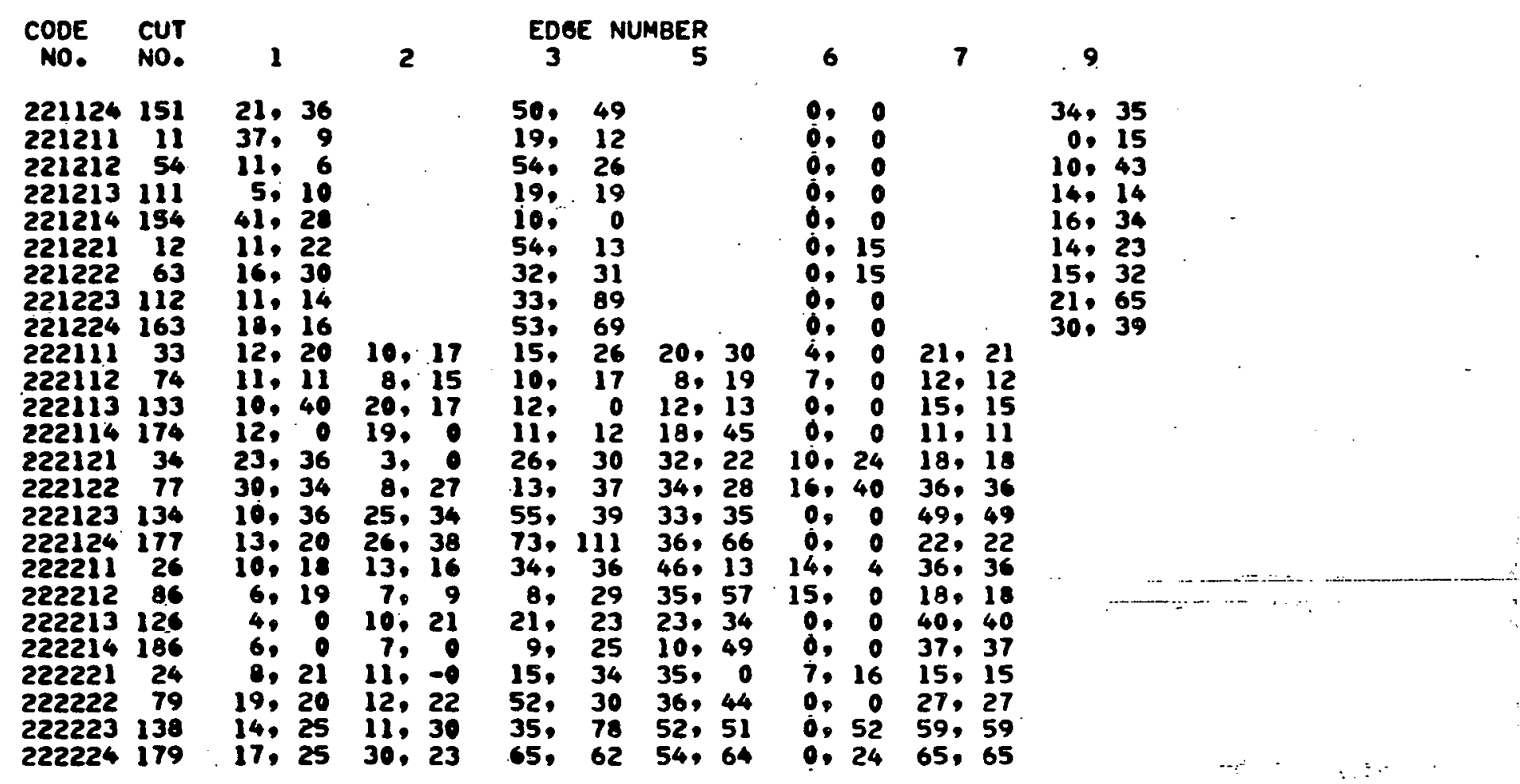

-VALUES SHOWN ARE IN O.000I INCH UNITS. 0.000I INCH 2.54 MICROMETERS. TWO MEASUREMENTS WERE MADE AT EACH COMBINATION OF VARIABLES

- CODE NUMBERS ARE IDENTIFIED IN TABLE 4 IN THE MAIN BODY OF THIS REPORT 
THIS PAGE

\section{WAS INTENTIONALLY \\ LEFT BLANK}


Table A-3. Burr Radius Measurements From End Milling

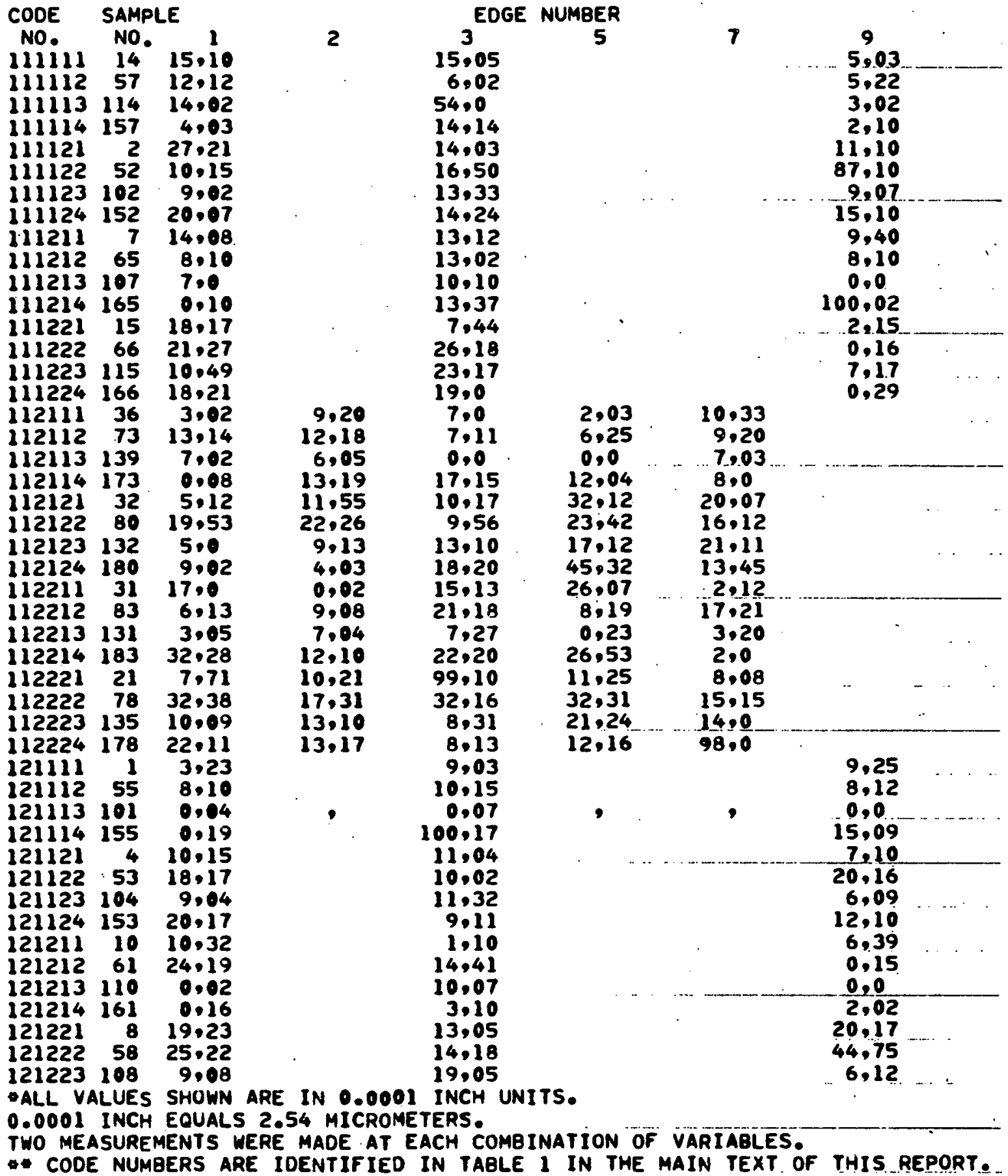


Table A-3 Continued. Burr Radius Measurements From End Milling

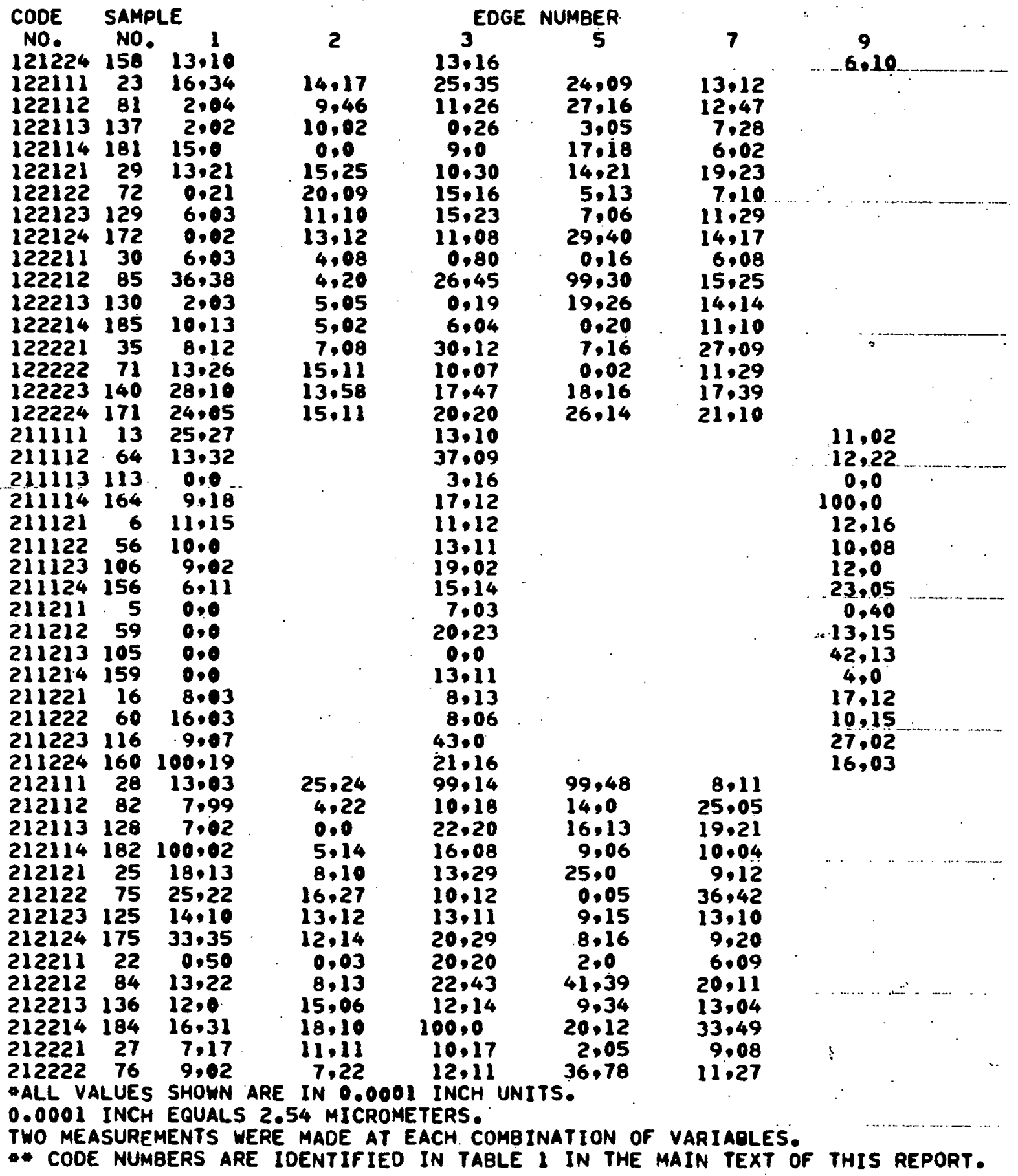


Table A-3 Continued. Burr Radius Measurements From End Milling

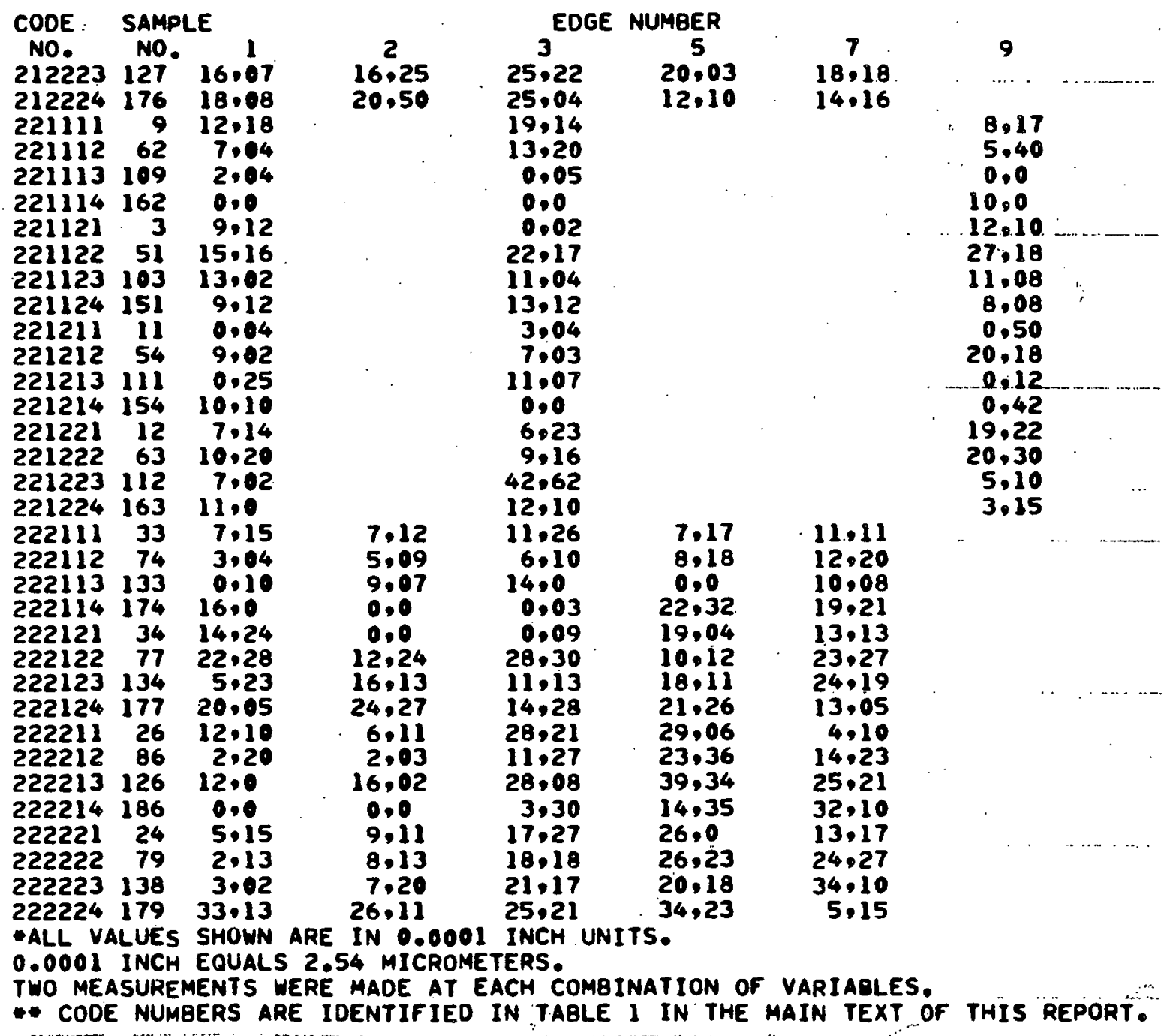


THIS PAGE

\section{WAS INTENTIONALLY LEFT BLANK}


Table A-4. Burr Height By End Milling

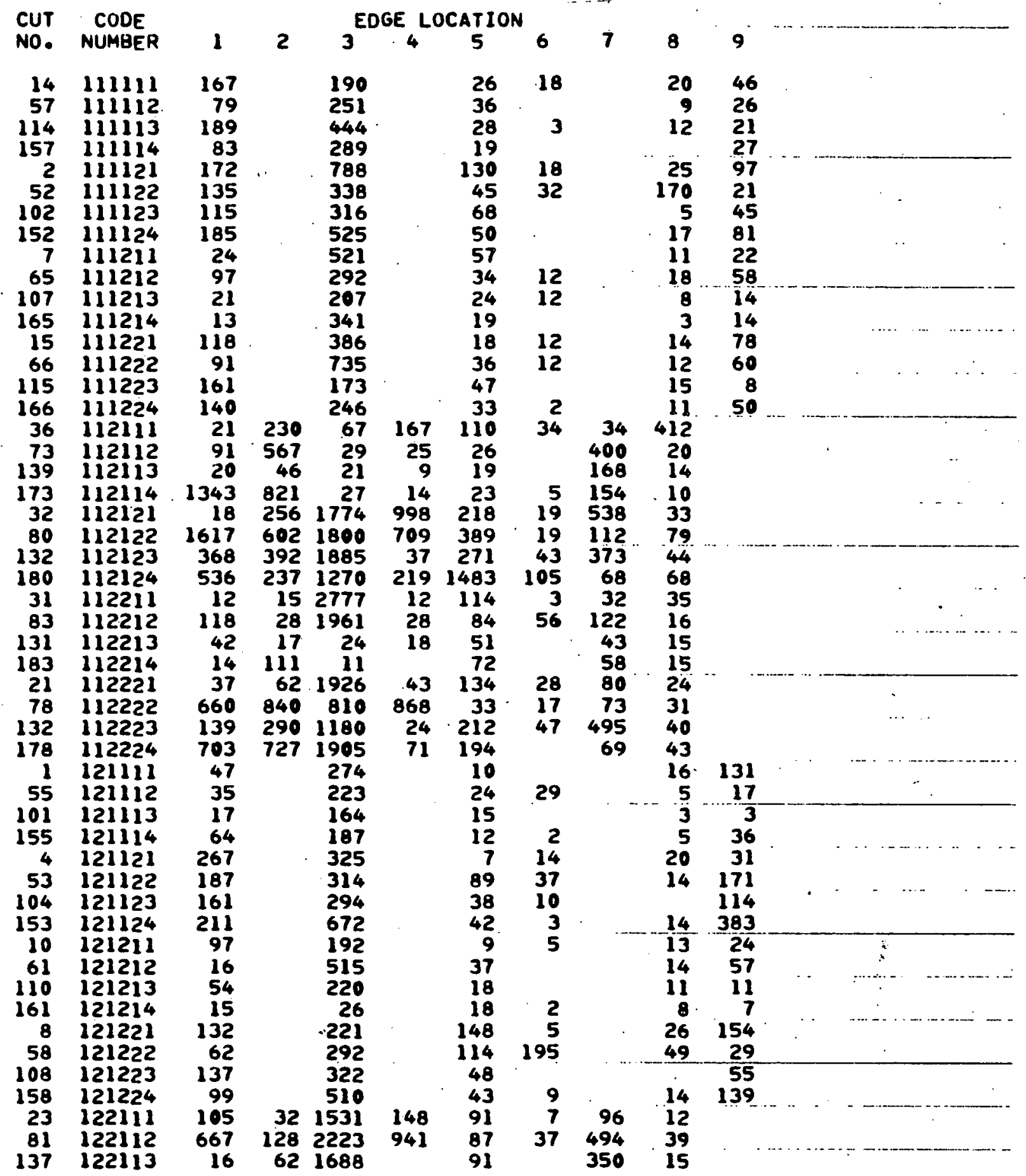

-VALUes shown are IN 0.0001 INCh UnITS. 0.0001 INCH EQUALS 2.54 MICROMETERS. BURRS WERE MEASURED OPIICALLY PRIOR TO CROSS SECTIONING 
Table A-4 Continued. Burr Height By End Milling

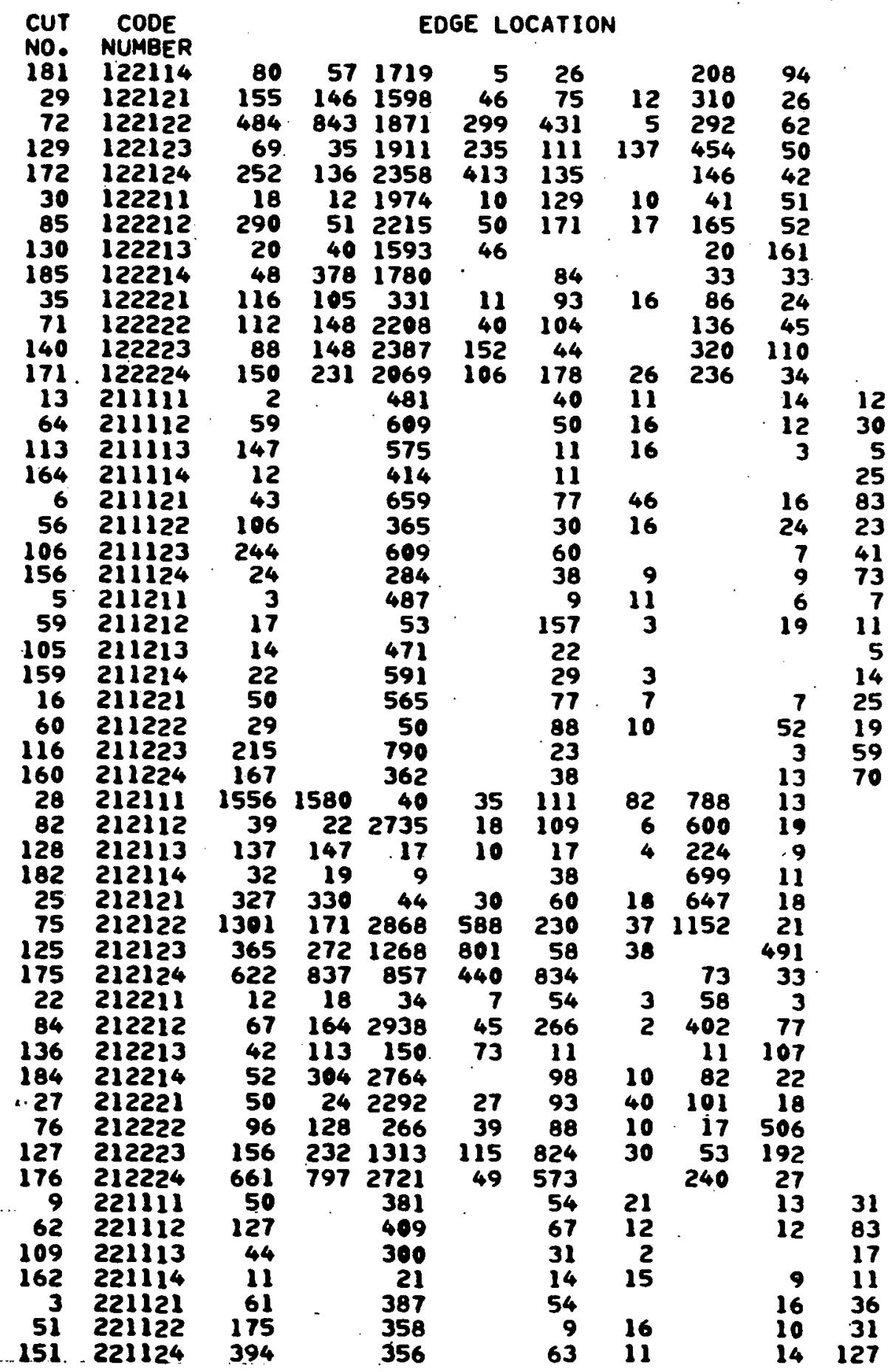

-VALUES SHOWN ARE IN 0.0001 INCH UNITS. 0.0001 INCH EQUALS 2.54 MICROMETERS. BURRS MERE MEASURED OPIICALLY PRIOR ,TO CROSS SECTIONING 
Table A-4 Continued. Burr Height By End Milling

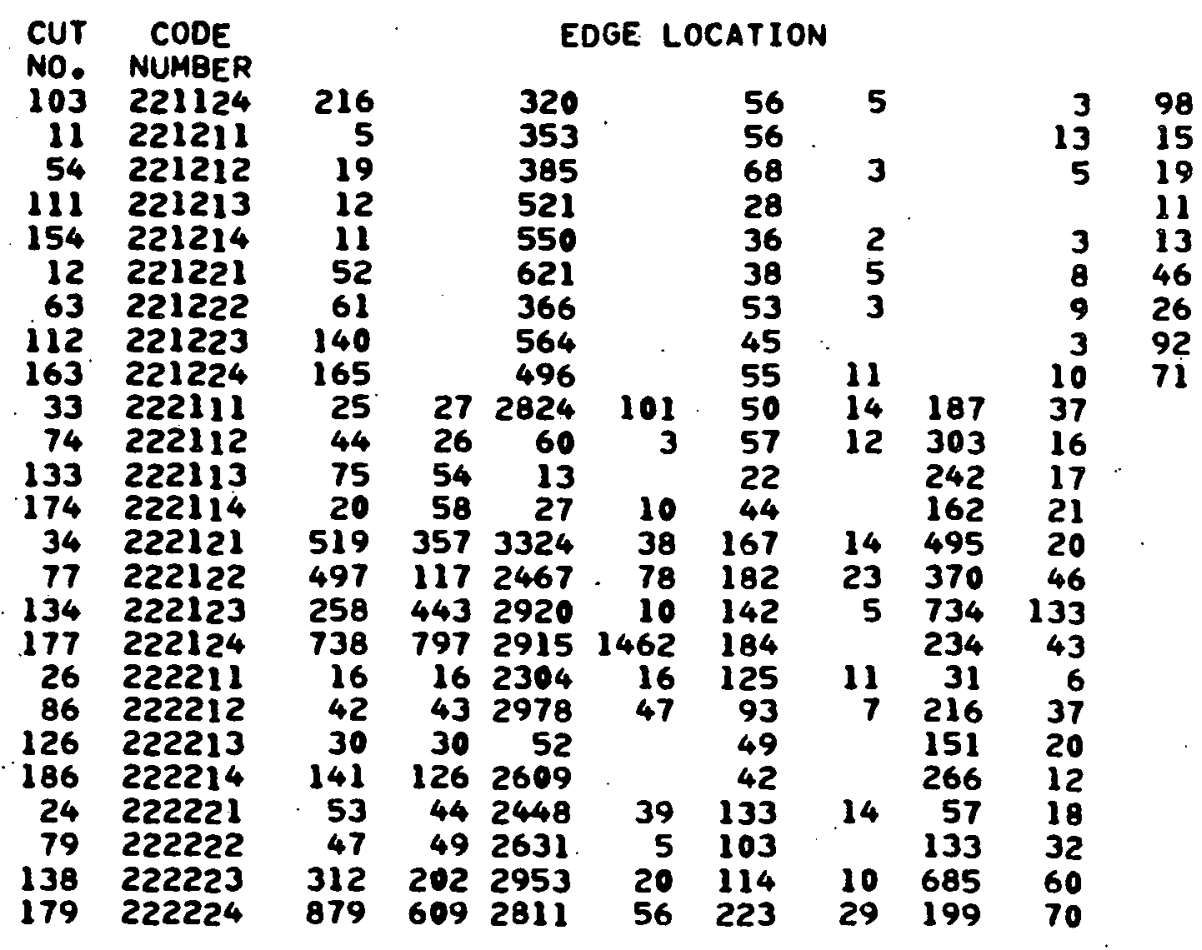

-VALUES SHOHN ARE IN 0.0001 INCH UNITS. 0.0001 INCH EQUALS 2.54 MICROMETERS. BURRS WERE MEASURED OPTICALLY PRIOR TO CROSS SECTIONING 
Table A-5. Effect of Length of Cut on Burr Properties in 303 Se Stainless Steel

SAMPLE TOTAL CUT:-___ BURR HEIGHT* BURR THICKNESS* BURR RADIUS* NO. LENGTH(INCH) INOICATOR MOUNT

- ALl values SHOWN ARE IN. 0.0001 INCH UNITS.

0.0001 INCH EOUALS 2.54 MICROMETERS.

HEIGHT MEASUREMENTS IDENTIFIED AS MOUNT, AND ALL THICKNESS AND RADIUS

MEASUREMENTS WERE MADE FROM METALLURGICAL MOUNTS SHOWING BURR CROSS SECTIONS. HEIGHT MEASUREMENTS IDENTIEIED AS INDICATOR WERE MAOE OY MECHANICAL DIAL IMDICATORS PRIOR TO PREPARATION OF METALLURGICAL MOUNTS. 
THIS PAGE

\section{WAS INTENTIONALLY \\ LEFT BLANK}




\section{Appendix B \\ DESCRIPTION OF CUTTERS USED}


THIS PAGE

\section{WAS INTENTIONALLY LEFT BLANK}




\section{Appendix B}

DESCRIPTION OF CUTTERS USED

\section{EFFECTS OF MACHINING CONDITIONS STUDY}

Bendix Tool Number 51103202

Special 0.25-inch-diameter, high-speed steel, 0.375-inch straight shank, right-hand spiral, right-hand cut, four-flute, two-flute, cutting to center, square end, double end, end mill; $0.625-$ inchflute length, 3.375-inch overall length. No radius for steel.

Bendix Tool Number 51105213

0.375-inch-diameter cobalt, high-speed steel, 0.375 -inch straight shank, right-hand spiral, right-hand cut, four-flute, two-flute cutting to center, square end, single end, end mill; 0.75-inchflute length, 2.5-inch overall length. No radius for 17-4 PH stainless steel.

EFFECTS. OF TOOL WEAR STUDY

Bendix Tool Number 51105222

See description for 51103202 .

END-MILLING HIPERCO 50 STUDY

Bendix Tool Number 51101520

$0.120 \pm 0.001$-inch-diameter, solid carbide (C-2) 0.625-inch straight shank, right-hand spiral, right-hand cut, four-flute, two-flute cutting to center, square end, single end, end mill; $0.375-$ inch-flute length, 1.5-inch overall length to cut.

\section{EFFECT OF HELIX ANGLE STUDY}

Bendix Tool Number 51103222

0.25 -inch-diameter, solid carbide (C-6) 0.25-inch straight shank, right-hand cut, two straight flutes, square end cut to center, single end, end mill; 0.75-inch-flute length, 2.5-inch overali length. No radius for steel. 
Bendix Tool Number 5:1103234

$0.2650 \pm 0.0005-$ inch-diameter, high-speed cobalt, $0.375-$ inch straight shank, right-hand spiral, right-hand cut, four-flute, center-cutting, single end, end mill; 0.625-inch-flute length, 2.4375-inch overall length. No radius for beryllium-copper.

Bendix Tool Number 51105206

$0.375+0.000,-0.002-i n c h-d i a m e t e r$, solid carbide, (C-2) 0.375-inch straight shank, left-hand spiral, right-hand cut, four-flute, square end, single end. end mili; 0.875-inch-flute length, 2.25-inch overall length. No radius. for epoxy-glass.

NOTE: $\quad 1$ inch $=25.4 \mathrm{~mm}$. 
R. Bulcock, ERDA-KCAO

A. A. Kenly, G. E.

J. W. Baker, RF

K. Thistlewood, RF

G. P. Ford, SLA

K. Gillespie, SLA

R. S. Pinkham, SLA

A. L. Thornton, SLA

H. L. Price, D/261, FU34

E. L. Young, D/261, FU34

J. D. Corey, D/554, BD50

L. Stratton, D/554, 2C44

R. F. Pippert, D/700, $1 \mathrm{~A} 42$

E. F. Felkner, D/752, 1A41

J. D. Johnson, D/752, 1A41

R. P. Frohmberg; - D $/ 800,2 A 39$

J.A. Morrison, D/800/D. D. Oswald/J. P. Dycus/ D. R. Wachter, D/822, $2 A 40$

J. L. Couchman/F. J. Boyle/B. W. Landes, D/821, $2 A 36$

R. K. Albright, $\mathrm{D} / 822,2 \mathrm{~A} 36$

L. K. Gillespie, $\mathrm{D} / 822,2 \mathrm{~A} 36$

G. E. Klement, $\mathrm{D} / 822,2 \mathrm{~A} 36$

W. P. McKay, D/822, 2A36

D. P. Roberts/C. E. Spitzkeit, D/823, 1 A27

R. W. Lange, $D / 861,2 A 31$

R. E. Kessler, $\mathrm{D} / 865,2 \mathrm{C} 40$ 